\title{
A GUIDE TO ODP TOOLS FOR DOWNHOLE MEASUREMENTS
}

\section{OCEAN DRILLING PROGRAM \\ TEXAS A\&M UNIVERSITY}

\section{Technical Note 10}

\author{
Andrew T. Fisher \\ Ocean Drilling Program \\ Texas A\&M University Research Park \\ 1000 Discovery Drive \\ College Station, Texas 77845-9547
}

U.S.A.

Keir Becker

Rosenstiel School of Marine and Atmospheric Science

University of Miami

4600 Rickenbacker Causeway

Miami, Florida 33149

U.S.A.

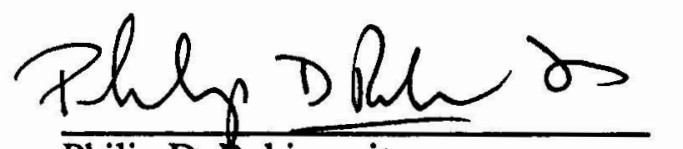

Philip D. Rabinowitz

Director

ODP/TAMU
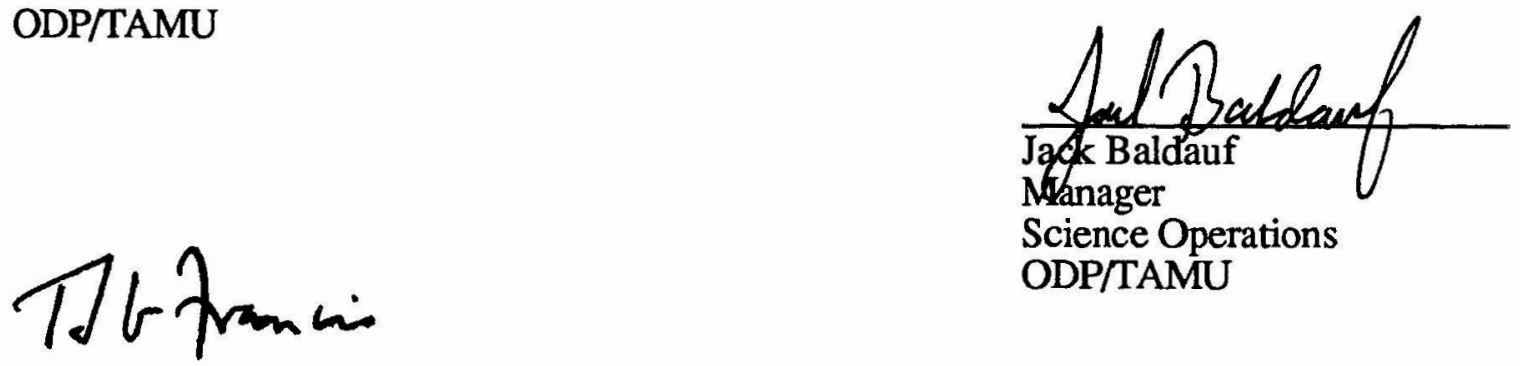

Timothy J.G. Francis

Deputy Director

ODP/TAMU 
Material in this publication may be copied without restraint for library, abstract service, educational, or personal research purposes; however, republication of any portion requires the written consent of the Director, Ocean Drilling Program, Texas A\&M University Research Park, 1000 Discovery Drive, College Station, Texas 77845-9547, U.S.A., as well as appropriate acknowledgment of this source.

Technical Note No. 10

First Printing 1988

Revised Printing 1993

Distribution

Copies of this publication may be obtained from the Director, Ocean Drilling Program, Texas A\&M University Research Park, 1000 Discovery Drive, College Station, Texas 77845-9547, U.S.A. Orders for copies may require payment for postage and handling.

\section{$\underline{D} \underline{I} \underline{\mathrm{S}} \underline{\mathrm{L}} \underline{\mathrm{A}} \underline{\mathrm{I}} \underline{\mathrm{M}} \underline{\mathrm{E}} \underline{\mathrm{R}}$}

This publication was prepared by the Ocean Drilling Program, Texas A\&M University, as an account of work performed under the international Ocean Drilling Program, which is managed by Joint Oceanographic Institutions, Inc., under contract with the National Science Foundation. Funding for the program is provided by the following agencies:

Academy of Sciences (Russia) - Inactive Canada/Australia Consortium for the Ocean Drilling Program Deutsche Forschungsgemeinschaft (Federal Republic of Germany) Institut Français de Recherche pour l'Exploitation de la Mer (France) Ocean Research Institute of the University of Tokyo (Japan) National Science Foundation (United States) Natural Environment Research Council (United Kingdom) European Science Foundation Consortium for the Ocean Drilling Program (Belgium, Denmark, Finland, Iceland, Italy, Greece, The Netherlands, Norway, Spain, Sweden, Switzerland, and Turkey)

Any opinions, findings, and conclusions or recommendations expressed in this publication are those of the author(s) and do not necessarily reflect the views of the National Science Foundation, the participating agencies, Joint Oceanographic Institutions, Inc., Texas A\&M University, or Texas A\&M Research Foundation. 


\section{TABLE OF CONTENTS}

\section{INTRODUCTION}
A. Purposes of This Manual
B. Advance Planning Requirements for Routine ODP Tools
C. Overview of Downhole Measurements Provided by ODP
1. Fluid sampling
2. Formation temperature measurements
3. Permeability measurements using packers
4. Orientation of APC and RCB cores
5. Long-term observatories (CORK)
6. Pressure core sampler (PCS)
D. Compatibility of ODP Tools with ODP Operations and Engineering Systems

\section{IN-SITU FLUID SAMPLING}
A. Introduction
B. Pore-Fluid Sampling with the WSTP
1. General tool design and preparation
2. Tool deployment
C. Borehole Fluid Sampling with WSTP and Kuster Tools
1. Operational considerations for sampling borehole fluids

\section{IN-SITU TEMPERATURE MEASUREMENTS}
A. Introduction
B. Temperature Measurements with the WSTP

1. WSTP geometry, structure, and recording capabilities

2. WSTP preparation and deployment

3. WSTP data recovery, processing, and archiving

C. APC Temperature Tool

1. APC tool design and components

2. APC tool preparation and deployment

3. Data retrieval and processing D. Use of ODP Temperature Tools for Discrete Temperature "Logs" 
1. Logging sediment temperatures without coring

2. Logging open-hole temperatures

\section{DRILL-STRING PACKERS}
A. Introduction
B. ODP Drill-String Straddle Packer
1. Packer elements
2. Inflation of packer elements using go-devils
3. Temperature limitations of the ODP drill-string packers
4. Compatibility of ODP drill-string packer with logging
5. TAM straddle-packer design
C. Formation Testing Using the Straddle Packer
1. Downhole pressure recorders
2. Pressures measured during formation testing
3. Active formation testing

\section{CORE ORIENTATION}
A. Introduction
B. APC Orientation
C. RCB Orientation

\section{CORK}
A. Introduction
B. Leg 146 CORK Operations
C. Leg 139 Reprint

\section{PRESSURE CORE SAMPLER}
A. Introduction
B. PCS Technical Description and Deployment Method
1. Latch subassembly
2. Actuator subassembly
3. Accumulator subassembly
4. Manifold subassembly 
5. Ball-valve subassembly

6. Detachable sample chamber

C. PCS Operation and Plans for Additional Development

\section{THIRD-PARTY AND DEVELOPMENTAL TOOLS}

A. JOIDES Policy for Third-Party Tool Development

1. Classification of tools

2. Development tools

3. Certified tools

4. Mature tools

5. Protocol for development

B. Examples of Recent Third-Party Tool Developments

1. Borehole-fluid samplers

2. Geoprops

3. Last I and II

4. Spinner flowmeter

5. "Active" fluid sampling

6. Additional developments

\section{REFERENCES}

Appendix A. Selected Reprints for ODP Downhole Measurements

Appendix B. Table of Downhole Tool Usage During ODP Legs 101-146 
Technical Note No. 10

Page 6

\section{INTRODUCTION}

\section{A. Purposes of This Manual}

Downhole measurements are vital components of almost every leg of the Ocean Drilling Program (ODP). These measurements augment the two other primary forms of ODP technology, drilling engineering and core recovery and analysis, and provide information about the formations below the seafloor at in-situ conditions. ODP uses three main kinds of downhole measurements: wireline logs, formation testers and samplers, and borehole observatories. For each of these measurement and tool types, there are "standard" instruments developed within the Deep Sea Drilling Project (DSDP) and ODP structure, and "third-party" instruments developed by independent investigators. Some tools are a combination of these categories. Because the ODP is committed to addressing a variety of problems and operating in a wide range of settings, downhole tools have changed rapidly since the first edition of this Technical Note was published (Becker, 1988). The present need for an updated Technical Note is evidence of the strong ODP commitment to downhole measurements in general.

The ODP runs the most advanced suite of routinely used downhole instruments of any scientific project in the world today. These tools change frequently and rapidly in terms of design and capabilities, and downhole tools specialists sailing on the JOIDES Resolution are often confronted with a bewildering array of instruments and procedures. With the short time available between establishment of the ship schedule and the start of individual legs, shipboard scientists often do not have access to instruments, or even manuals, prior to sailing. The primary purpose of this manual is, therefore, to provide some guidance for scientists interested in those downhole tools that ODP routinely provides by describing several key aspects regarding these tools: requirements for advance planning, general procedures for shipboard operations, and basic methods for data interpretation. For many of the ODP downhole tools, fully detailed operating instructions written by the tool designers or manufacturers are available at ODP and on board JOIDES Resolution, and will only be briefly summarized here, emphasizing those factors that are important in planning and conducting measurements. Interested scientists should contact the Science Operations or Technical Support departments at ODP for additional, more detailed, information. 
The purpose of this note is similar to that of the ODP Logging Manual, which describes the logging tools and scientific logging services provided by the Borehole Research Group (BRG) at Lamont-Doherty Earth Observatory (LDEO). Copies of the latest (1990) ODP Logging Manual are available from BRG. Worthington et al. (1987) wrote a brief, useful summary of the ODP logging facilities. In addition ODP recently produced a glossy booklet (Worthington et al., 1992) containing general information on ODP downhole measurements and examples of how these tools are applied to solve geological problems.

In this Technical Note, "ODP” will be used to refer to the ODP Science Operator at TAMU, and “LDEO” will refer to the ODP Logging Contractor. ODP and LDEO divide responsibilities for downhole tools in a general way as follows: LDEO is responsible for providing logs measured with tools run on the seven-conductor logging cable (or "wireline"), whereas ODP is responsible for those tools used with the drill string and/or the nonconducting coring line (or "sand line"). This division has become somewhat fuzzy over the last several years; contact ODP or LDEO to determine which organization is responsible for any particular tool.

Most of this Note consists of descriptions of the following types of measurements that can be "routinely" made with tools provided by ODP: (1) borehole- or pore-fluid sampling, (2) temperature measurements in sediments or in an open borehole, (3) permeability measurements using a drill-string packer, (4) orientation of advance piston core (APC) and rotary core barrel (RCB) cores, (5) borehole observatories (CORK's), and (6) sampling of soft to semilithified sediments and fluids under hydrostatic pressure (PCS). Many other types of measurements are possible, and several new tools are being developed by ODP and outside investigators. The final chapter of this manual describes some of the new tools now under development, and specifies the conditions that must be satisfied before ODP will assume responsibility for routinely providing new kinds of measurements.

The remainder of this introductory chapter summarizes the information that is essential to assure that the routine measurements provided by ODP can actually be made in a manner that satisfies scientific goals: (1) requirements for advance planning for measurements using ODP tools, (2) an 
Technical Note No. 10

Page 8

overview of the tools routinely available from ODP, and (3) the compatibility of these tools with the various ODP coring and engineering systems.

\section{B. Advance Planning Requirements for Routine ODP Tools}

It is important to understand that just because a measurement is called "routine" does not mean that it can be made under all circumstances or without significant preparation by ODP technical support staff. Successful use of all downhole tools generally requires some warning prior to sailing, to make sure that proper supplies are available, and to undertake training of scientific and technical personnel. To ensure successful use of specific ODP downhole tools on a particular leg, it is advisable to start planning at least 1 year pre-cruise, and it is essential to keep two organizations fully informed: ODP itself, and the JOIDES panel structure via the Downhole Measurements Panel (DMP).

ODP is charged with implementing the scientific planning approved by the JOIDES Planning Committee (PCOM), which acts with the advice of the JOIDES panels, including DMP. About one year pre-cruise, DMP considers the proposed programs for logging and downhole measurements for each site of each leg, and passes its advice to PCOM, to ODP, and to LDEO. In its deliberations, DMP reviews measurements included within normal drilling proposals and separate proposals for special experiments. During the first 9 operating years of ODP, DMP has generally endorsed full programs of logging and downhole measurements at most sites, and PCOM has often accepted this advice unless ship time is very limited.

Thus, "normal" programs for use of ODP tools are usually approved for all sites by DMP and PCOM. However, details of implementing these programs are often not considered by these committees, but instead are left to the co-chief scientists to specify at the cruise planning meeting that normally occurs about 4-8 months pre-cruise at ODP. Co-chiefs for individual legs generally value the advice of DMP and consider it carefully when planning cruise operations. To ensure that ODP is fully equipped and staffed to support a program of routine downhole measurements on a given leg, it is essential that the co-chief scientists develop a comprehensive plan for these measurements well before this pre-cruise meeting. 
For extraordinary programs of downhole measurements with ODP tools - e.g., special holes devoted to pore-water sampling and temperature measurements, long-term observatories, or extensive programs of packer measurements - JOIDES approval is required well before the precruise meeting to guarantee the necessary ship time and extra effort by ODP. Such approval can be obtained by including the plans for special downhole measurements in the original drilling proposals considered by the JOIDES panels, or by submitting special proposals to JOIDES for consideration by DMP and PCOM. The most important point to glean from this manual is that use of these tools almost always requires some advance warning and preparation.

ODP technical staff (marine specialists) are now asked to perform more and more complicated tasks than they were when the program started. Due to berthing restrictions, there are never enough marine specialists to cover all shipboard labs 24 hours per day. ODP will generally staff each leg with at least one marine specialist trained in the use of one or more downhole tools, although this person will probably have catwalk, core lab, and other duties. The downhole tools marine specialist is generally responsible for preparing and deploying tools, initial transfer of raw data to the shipboard computer, and standard processing for archival at ODP. The shipboard scientists are then responsible for further processing and data interpretation. Some of the computer programs available shipboard for this processing are discussed in later chapters. The boundary between science and technical support for downhole tools is necessarily vague and depends strongly on the experience of the persons involved, the shipboard workload, and the scientific needs of each cruise.

Extra attention should be paid to laying groundwork for the use of nonstandard, third-party downhole tools during ODP cruises. The official guidelines for development, testing, and deployment of third-party tools during ODP cruises have been published in the JOIDES Journal (February 1991) and are now being prepared for general distribution as a pamphlet; these guidelines are listed and discussed in Chapter VIII of this Technical Note. Note that these are conceptual and planning guidelines; they do not include technical specifications (tool size and weight restrictions, data formats, etc.). It is the responsibility of the tool developer to contact and work with representatives of ODP and LDEO to make sure that third-party tools are compatible with shipboard operations. 
Technical Note No. 10

Page 10

\section{Overview of Downhole Measurements Provided by ODP}

ODP provides tools and technical support to allow downhole sampling of pore fluids from soft and semilithified formations, borehole fluids, fluids and core under pressure, and the measurement of several basic physical parameters: temperature, borehole pressure, bulk permeability, and APC and RCB core orientation. For some parametric measurements, several different tools are available for use in different situations, e.g., while coring sediments, between cores, or in open hole. In addition, the same tool often can be deployed in different configurations, or using several different techniques or strategies; a method that works well under some circumstances may fail in others. Some tools work well only under ideal hole conditions, some only in basement. Downhole tools scientists are advised to consult scientists and marine specialists who have experience running these tools to plan for particular legs and environments.

The ODP tools are generally not used with the logging cable, but instead are deployed using the drill string and/or coring line in several possible modes: (a) lowered on the coring line to either seat in the bit or run beyond the bit in open hole, (b) lowered to the bit as part of a coring assembly, (c) dropped down the drill pipe under "free-fall" conditions and later retrieved using the coring line, (d) built into the drill string, or (e) installed for long times in the seafloor. Often, the use of a particular downhole tool or technology (perhaps a combination of tools) requires careful advance planning in terms of the bottom-hole assembly (BHA) run at the end of the drill pipe. There are many options for using these tools, and the focus of this section and the next is to outline these options, leaving other details for subsequent chapters.

A sample ODP data sheet for downhole tools is shown in Figure I-1. This data sheet is used to maintain a deployment record for the WSTP and APC-tool; other downhole tools may require more or less complicated record keeping.

\section{Fluid sampling}

Two or three water-sampling temperature probes (WSTP) are routinely available for sampling fluids ahead of the bit in sediments soft enough for the probe to penetrate without cracking. As the 


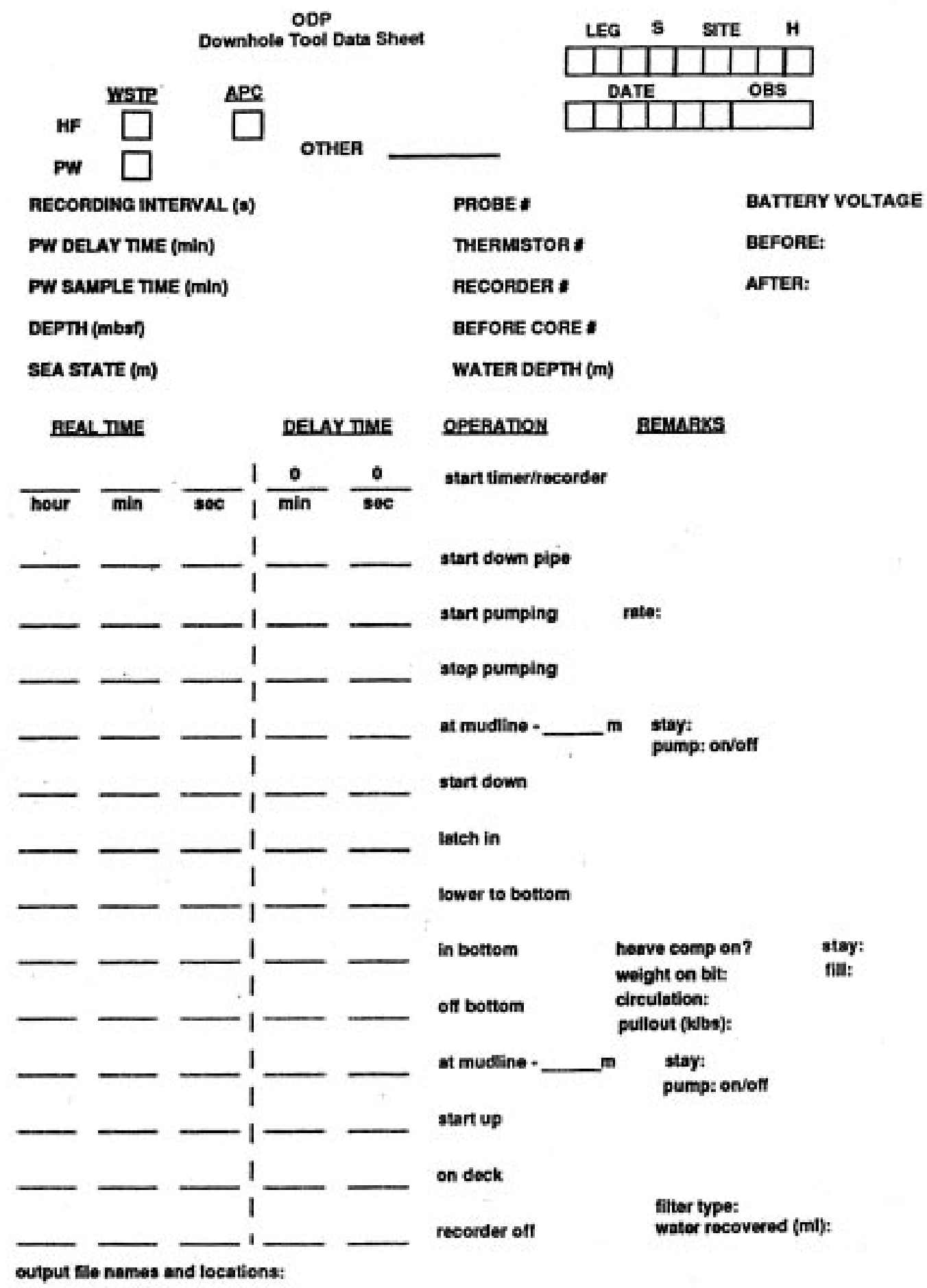

Figure 1-1. Downhole tools data sheet for WSTP and APC temperature tool. This sheet has been modified during ODP cruise for use with many downhole instruments. 
name implies, the WSTP is also capable of measuring temperature; an earlier version of the WSTP was equipped to measure hydrostatic and formation pressure as well. The WSTP is sometimes referred to as the Barnes/Uyeda probe or the Barnes sampler, after the original proponents and developers, R. Barnes and S. Uyeda.

The WSTP is run on the coring line between cores and therefore requires a break in coring and drilling operations (perhaps as long as 2-4 hours, depending on water and hole depth and measurement plan) to collect a sample. The probe lands in the BHA so that it extends up to $1 \mathrm{~m}$ into the sediment ahead of the bit; thus, the sediment to be cored next is disturbed. The WSTP presently collects three distinct fluid samples of varying size and quality. The sample chambers are arranged in series, and because of the sampling method (fluid is driven into the chamber by the contrast between ambient [hydrostatic] pressure in the formation and surface atmospheric pressure initially trapped in the sampling system), only a single sampling attempt can be made during each deployment. Fluid is drawn into the WSTP through a series of titanium, stainless-steel, and/or polyester filters, and through the end of a 1/16-in.titanium sampling tube mounted near the tip of the probe.

In open hole, the WSTP also can be used to sample borehole fluids ahead of the bit. Also, a largevolume borehole sample $(0.5 \mathrm{~L})$ can be taken with a tool made by Kuster Company, which is run on the coring line to a distance ahead of the bit deemed safe by the ODP Operations Superintendent. On recent ODP Legs 137, 139, and 148 third-party tools were borrowed "at cost" from Sandia National Laboratory and the Lawrence Berkeley Laboratory, for sampling hightemperature, potentially corrosive fluids. (In addition, Schlumberger tools for sampling open-hole fluids may be available through LDEO.)

\section{Formation temperature measurements}

Two types of ODP tools are routinely available for measuring temperatures in sediment and in open hole: the WSTP mentioned above, and miniature instruments deployed within special APC cutting shoes. These tools are normally used separately to obtain single measurements of temperature at discrete depths during a sequence of coring a hole through sediments. In addition, they can be configured together for simultaneous use without coring. Either tool or the 
Technical Note No. 10

Page 12

combination can be washed and pushed through soft sediments or run into open hole, to measure temperatures at multiple depths during a single lowering.

The first generation of APC temperature recorders was developed by R. Von Herzen and colleagues during the last several years of DSDP; ODP recently purchased 10 new instruments designed and built by Adara, a Canadian geotechnical firm. Like its predecessor, the new device monitors the temperature of a single sensor within the APC cutting shoe. The tool contains its own microprocessor, which is programmed to cycle through a series of sleeping and sampling periods. On penetration, the coring shoe must be held in the sediments for 10-15 minutes to obtain enough data to allow extrapolation beyond the thermal disturbance of insertion to in-situ temperature. The APC tool is relatively easy to operate, and with sufficient personnel can be run on successive cores in an APC hole. The tool is limited to depths where the force required for pullout is within safe limits (usually less than 80k-100k lb). The pullout force is generally greater when the APC temperature tool is run, compared to when an the ordinary APC shoe is run, because leaving the core barrel in the bottom for several minutes for the temperature measurement allows sediments to become packed in around the barrel. In practice, this pullout limit is often reached within the upper 100-150 m of sediment below the seafloor.

In contrast the WSTP has been run to depths greater than 400 mbsf, but it may require several hours per run on the coring line between cores. The WSTP data logger contains no microprocessor, and instead continuously samples at a fixed time interval the resistance of one or more thermistors mounted in a cylindrical probe. The WSTP is attached to the front end of a special core barrel, which functions as a pressure case for the electronics, batteries, data logger, and hydraulics, and is lowered down the drill string and pushed into the sediments. Again, the probe must be held in place for 10-15 minutes to obtain enough data to allow extrapolation to in-situ temperature.

\section{Permeability measurements using packers}

A packer produces a hydraulic seal in a borehole, allowing the hydrologic properties of the formation to be tested by applying differential fluid pressures to the isolated section. One packer is available for regular use in ODP, a drill-string straddle packer developed by K. Becker with an 
NSF grant to the University of Miami. This packer was manufactured by TAM International, and uses inflatable rubber/steel elements to seal the borehole. Several other packers have been brought aboard the Resolution as part of ODP cruises over the past several years, although none has been deployed successfully. These other tools included a rotatable drill-string packer and a wireline sampler, both of which have been retired, and the Geoprops probe (which has not yet undergone full field testing, on land or at sea).

With sufficient advance notice, the drill-string straddle packer is available for regular ODP use. The straddle packer can be run only as part of a noncoring BHA in reentry holes that penetrate reasonably stable formations, or possibly in less stable formations which have been "stabilized" with casing and a perforated liner. Permeability measurements in holes that penetrate unstable formations or in single-bit holes are not yet possible, although it was hoped that the WSTP (when it was equipped with pressure sensors) or the Geoprops probe might provide this information.

Any use of the drill-string packer requires considerable preparation, a significant amount of ship time, and the cooperation of several key shipboard personnel. The experienced ODL (SEDCO) core technicians take responsibility for preparing the drill string packer for deployment: the Operations Superintendent is responsible for finalizing the layout of the BHA, and technical support staff will assist with data logging. On some legs there may be a dedicated special tools engineer who can also assist with preparation and planning. The important task of directing the packer experiments (choosing depths from core and log data, supervising the test sequence, setting pump rates and volumes) falls to the packer scientist. The procedures for formation testing with the drill-string packers are somewhat complicated; interested scientists will need to become familiar with numerous aspects of ODP operations and procedures. A more complete discussion of packer measurements and data analysis is presented in Becker (1990a).

The prime data in packer testing are fluid pressures measured with gauges that are run from the rig floor and within the isolated zone when the packer is inflated. ODP supports the use of mechanical Kuster pressure recorders attached to "go-devils" that are dropped down the drill string into the packer and also enable the mechanisms for inflating the packer. The Kuster pressure records are scratched (quite accurately) onto small metal charts, which are read with a Kuster chart reader. 
Technical Note No. 10

Page 14

Becker owns a Kuster chart reader, as well as two digital pressure gauges built by Geophysical Research Corporation, which were deployed successfully during recent legs.

Formation-testing procedures at each setting depth typically run 6-8 hours, including the time required to drop and retrieve the go-devils. For permeability measurements using the straddle packer after coring a reentry hole, up to 24 hours may be required for a pipe trip (depending on water depth) to build the packer into a logging BHA. In some cases this operation will not actually involve extra time, as the packer is compatible with logging and it may be possible to accomplish a full program of logging and packer measurements during the single pipe trip required to deploy a logging BHA into a reentry hole. In the oil field, drill-string packers are often used in conjunction with borehole-fluid samplers (sometimes in the form of "sampling go-devils") to draw fluids from the isolated portion of the borehole. To date, this technology has not been applied in ODP, but it should be possible to do so in the future, provided there is interest and resources are allocated for the development of special samplers. Probably the greatest problem with sampling borehole fluids during packer testing is that the formation is likely to be charged with surface seawater which has been pumped down the pipe during drilling and earlier packer operations.

\section{Orientation of $A P C$ and $R C B$ cores}

In the past, the azimuth and deviation from vertical of (nonrotary) cores taken with the APC were routinely measured using an Eastman-Christensen magnetic "multishot" camera. This device records photographs of a magnetic compass and pendulum taken at pre-selected intervals. It is installed in a nonmagnetic sinker bar/pressure case that connects the coring line to the APC barrel, and must be used with a special nonmagnetic drill collar in the BHA.

An electronic replacement, or "digital multishot", has been developed for ODP use by Tensor, Inc. This instrument uses two accelerometers and three orthoganal magnetometers in combination with the nonmagnetic BHA and running hardware listed above. The tool records hole inclination (drift), azimuth, and magnetic tool face (core alignment) direction, either in single-shot or continuous modes. 
Because of specific BHA requirements, the decision to obtain oriented piston cores at a given site must be made before the BHA is made up and the pipe run into the hole. An extra 5 to 10 minutes per oriented core is required for handling the multishot assembly. Oriented piston cores can be obtained only to depths that are safe to core with the APC, typically on the order of 100-300 mbsf, depending on the force required for pullout.

The orientation of hard-rock cores is an exciting new ODP development. This technology has four independent components: electronic core orientation, sonic core monitor, core-scribing cutting shoe, and bit-depth indicator. The first two components listed above are presently digital, while the latter two are analog. Core orientation is accomplished with the electronic multishot, as described previously. The sonic core monitor is deployed as part of the core-barrel assembly; it records the time at which individual pieces of core enter the core barrel. The core scribe marks the core as it enters the barrel, with reference to a fixed direction. The bit-depth indicator records the position of the bit relative to the rig floor. Because hard-rock cores tend to break off during drilling, forming pieces centimeters to meters in length, each piece of core must be marked and oriented separately. At present the merging of all four data types described above is done manually.

\section{Long-term observatories (CORK)}

For some forms of downhole measurements, it is necessary to hold instrumentation in place for days to years, longer than is practical with the drill ship. In addition, there are occasions when having the borehole open to the overlying ocean compromises the critical parameters of interest

(e.g., formation pressure or borehole-fluid chemistry). In these instances, it will sometimes be desirable to initiate a long-term experiment using the CORK system, developed jointly by T. Pettigrew of ODP engineering, and collaborating scientists E. Davis, K. Becker, and B. Carson (Davis et al., 1992).

The CORK system is a combination of modified seafloor-reentry hardware, a hydraulic seal, and an instrumented sensing and logging package. Systems deployed thus far include the seal (consisting of a standard reentry cone with a modified casing hanger, plus the plugging device itself), a thermistor and pressure-sensor string, a fluid-sampling tube and a means of passing 
Technical Note No. 10

Page 16

borehole fluid through the CORK, and a data logger with a long-term power supply and the capability of dumping data to a submersible or remotely operated vehicle (ROV). Future systems may include data telemetry capabilities. The seal comprises two parts, an outer section which must be deployed and recovered by the drillship, and an inner section with the data logger and pressure case which can be recovered by the drillship or with an ROV.

The reentry system with cone and casing is first deployed as part of regular operations. A reentry hole is drilled and cased to the necessary depth with enough open hole left below the casing as required for the experiment (perforated casing or a liner also can be installed). The CORK seal itself is then made up, with one or more drill collars hanging below the CORK to hold the tool in place inside the reentry cone before the CORK is latched in. The CORK is lowered to the seafloor attached to the drill pipe and positioned with the drill collars in the throat of the cone. Borehole instrumentation and a data logger are lowered down inside the drill string on a coring line. The sensors pass through the CORK and into the cased hole, the data logger is latched inside the CORK, and the coring line is retrieved. The CORK is then set inside the reentry cone, and a ball is pumped down the drill pipe to land in the CORK running tool and allow the drill pipe to become pressurized. The pressure in the drill pipe is used to activate a latch ring in the CORK, which mates with grooves near the top of the casing inside the cone. This latching mechanism prevents the CORK from being forced out of the hole if the borehole below the cone becomes overpressured. After the CORK is latched in, a submersible/ROV platform is made up around the drill pipe and dropped to the seafloor. The drill pipe is then disconnected from the CORK and brought back to the surface, ending CORK installation.

\section{Pressure core sampler (PCS)}

The PCS is a free-fall deployable, hydraulically actuated, wireline-retrievable sampling device intended to return formation sediment and fluid samples at hydrostatic pressure. The system is fully compatible with standard APC/XCB drilling and coring hardware, allowing pressurized samples to be collected at any time from the mud line down to the depth of indurated formations or hard rock. The PCS is of particular interest to scientists studying frozen hydrates, gases, or other pressure-sensitive materials which tend to degrade during conventional core retrieval and rig-floor handling. Unlike the WSTP, which draws fluid and gas into an evacuated chamber and can 
therefore alter the chemistry of the sample, the PCS is intended to trap ambient pressure at the time that the sample is collected; also unlike the WSTP, the PCS returns a solid sample.

The PCS comprises several components: a detachable sample chamber, a ball-valve subassembly that traps pressure in the chamber, an actuator assembly that catches the ball valve and pulls the core tube into the sample chamber, a latch assembly that directs torque to the PCS cutting shoe and serves other standard coring functions, an accumulator that maintains pressure in the sample chamber, and a manifold assembly that allows fluid and gas within the PCS to be monitored and accessed under pressure. The PCS can recover a 42-mm-diameter core sample, $0.86 \mathrm{~m}$ long, at pressures up to $68.9 \mathrm{MPa}(10,000 \mathrm{psi})$. A detailed description of the PCS with tool drawings is available as ODP Technical Note 17 (Pettigrew, 1992).

\section{Compatibility of ODP Tools with ODP Operations and Engineering Systems}

ODP is an advanced and specialized drilling program, and has developed a wide range of engineering and coring systems for use in various operational situations. The ODP tools for downhole measurements are not compatible with certain engineering and coring systems, and care must be taken to verify that measurements can actually be made as planned.

Table I-1 summarizes the situations in which ODP downhole tools are normally used; these normal methods are discussed in the following chapters. There are many other operational configurations that are not listed in Table I-1 in which it may still be possible to make these kinds of measurements. The greater range of possibilities is considered in Table I-2, which summarizes the compatibility of the ODP downhole tools with the various ODP engineering and coring systems. The ODP downhole tools, coring systems, and engineering systems will be modified as necessary for enhanced performance, and the information presented in Tables I-1 and I-2 and in this manual is certain to change; this information is current as of the end of Leg 146 in November 1992. For further information, clarification, or updates regarding the compatibility of possible configurations, please contact the ODP Manager of Science Operations, Supervisor of Drilling Operations, or Supervisor of Development Engineering. 
Table I-1. "Normal" configurations for routine deployment of ODP downhole tools.

\begin{tabular}{|c|c|c|c|}
\hline Type of Measurement & Tool Used & Deployment Method & $\begin{array}{l}\text { Time Requireda } \\
\text { (hours) }\end{array}$ \\
\hline Pore water sampling & WSTP & Lowered on coring line & $2-4$ \\
\hline Borehole water sampling & $\begin{array}{l}\text { Kuster sampler } \\
\text { WSTP }\end{array}$ & $\begin{array}{l}\text { Lowered on coring line } \\
\text { Lowered on coring line }\end{array}$ & $\begin{array}{l}2-4 \\
2-4\end{array}$ \\
\hline Borehole pressure & Kuster K-3 & $\begin{array}{l}\text { Free fall with go-devil } \\
\text { Into packer }\end{array}$ & 3-6 \\
\hline Sediment temperature & $\begin{array}{l}\text { WSTP } \\
\text { APC tool (w/coring) } \\
\text { APC tool } \\
\text { (w/out coring) }\end{array}$ & $\begin{array}{l}\text { Lowered on coring line } \\
\text { Free fall with APC barrel } \\
\text { Lowered on coring line }\end{array}$ & $\begin{array}{l}2-4 \\
0.3 \\
2-4\end{array}$ \\
\hline Borehole temperature & $\mathrm{WSTP} \pm \mathrm{APC}$ & Lowered on coring line & $2-3$ \\
\hline APC-core orientation & Electronic multishot & with APC sinker bar & 0.2 \\
\hline $\mathrm{RCB}$-core orientation & $\begin{array}{l}\text { Electronic multishot } \\
\text { Sonic core monitor } \\
\text { Core scriber } \\
\text { Bit-depth indicator }\end{array}$ & $\begin{array}{l}\text { with } \mathrm{RCB} \text { barrel } \\
\text { with } \mathrm{RCB} \text { barrel } \\
\text { with } \mathrm{RCB} \text { core catcher } \\
\text { rig-floor indicator }\end{array}$ & $\begin{array}{l}0.2 \\
0.2 \\
0.2 \\
--\end{array}$ \\
\hline Permeability & Straddle packer & lowered with BHA & $6+$ \\
\hline Long-term observation & CORK & $\begin{array}{l}\text { varies, requires full } \\
\text { reentry system }\end{array}$ & $\begin{array}{l}12-24 \\
\text { plus cone } \\
\pm \text { casing }\end{array}$ \\
\hline $\begin{array}{l}\text { Pressurized core } \\
\text { and fluid sample }\end{array}$ & PCS & Free-fall core barrel & $2-4$ \\
\hline
\end{tabular}

- The times listed are in addition to regular coring operations. Times vary in almost all cases with water and hole depth, hole conditions, and overall scientific goals. For instruments requiring reentry cones or casing, additional time must be allocated for these operations. 


\begin{tabular}{|c|c|c|c|c|c|c|c|c|c|c|c|c|}
\hline & \multicolumn{2}{|c|}{ WSTP } & \multicolumn{3}{|c|}{ APC Temperature } & \multirow[b]{2}{*}{ 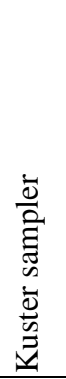 } & \multirow[b]{2}{*}{ 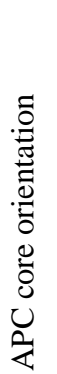 } & \multirow[b]{2}{*}{ 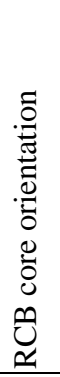 } & \multirow[b]{2}{*}{ 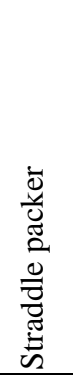 } & \multirow[b]{2}{*}{ 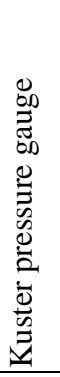 } & \multirow[b]{2}{*}{$\begin{array}{l}\frac{v}{0} \\
0 \\
0\end{array}$} & \multirow[b]{2}{*}{ 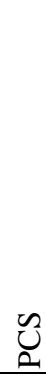 } \\
\hline & 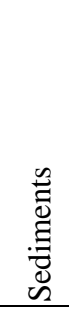 & 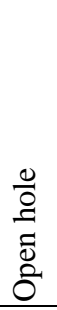 & 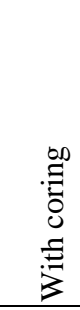 &  & $\begin{array}{l}\frac{0}{0} \\
\frac{1}{\tilde{D}} \\
\stackrel{0}{0}\end{array}$ & & & & & & & \\
\hline \multicolumn{13}{|l|}{ Downhole Tools } \\
\hline WSTP (sediments) & - & $?$ & $\mathrm{P}$ & $\mathrm{C}$ & $?$ & $\mathrm{P}$ & $\mathrm{P}$ & $\mathrm{P}$ & $\mathrm{X}$ & $?$ & $\mathrm{X}$ & $\mathrm{P}$ \\
\hline WSTP (open hole) & $?$ & - & $\mathrm{P}$ & $\mathrm{P}$ & $\mathrm{C}$ & $\mathrm{P}$ & $\mathrm{P}$ & $\mathrm{P}$ & $\mathrm{P}$ & $\mathrm{P}$ & $\mathrm{X}$ & $\mathrm{P}$ \\
\hline APC temperature (with coring) & $\mathrm{P}$ & $\mathrm{P}$ & - & $\mathrm{P}$ & $?$ & $?$ & $\mathrm{C}$ & $\mathrm{X}$ & $\mathrm{X}$ & $\mathrm{P}$ & $\mathrm{X}$ & $\mathrm{P}$ \\
\hline APC temperature (without coring) & $\mathrm{C}$ & $\mathrm{P}$ & $\mathrm{P}$ & - & $?$ & $?$ & $?$ & $\mathrm{X}$ & $\mathrm{X}$ & $?$ & $\mathrm{X}$ & $\mathrm{P}$ \\
\hline APC temperature (open hole) & $?$ & $\mathrm{C}$ & $?$ & $?$ & - & $\mathrm{P}$ & $?$ & $\mathrm{X}$ & $\mathrm{P}$ & $\mathrm{P}$ & $\mathrm{X}$ & $\mathrm{P}$ \\
\hline Kuster sampler & $\mathrm{P}$ & $\mathrm{P}$ & $?$ & $?$ & $\mathrm{P}$ & - & $?$ & $?$ & $\mathrm{P}$ & $\mathrm{P}$ & $\mathrm{X}$ & $\mathrm{P}$ \\
\hline APC core orientation & $\mathrm{P}$ & $?$ & $\mathrm{C}$ & $?$ & $?$ & $?$ & - & $\mathrm{X}$ & $\mathrm{X}$ & $\mathrm{P}$ & $\mathrm{X}$ & $\mathrm{P}$ \\
\hline $\mathrm{RCB}$ core orientation & $\mathrm{P}$ & $?$ & $\mathrm{X}$ & $\mathrm{X}$ & $\mathrm{X}$ & $?$ & $\mathrm{X}$ & - & $\mathrm{X}$ & $?$ & $\mathrm{X}$ & $\mathrm{X}$ \\
\hline Straddle packer & $X$ & $\mathrm{P}$ & $X$ & $\mathrm{X}$ & $\mathrm{P}$ & $\mathrm{P}$ & $\mathrm{X}$ & $\mathrm{X}$ & - & $\mathrm{C}$ & $\mathrm{X}$ & $\mathrm{X}$ \\
\hline Kuster pressure & $?$ & $\mathrm{P}$ & $\mathrm{P}$ & $?$ & $\mathrm{P}$ & $\mathrm{P}$ & $\mathrm{P}$ & $?$ & $\mathrm{C}$ & - & $\mathrm{X}$ & $?$ \\
\hline CORK & $X$ & $\mathrm{X}$ & $\mathrm{X}$ & $\mathrm{X}$ & $X$ & $\mathrm{X}$ & $\mathrm{X}$ & $\mathrm{X}$ & $\mathrm{X}$ & $\mathrm{X}$ & - & $\mathrm{X}$ \\
\hline Pressure core sampler & $\mathrm{P}$ & $\mathrm{P}$ & $\mathrm{P}$ & $\mathrm{P}$ & $\mathrm{P}$ & $\mathrm{P}$ & $\mathrm{P}$ & $\mathrm{X}$ & $\mathrm{X}$ & $?$ & $\mathrm{X}$ & - \\
\hline \multicolumn{13}{|l|}{ Rig Floor Systems } \\
\hline Coring line & $\mathrm{R}$ & $\mathrm{R}$ & $\mathrm{R}$ & $\mathrm{R}$ & $\mathrm{R}$ & $\mathrm{R}$ & $\mathrm{R}$ & $\mathrm{R}$ & $\mathrm{R}$ & $\mathrm{R}$ & $\mathrm{R}$ & $\mathrm{R}$ \\
\hline Drill-string heave compensator & $\mathrm{C}$ & $\mathrm{C}$ & $\mathrm{C}$ & $\mathrm{C}$ & $\mathrm{C}$ & $\mathrm{C}$ & $\mathrm{C}$ & $\mathrm{C}$ & $\mathrm{R}$ & $\mathrm{C}$ & $\mathrm{R}$ & $\mathrm{R}$ \\
\hline Wireline logging & $\mathrm{P}$ & $\mathrm{P}$ & $\mathrm{P}$ & $\mathrm{P}$ & $\mathrm{P}$ & $\mathrm{P}$ & $\mathrm{P}$ & $\mathrm{P}$ & $\mathrm{P}$ & $\mathrm{P}$ & $\mathrm{X}$ & $\mathrm{P}$ \\
\hline Side-entry subassembly & $\mathrm{P}$ & $\mathrm{P}$ & $\mathrm{P}$ & $\mathrm{P}$ & $\mathrm{P}$ & $\mathrm{P}$ & $\mathrm{P}$ & $\mathrm{P}$ & $\mathrm{P}$ & $?$ & $\mathrm{X}$ & $\mathrm{X}$ \\
\hline \multicolumn{13}{|l|}{ Hole Types and Casing Systems } \\
\hline Single-bit hole (no re-entry) & $\mathrm{C}$ & $\mathrm{C}$ & $\mathrm{C}$ & $\mathrm{C}$ & $\mathrm{C}$ & $\mathrm{C}$ & $\mathrm{C}$ & $\mathrm{C}$ & $\mathrm{X}$ & $?$ & $\mathrm{X}$ & $\mathrm{C}$ \\
\hline Cased reentry hole & $X$ & $\mathrm{C}$ & $\mathrm{X}$ & $\mathrm{X}$ & $\mathrm{C}$ & $\mathrm{C}$ & $\mathrm{X}$ & $\mathrm{C}$ & $\mathrm{C}$ & $\mathrm{C}$ & $\mathrm{C}$ & $\mathrm{X}$ \\
\hline Free-fall funnel reentry hole & $\mathrm{C}$ & $\mathrm{C}$ & $\mathrm{C}$ & $\mathrm{C}$ & $\mathrm{C}$ & $\mathrm{C}$ & $\mathrm{C}$ & $\mathrm{C}$ & $\mathrm{C}$ & $\mathrm{C}$ & $\mathrm{X}$ & $\mathrm{C}$ \\
\hline Drill-in casing & $\mathrm{C}$ & $\mathrm{C}$ & $\mathrm{C}$ & $\mathrm{C}$ & $\mathrm{C}$ & $\mathrm{C}$ & $\mathrm{C}$ & $\mathrm{C}$ & $\mathrm{X}$ & $\mathrm{C}$ & $\mathrm{X}$ & $\mathrm{C}$ \\
\hline Hard-rock guide base & $X$ & $\mathrm{C}$ & $\mathrm{X}$ & $\mathrm{X}$ & $\mathrm{X}$ & $\mathrm{C}$ & $\mathrm{X}$ & $\mathrm{C}$ & $\mathrm{C}$ & $\mathrm{C}$ & $\mathrm{X}$ & $\mathrm{X}$ \\
\hline Unsupported hard-rock spud & $\mathrm{X}$ & $\mathrm{C}$ & $\mathrm{X}$ & $\mathrm{X}$ & $\mathrm{X}$ & $\mathrm{C}$ & $\mathrm{X}$ & $\mathrm{C}$ & $\mathrm{X}$ & $\mathrm{C}$ & $\mathrm{X}$ & $\mathrm{X}$ \\
\hline \multicolumn{13}{|l|}{ Coring Systems } \\
\hline Rotary coring system & $\mathrm{P}$ & $\mathrm{P}$ & $\mathrm{X}$ & $\mathrm{X}$ & $\mathrm{X}$ & $\mathrm{P}$ & $\mathrm{X}$ & $\mathrm{C}$ & $\mathrm{X}$ & $\mathrm{P}$ & $\mathrm{X}$ & $\mathrm{X}$ \\
\hline Advanced piston corer & $\mathrm{P}$ & $\mathrm{P}$ & $\mathrm{C}$ & $\mathrm{C}$ & $\mathrm{P}$ & $\mathrm{P}$ & $\mathrm{C}$ & $\mathrm{X}$ & $\mathrm{X}$ & $\mathrm{P}$ & $\mathrm{X}$ & $\mathrm{P}$ \\
\hline Extended core barrel & $\mathrm{P}$ & $\mathrm{P}$ & $\mathrm{P}$ & $\mathrm{P}$ & $\mathrm{P}$ & $\mathrm{P}$ & $\mathrm{P}$ & $\mathrm{X}$ & $\mathrm{X}$ & $\mathrm{P}$ & $\mathrm{X}$ & $\mathrm{P}$ \\
\hline Motor-driven core barrel & $\mathrm{P}$ & $\mathrm{P}$ & $\mathrm{P}$ & $\mathrm{P}$ & $\mathrm{P}$ & $\mathrm{P}$ & $\mathrm{P}$ & $\mathrm{X}$ & $\mathrm{X}$ & $\mathrm{P}$ & $\mathrm{X}$ & $\mathrm{P}$ \\
\hline Diamond coring system & $X$ & $\mathrm{X}$ & $X$ & $\mathrm{X}$ & $\mathrm{X}$ & $\mathrm{X}$ & $\mathrm{X}$ & $\mathrm{X}$ & $\mathrm{X}$ & $?$ & $\mathrm{X}$ & $\mathrm{X}$ \\
\hline \multicolumn{13}{|l|}{ Bit Releases and Float Valves } \\
\hline Mechanical bit release & $\mathrm{C}$ & $\mathrm{C}$ & $\mathrm{C}$ & $\mathrm{C}$ & $\mathrm{C}$ & $\mathrm{C}$ & $\mathrm{C}$ & $\mathrm{C}$ & $\mathrm{X}$ & $?$ & $\mathrm{X}$ & $\mathrm{C}$ \\
\hline Passive float valve & $\mathrm{C}$ & $\mathrm{C}$ & $\mathrm{C}$ & $\mathrm{C}$ & $\mathrm{C}$ & $\mathrm{C}$ & $\mathrm{C}$ & $\mathrm{C}$ & $?$ & $?$ & $\mathrm{X}$ & $\mathrm{C}$ \\
\hline Lockable float valve & $\mathrm{C}$ & $\mathrm{C}$ & $\mathrm{C}$ & $\mathrm{C}$ & $\mathrm{C}$ & $\mathrm{C}$ & $\mathrm{C}$ & $\mathrm{X}$ & $?$ & $?$ & $\mathrm{X}$ & $\mathrm{C}$ \\
\hline \multicolumn{13}{|l|}{$\mathrm{P}=$ can do on same pipe trip } \\
\hline \multicolumn{13}{|c|}{$\mathrm{C}=$ can do on same wireline trip, or fully compatible with listed system } \\
\hline \multicolumn{8}{|c|}{$\mathrm{R}=$ required for operation of tool } & & & & & \\
\hline $\mathrm{X}=$ incompatible in same pipe trip, & & & & & & & & & & & & \\
\hline
\end{tabular}


Technical Note No. 10

Page 18

\section{IN-SITU FLUID SAMPLING}

\section{A. Introduction}

Tools to sample fluids in situ in oceanic boreholes were first built during DSDP and have continued to evolve during ODP. Barnes (1979) pioneered this effort, and has developed two generations of tools designed to sample sedimentary pore fluids through a probe that extends about $1 \mathrm{~m}$ ahead of the bit. The first-generation tool was modified during DSDP to allow concurrent measurements of temperature (Yokota et al., 1980; Uyeda and Horai, 1982) and/or fluid pressure (von Huene, 1985). These capabilities were integrated into the redesigned second-generation tool (Barnes, 1988), which could accomplish all three objectives. This design was refined before Leg 139 to facilitate sampling of high-temperature $\left(200^{\circ} \mathrm{C}\right)$, highly reactive fluids. The Leg 139 iteration of the WSTP did not have the pressure-sensing capabilities available with the previous generation, as the section of the tool which contained the pressure transducers was refitted with a high-temperature, high-pressure electrical feed-through to hydraulically isolate the tool electronics from the probe tip. Discovery of corrosion on some of the high-temperature fittings (which were difficult to clean) during Leg 143 led to the retrofitting of the WSTPs with some lower temperature components. The tools will probably remain outfitted with a mixture of high- and lower temperature components and single thermistors for the next few years, until scheduled hightemperature work requires their upgrading.

Barnes' (1979) goals were to sample sedimentary pore fluids in situ in order to (1) complement and calibrate the chemical analyses of pore fluids squeezed from cores, and (2) provide undisturbed samples for determination of in-situ concentrations of dissolved gases. The tools developed for these purposes have also proven useful in sampling borehole fluids that have partially re-equilibrated with pore fluids in reentered basement holes, such as Holes 418A and 504B. However, the borehole fluids that the WSTP samples in the vicinity of the bit are often displaced and/or contaminated by the massive drill string. When it is essential to avoid the effect of the drill string on borehole fluids in a reentry hole, ODP has available Kuster water samplers that can be run on the coring line through the bit, to sample fluids from open, undisturbed holes. ODP 
has also borrowed more sophisticated borehole samplers for some applications, and additional sampling projects are being developed (see Chapter VIII).

For a variety of reasons, the WSTPs are not presently scheduled to be refitted with pressuresensing capabilities. Pore pressure and permeability are crucial parameters that reflect and influence hydrogeologic and tectonic processes, but they are difficult to measure in situ because the emplacement of a measuring tool often disturbs the formation and fluid pressures in the vicinity of the tool. Perhaps in part for this reason, pressure data collected with the WSTP during DSDP Leg 84 and ODP Legs 110 and 112 have never been interpreted quantitatively. Numerical modeling suggests that in clay-rich sediments, decay of enough of the pressure disturbance resulting from probe insertion to make possible extrapolation to in-situ conditions and/or calculation of permeability is likely to require leaving the tool in bottom for hours to tens of hours (W. Fang and M. Langseth, pers. comm., 1992), which is not possible during ODP operations. In more permeable sediments, this decay may occur more quickly, but more permeable sediments are also more likely to be charged with fluids (surface seawater) which are pumped into the formation at high pressure during coring and drilling. Finally, in any kind of sediments, drilling requires putting substantial weight on the bottom of a hole. Insertion of the WSTP also requires setting the bit on bottom for a few seconds during deployment with an APC/XCB BHA, or leaving the bit on bottom in the case of RCB deployment. As the drill-string heave compensator can control bit weight to no better than $\pm 5000 \mathrm{lb}$, sediments and pore pressures immediately below the bit are sure to be modified by drilling and probe insertion to such an extent that interpretations of WSTP pressure data are likely to be of questionable value.

\section{B. Pore-Fluid Sampling with the WSTP}

Barnes (1979) describes the first generation of WSTP, which was modified several times during DSDP, and was often called the "Barnes sampler" or the "Barnes-Uyeda probe". Barnes (1988) describes the redesigned WSTP, and the excellent results obtained with the prototype during Leg 110. Figure II-1 is a cartoon drawing of the latest WSTP design. The WSTP is a self-contained, battery-powered tool adapted to an inner core-barrel assembly that is deployed in the BHA. The sample chamber and electronics (timer and temperature/pressure data recorder) are contained 


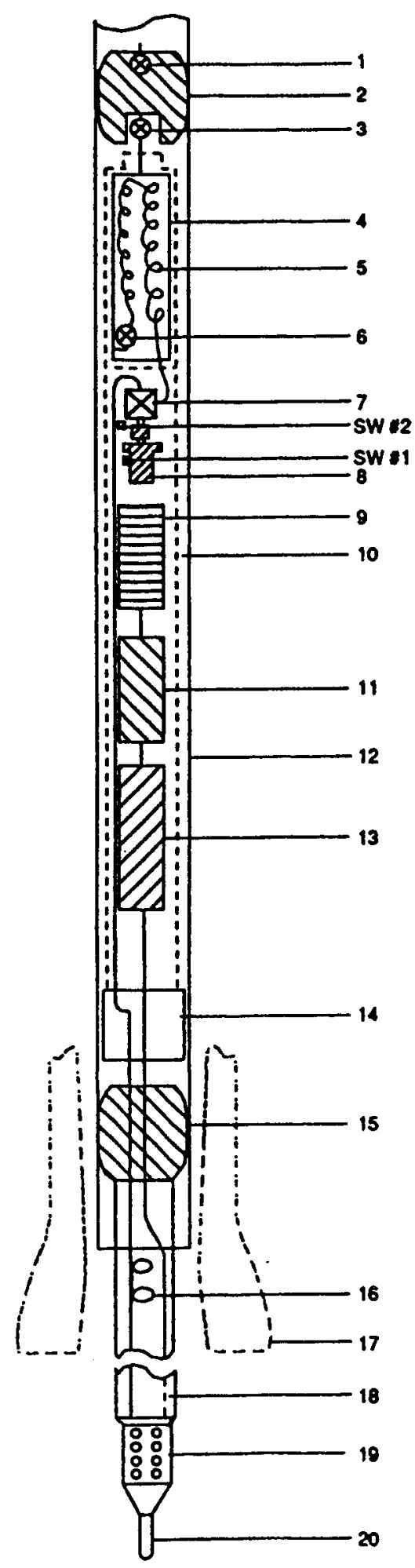

Figure II-1. Block diagram (not to scale) of water-sampling temperature probe (WSTP). Solid lines reveal fluid pathways.

1. pressure case relief valve;

2. upper pressure case bulkhead;

3. sample chamber pressure relief valve;

4. sample overflow chamber;

5. sample coil;

6. sample coil pressure relief check valve;

7. sampling control valve;

8. DC gear motor $(S W \# 1=$ motor shut-off and reversing switch, SW\#2 = manual motor switch);

9. timer controller;

10. inner case assembly;

11. battery pack (NiCad or Lithium);

12. pressure case (modified core barrel);

13. data logger;

14. high-temperature electrical pass-through (used for high-temperature work only);

15. lower pressure case bulkhead;

16. fluid sampling tubing;

17. drill bit;

18. electrical connection to thermistor;

19. pore-fluid filter and sampling assembly;

20. thermistor housing tip. 
Technical Note No. 10

Page 20

within the inner core barrel; only a strong shaft and probe tip (containing the sampler filter and temperature sensors) protrude beyond the bit.

ODP staff have written a detailed shipboard operating manual for the new generation of WSTPs, copies of which are available at ODP/TAMU and on the drillship. Table II-1 shows a list of topics covered in the WSTP "cookbook". The cookbook is available in hard and electronic form so that it can be updated as tool specifications and protocols change. Table II-2 shows the specifications for the WSTP, as configured during Leg 146. These specifications are subject to change on a leg by leg basis; interested scientists are advised to check with technical support staff in advance of their cruise for updated specifications.

The WSTP has always been a tool of compromise, remaining relatively unchanged in basic design since its introduction. The tool has never returned geochemically useful samples better than about $50 \%$ of the time on a leg, even in ideal lithologies and hole conditions. Successful in-situ fluid sampling with the WSTP requires that 1) the probe penetrate well into virgin formation, 2) the formation "pack off" around the sample filter, 3) the water content of the sediment be high enough to allow rapid drainage when the formation is exposed to a pressure differential (as the tool begins sampling), 4) the formation is not so hard as to crack on tool penetration, and 5) the formation is not so fine grained as to clog the filter assembly. These requirements are likely to remain until the WSTP undergoes a radical redesign or is replaced, neither of which is presently budgeted or planned.

The following overview of the methods to deploy the WSTP for sampling pore fluids from sediments is excerpted from sections of the most recent WSTP cookbook.

\section{General tool design and preparation}

In fluid sampling mode, the WSTP consists of a probe tip and filter assembly; a probe shaft; a lower bulkhead with hydraulic and electrical feed-troughs; a stainless steel cylindrical shell comprising several compartments containing an electrical pass-through, a data logger (for temperature data), batteries, and a fluid sampling timer; an upper bulkhead; and sampling coils 
Table II-1. List of topics covered in the water-sampling temperature probe (WSTP) cookbook.

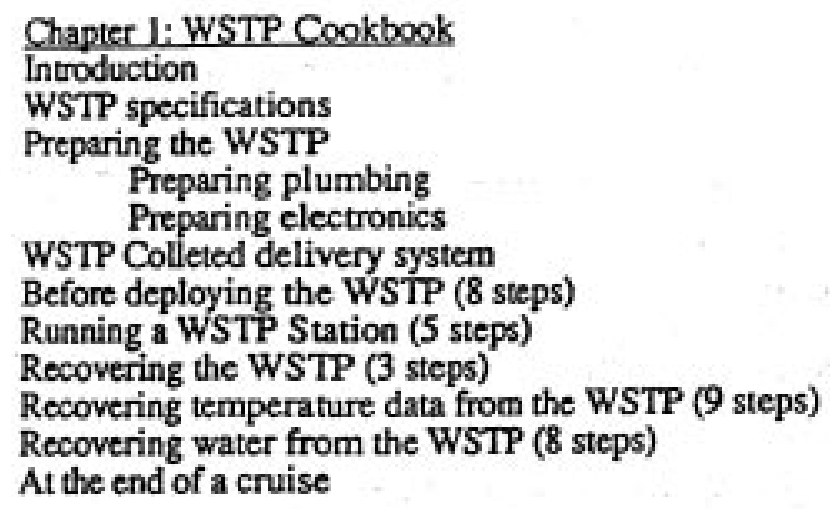

Appendix I: Thermistor ranges

Appendix II: Photos

Appendix III: Installing WSTPfis

Appendix IV: Example input/output

Appendix V:Decay files

Appendix VI: Data shees

Appendix VII: Data dumping and conversion

Appendix VIII:Parts lists

Appendix DX:Memos and notes

Appendix X: Wiring and electrical

Appendix XI: Timer

Appendix XII: Parts drawings

Appendix XIII: Coils and filters 
Table II-2. WSTP specifications as of Leg 146.

Materials of construction: $\quad 304$ and 316 stainless steel, 4130 alloy, nitrile (high-temperature configuration includes titanium, teflon, Kalrez)

Maximum depth: $\quad 10,000 \mathrm{~m}$ at $0-30^{\circ} \mathrm{C}, 6500 \mathrm{~m}$ at high temperatures

Maximum temperature: $\quad 125^{\circ} \mathrm{C}$ operating and environmental, $200^{\circ} \mathrm{C}$ environmental with minor modifications (o-rings, seals, wiring)

Number of fluid

samples per run:

One (in as many as three splits)

Sample volumes:

High quality sample in stainless or titanium tubing - 6-10 ml High quality sample in copper (for fluids and gas) - 20-40 ml Overflow sample with approximately $70 \mathrm{ml}$ distilled water $-1000 \mathrm{ml}$ All samples may be available simultaneously; chambers filled in order above

Operating time: $\quad$ Fluid sample delay $-0.0-6.6$ hours Fluid sampling time $-0-59$ minutes accuracy $- \pm 0.4 \%$

Temperature samplingfrequency: $\quad 4.369 \mathrm{~s}$

Number of temperature measurements: 2048

Digital resolution: 12-bit

Maximum temperature measurement time: $\quad 2.5$ hours

Temperature accuracy: $\quad 0.1-2{ }^{\circ} \mathrm{C}$ nominal, $1^{\circ} \mathrm{C}$ at upper temperature limit

Temperature resolution: $\quad 0.05^{\circ} \mathrm{C}$

Limitations: $\quad$ Successful in-situ fluid sampling with the WSTP requires that 1 ) the probe penetrate well into virgin formation, 2) the formation "pack off" around the sample filter, 3 ) the water content of the sediment be high enough to allow rapid drainage when the formation is exposed to a pressure differential (as the tool begins sampling), 4) the formation is not so hard as to crack on tool penetration, and 5) the formation is not so fine-grained as to clog the filter assembly. Requirements are relaxed somewhat for temperature measurements, although sea conditions also must allow probe to remain stable. 
surrounded by an overflow chamber (Fig. II-1). The main body of the WSTP is contained within a long cylindrical shell, split longitudinally. The lower half of the shell is constructed from a single piece of metal, while the upper half is divided into two or more pieces, each of which covers separate compartments.

Most of the WSTP is stainless steel, but some components are titanium. Titanium parts presently include the probe filter assembly (including inner and outer perforated sleeves, Fig. II-2), 1/16-in. and 1/8-in. fluid sampling tubing, and some fittings and valves. Fluid filters are composed of titanium and stainless screen or titanium and polyester screen, and are held together with hightemperature (Philly Clad) epoxy (Fig. II-2). The filter is housed below a protected titanium sheath, which is perforated with 1/4-in. holes. The filter covers a section of 1/16-in. titanium tubing, connected at one end to the hydraulics of the WSTP via a plug in the lower bulkhead, and open at the other end near the middle of the filter assembly. The opening in this tubing is the fluid-intake port.

A single fluid sample can be collected during each run of the tool. The fluid-sampling chamber is separated into three distinct parts. About 10-15 mL of fluid is trapped within reusable 1/8-in. (stainless or titanium) tubing wrapped in a coil; up to $50 \mathrm{~mL}$ is trapped in a copper coil, which can be crimped for later gas analyses; up to $1000 \mathrm{~mL}$ of sample (mixed with approximately $75 \mathrm{~mL}$ of distilled water and drill water) may be trapped in a stainless steel overflow chamber which surrounds the smaller coils.

Running the WSTP to collect a fluid sample may require the following operations (depending on run parameters and tool status): partial assembly and disassembly of the inner case, pressure case, and probe; flushing and back pressuring the water lines before a run, and extracting the fluid sample after a run; setting the timer for the appropriate delay and sample intervals; checking and/or changing and/or charging the batteries; keeping the driller advised of scientific and operational considerations during the station; recording events on a Downhole Tools data sheet during the station; and monitoring the condition of all sampler parts and repairing or replacing them before they cause problems. 
Technical Note No. 10

Page 22

Before each use the sampler plumbing is flushed with distilled water using a high-pressure pump and assorted rigging in the Downhole Tools lab. Sample coils of an appropriate volume are available on the ship or can be constructed from spare tubing. There is a check valve installed in front of the coils which holds some of the in-situ pressure in the sample coils upon recovery (generally up to 500-1000 psi). A timer is set so that a motor will be activated to open and close the valve connecting the sampling tube behind the filter to the sample coils and chamber, which are kept at surface atmospheric pressure. The timer is set with a delay time (after which the valve is opened) and a sampling time interval (after which the valve is closed). The timer is activated by hooking it up to a charged battery pack and depressing a reset switch.

\section{Tool deployment}

After the WSTP is dressed for deployment, a landing sub is screwed in place around the base of the probe shaft, and the tool is carried out to the rig floor and made up to its pressure case. The landing sub provides protection during deployment and acts as an upset to limit the extension of the tool through the bit. The WSTP pressure case is a modified core barrel which screws onto the lower bulkhead, covering everything from the bulkhead to the back of the tool (Figure II-1). The tool is lowered down the drill pipe on the coring line. Downhole conditions vary, and the procedures used to collect a useful sample will vary accordingly. Fill at the bottom of a hole is a normal occurrence, however, so it is important to remove as much fill as possible and permit the probe to penetrate undisturbed sediment. The driller can keep fill washed out of the hole by pumping continuously as the tool descends. The operator may wish to stop pumping and tool descent just above mud line for 5-10 minutes to record the ambient bottom water temperature, if temperature data are being collected. Pumping then resumes, and the tool is lowered into the BHA and landed. Immediately before the tool is latched in, the driller can lower the bit and "clean up" the bottom of the hole. The bit should then be raised several feet above hole bottom for long enough to latch the sampler into place, with only the probe shaft and filter tip extending beyond the drill bit. The drill string is then lowered (while still pumping) until the bit reaches the hole bottom, as indicated by a loss of hook weight. The probe is usually pressed in with about 10,000-12,000 lb. The probe should be lowered into the bottom at least several minutes before the timer causes the motor to open the sampling valve, and held in bottom until several minutes after the sampling time ends (when the sampling valve is closed). 
Several deployment methods have been devised for the WSTP over the years, with (a) latched-in operation (RCB)and (b) colleted delivery (APC/XCB) being the safest and most reliable. Free-fall deployment, which has been used in the past, may damage the probe tip and filter assembly of the WSTP and probably should not be attempted.

\section{a. Latched-in operation}

Latched-in operation can be used during any drilling mode, but it is the only normal deployment method available during RCB drilling. The WSTP is landed at the bit and mechanically held in place. The bit is then lowered to bottom to force the tool into the formation. Should the formation prove too hard for WSTP penetration, the probe will retract back into the bit. The bit is held on bottom with at least $5000 \mathrm{lb}$ of collar weight, and the drill string heave compensator is engaged. After the sampling time has expired, the BHA and WSTP are raised off bottom, and the tool is retrieved.

\section{b. Colleted delivery operation}

The colleted delivery system is compatible with the APC/XCB drilling BHA, and allows the drill pipe to be decoupled from the WSTP during sampling. Deployment procedures are the same as for latched-in operation, as described above, until the WSTP is pressed into the seafloor. With the collet system, the driller can press the tool into the formation, then lift the bit off bottom. The tool remains in the formation, and the drill pipe and BHA can stroke over a total range of about $7 \mathrm{~m}$ without disturbing the tool. When the WSTP sampling time has expired, the tool is pulled out of the formation by raising the BHA then retreived with the wireline. As with the RCB deployment system, if the formation proves to be too hard to allow WSTP penetration, the tool retracts back into the bit.

When it is equally important to measure in-situ temperature as to collect a fluid sample, it may be necessary to modify these methods, as described in Chapter III. For example, while only one water sample can be taken during a single deployment, it is possible to make several measurements of temperatures at different depths during the same deployment. It is critical to 
Technical Note No. 10

Page 24

carefully plan the testing sequence so that the probe is at the desired depth at the proper time for fluid sampling.

Both latched-in operation and colleted delivery allow the WSTP to retract back inside the bit if the formation proves too hard for penetration, so ODP scientists should not be overly concerned with damaging the tool or breaking off a probe because the formation is lithified. Some surprisingly hard formations have yielded good fluid samples with the WSTP, although it is likely that the formation will fracture during probe penetration before it becomes too hard for WSTP insertion. A fractured formation will generally allow borehole water to be drawn in through the WSTP filter, compromising the fluid sample. A reliable temperature measurement (as described in the next section) is not necessarily an indication that a good fluid sample has been collected, nor is the reverse true. Each fluid sample and set of temperature measurements must be judged on its own merits.

Fluid circulation can continue while the WSTP is in bottom throughout the sampling period, provided that the formation is reasonably competent. Often it is desirable to continue circulation throughout a station to keep the tool (1) free of fill which might bury and trap it in an unstable hole, or (2) cool in a hydrothermal setting. It is difficult to sample pore fluids from very shallow sediments, as the sediments generally are not competent enough to support the weight of the bit (or even the tool) and may be washed away by circulating fluids. Also, the WSTP is usually not deployed until enough hole has been drilled so that a significant portion of the BHA is below mud line, often after the third or fourth core. In practice, the WSTP has been effective at depths of about twenty to several hundred meters below seafloor.

When the tool is brought back on deck, the downhole tools scientist or marine specialist should remind the rig crew to clean off the filter tip with a high-pressure ("car-wash") water hose. Mud that is packed around the filter assembly is very difficult to clean when dry, and could potentially clog the filter during later deployments. After the probe tip is clean, the WSTP is brought up to the Downhole Tools Lab and placed on a bench. Downhole-tools marine specialists will assist with recovery of the fluid sample, clean out (or exchange) the filter if necessary, and prepare the tool for its next deployment. 


\section{Borehole Fluid Sampling with WSTP and Kuster Tools}

In addition to sampling pore fluids in sediments, the WSTP can also be used to sample borehole fluids, as can fluid samplers made by Kuster Company of Long Beach, California. The WSTP is described in the previous section; Figure II-3 shows the Kuster sampler, and Table II-3 gives its operating specifications. ODP purchased three of the 500-mL Kuster samplers for Leg 111 . The Kuster tools were never operated successfully during Leg 111, primarily because the tools tended to trigger prematurely. Kuster has refurbished one of these tools with a more robust triggering mechanism, and that tool is now available for use on future cruises, although it has never been field tested. Kuster provided relatively brief operating instructions, which are available from ODP and are summarized in the following paragraph.

The Kuster sampler is a simple tool consisting of a sample bottle with an inlet valve, two nonreturn valves, a locking device, and a mechanical clock. In operation, the clock is wound and the tool is lowered into open hole on the coring line. When the clock reaches the programmed sampling time (60 or 150 minutes after being wound), it releases the locking mechanism, allowing the inlet valve to open and the sample chamber to fill. When the fluid pressure inside the chamber plus the spring pressure of the non-return valve reaches in-situ fluid pressure, the non-return valves close and seal the sample chamber. Once the sample has been taken, the sampler should not be lowered any deeper into the hole, as increasing the external pressure will re-open the valves and allow the sample to be contaminated. There may also be leakage if warm sampled fluids are cooled during ascent, resulting in a significant reduction in fluid specific volume. The associated reduction in pressure inside the sampler may be sufficient to overcome the strength of the spring which seats the sampler valve.

When the tool is retrieved to the surface, the pressurized sample must be released using a special extractor body, to which a system of high-pressure valves and hoses is attached. There is no "standard" valve/hose system available, and a custom system may need to be constructed for each leg, depending on such factors as anticipated sample pressures, requirements to preserve dissolved gases, etc. It is the responsibility of the co-chief scientists, in consultation with participating fluid 
Table II-3. Kuster water sampler specifications.

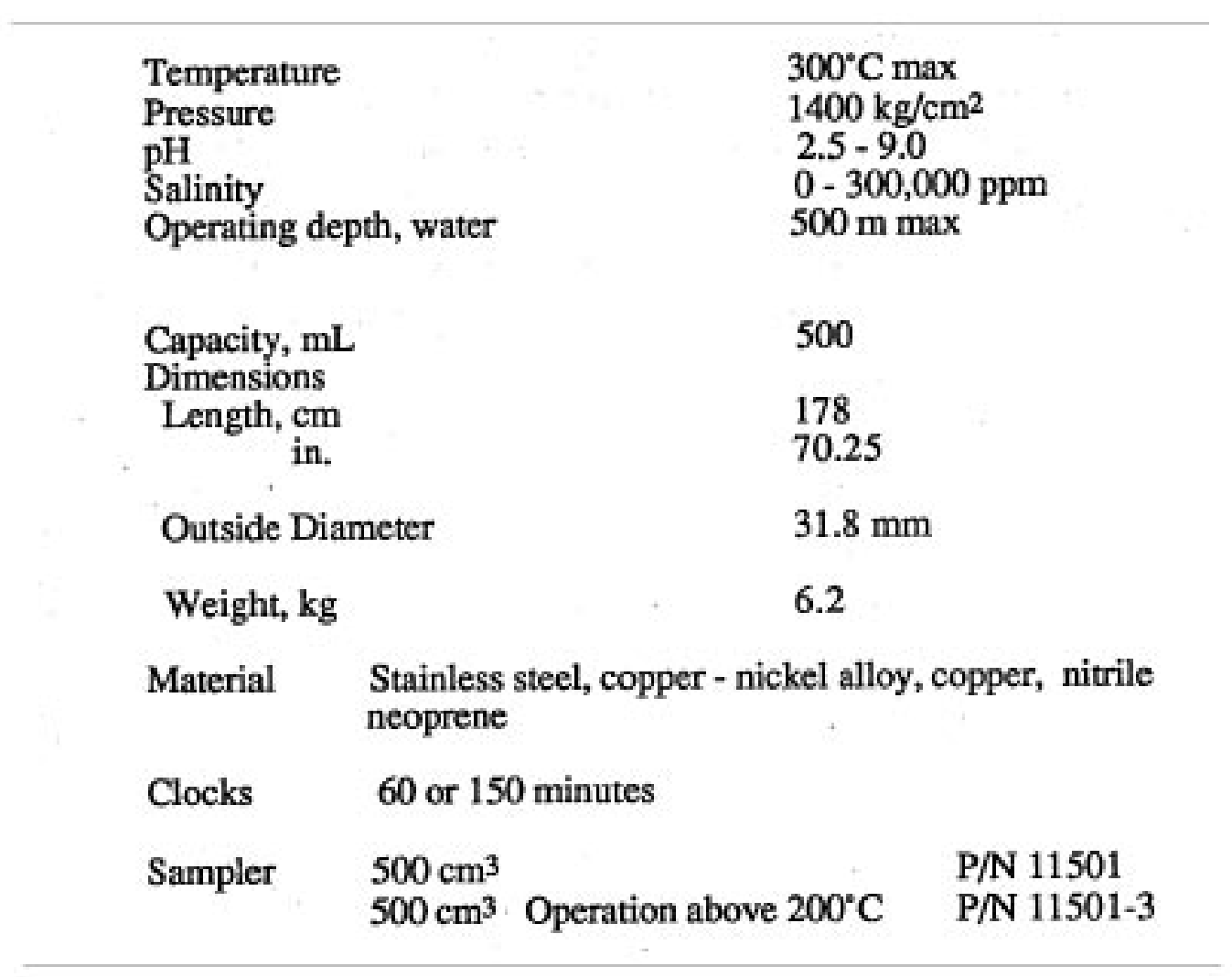

1. For operation above $200^{\circ} \mathrm{C}$ use hi-temp O-rings

2. For continued operation above $260^{\circ} \mathrm{C}$ use perfluoroelastomer O-rings 


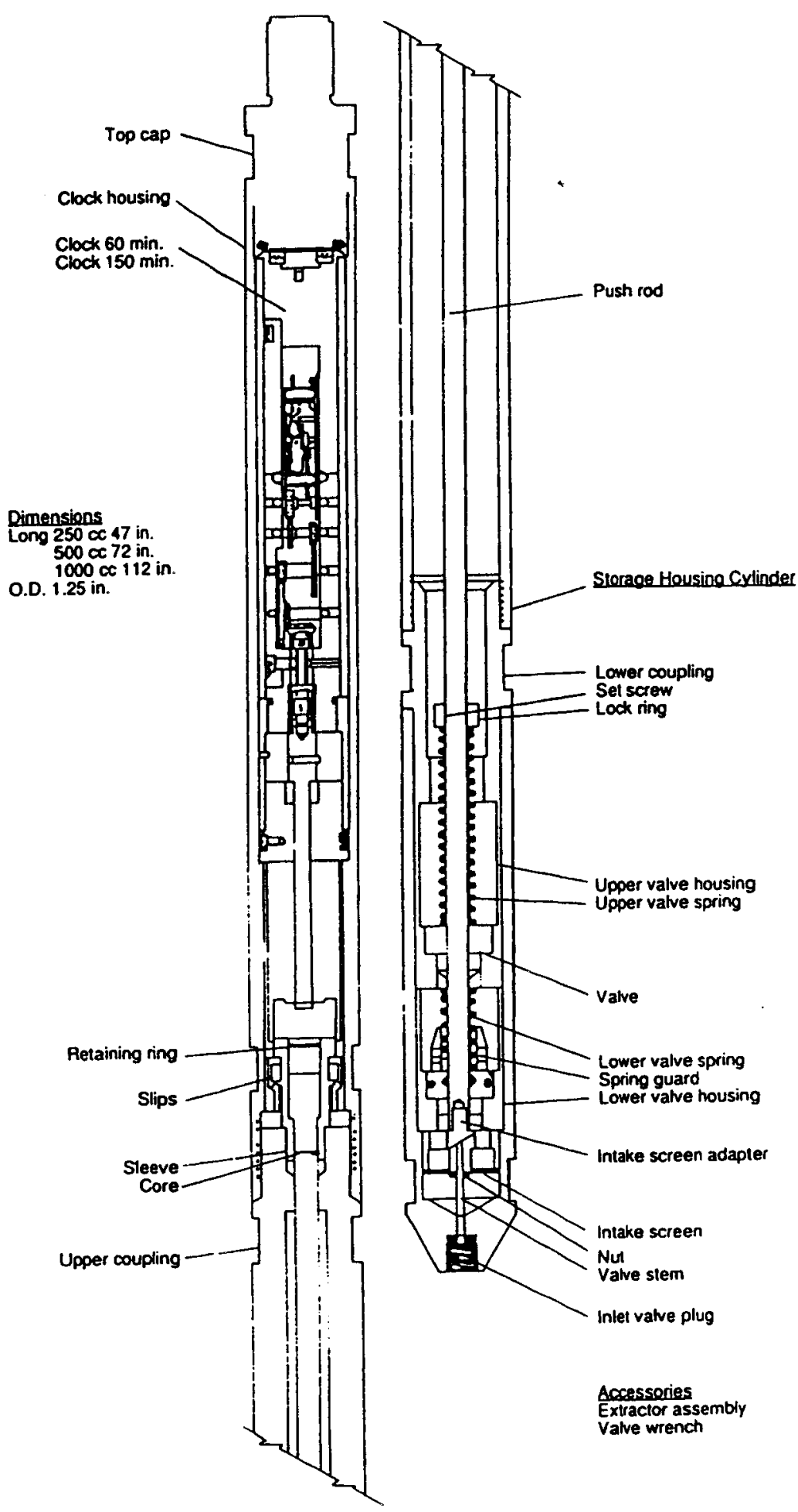

Figure II-3. Schematic of Kuster borehole fluid sampler, from operator's manual. 
Technical Note No. 10

Page 26

chemists, to specify any special requirements for such a sample-extraction system at the pre-cruise meeting.

During ODP Legs 137, 139, and 148 third-party borehole fluid samplers were deployed from the JOIDES Resolution. Scientists interested in using sophisticated third-party fluid samplers during ODP legs should discuss this possibility with ODP personnel as soon as possible after a leg is scheduled (see Chapter VIII for a description of sampler operations during Leg 137).

\section{Operational considerations for sampling borehole fluids}

Immediately after drilling, borehole fluids are composed primarily of the surface seawater used to flush cuttings from the hole. Thus it is normally of interest to sample borehole fluids only if considerable time has elapsed since the hole was drilled, so that the fluids have partially reequilibrated with in-situ pore fluids - a situation that occurs only when a reentry hole is revisited. (While it is conceptually possible for a "producing" formation to rapidly displace drilling fluid to the extent that a formation-fluid sample could be collected in the borehole, this process has never been documented during an ODP cruise.) If borehole fluids are to be sampled when a reequilibrated borehole is reentered, it is essential that this be done before any significant disturbance to the borehole fluids, as might be produced by reaming the hole, or circulating to condition for logging, or even running a sinker bar on the coring line to verify that the hole is open.

Both the WSTP and Kuster tool can be run out into open hole. If the WSTP is run with the colleted delivery system and landed in an APC/XCB bottom-hole assembly, the tool will scope out about $6 \mathrm{~m}$ ahead of the bit. If the collet is left off, and the WSTP is connected directly to the coring line, the WSTP can be run out into open hole, just like the Kuster tool. Running the WSTP or Kuster tool into open hole might be facilitated by running a logging or other BHA for reentry, as the opening at the end of a coring BHA could be small enough to upset either sampler as it is being retrieved into the drill string. However, if there is any chance of obstructions, it is safer to reenter the hole with a cleanout bit and run the drill string to the bottom of the hole, rotating and circulating where necessary to clean the hole. As the bit is worked down the hole during such a cleanout process, it is possible to pause at nearly any depth in the hole, to lower the WSTP into the bit and 
sample borehole fluids just ahead of the bit, which may be affected to some degree by any required rotation and/or circulation.

There will probably be concerns about hole conditions while reentering holes into sedimentary formations, holes into rubbly basement, and basement holes in which the sediments are not completely cased off. Such concerns should be considered carefully by the co-chief scientists and ODP engineers at the pre-cruise meeting, where the decision should be made as to what apparatus is to be run first into a reentered hole. These concerns will be relatively minor in reentering a properly cased basement hole with a good drilling history and no indications of hole stability problems.

Two examples may be helpful:

(1) Leg 102 reentered Hole 418A in 1985, about 8 years after it was drilled with little difficulty during Legs 51 and 52. However, as the lower $200 \mathrm{~m}$ of sediment had never been cased, and a logging tool was feared to have been lost in the hole during Leg 52, the initial reentry was made with a cleanout bit, which was run to hole bottom, encountering bridges but no logging tool. During two pauses in this cleanout pipe trip, the WSTP tool was lowered into the bit, to sample borehole fluids and measure borehole temperatures, with fair results (Salisbury, Scott, Auroux, et al., 1986). During later wireline reentry attempts, Hole 418A was found to be filled with sediments which had settled in around the uncased portion of the hole, then extruded up the cased section to the seafloor (Speiss and Boegeman, 1990).

(2) When Legs 70, 83, and 92 revisited Hole 504B, the initial reentries were made with a cleanout bit, and the WSTP was deployed several times during the cleanout pipe trips. As no obstructions were encountered, no rotation or circulation was required, and the fluid samples and temperature measurements were generally good (Mottl et al., 1983, 1985; Gieskes et al., 1986; Becker et al., 1983a, 1983b, 1985). When Leg 111 reentered Hole 504B, no hole problems were expected, and the initial reentry was made with a lightweight French temperature logging tool, which was run to within $55 \mathrm{~m}$ of hole bottom, followed 
Technical Note No. 10

Page 28

by several runs of Kuster water samplers and a Schlumberger water sampler. The temperature data were excellent, but the water samplers were plagued by tool failures unrelated to hole conditions (Becker, Sakai, Merrill, et al., 1988). 
Technical Note No. 10

Page 29

\section{IN-SITU TEMPERATURE MEASUREMENTS}

\section{A. Introduction}

The geothermal gradient is a fundamental property of the crust that influences and reflects the effects of tectonic, hydrologic, and geochemical processes, and accordingly temperature was among the first downhole properties to be measured during DSDP. In fact, Von Herzen and Maxwell (1964) actually measured sediment temperatures during drilling at the preliminary Mohole site, and a strong effort was made to measure downhole temperatures from the beginning of DSDP. Erickson et al. (1975) and Hyndman et al. (1987) reviewed the downhole-temperature measurements made during DSDP and the techniques for determining in-situ temperatures from the measured values.

Two primary methods are presently available in ODP to measure in-situ sediment temperatures the water-sampling temperature probe (WSTP) and the APC coring-shoe temperature recorder (APC tool). Logging tools operated by LDEO and some independent investigators can also be used to measure temperatures in open boreholes. The use of the WSTP and APC tools in their primary mode, measuring sediment temperatures during the process of coring a hole, are described in detail in this chapter. In addition, the use of these tools to obtain profiles of borehole temperatures in open hole or of sediment temperatures in an uncored "hole" is discussed.

While the WSTP and APC tool can both be used to measure sediment temperatures, they differ in their application in three key ways: (1) The WSTP is used to measure temperatures between cores, and thus requires 1-3 hours for each measurement, whereas the APC tool is used during the process of cutting a hydraulic piston core, and only requires 10-20 minutes additional time; (2) during a measurement, the WSTP is pushed into uncored sediments and will disturb the section to be cored next, whereas the APC tool should not affect the quality of the next core; (3) the WSTP can be used to depths at which the sediments can be penetrated without fracturing, typically several hundred meters below the seafloor. In contrast, the APC tool can be used only to depths at which the force required on pull out is within safe limits (80k-100k lb overpull), typically 50-120 mbsf. 
Technical Note No. 10

Page 30

Neither the WSTP nor the APC tool is effective at extremely shallow depths ( $<20 \mathrm{mbsf}$ ), where the sediments are not competent enough to hold the probes stable.

Temperatures measured in boreholes do not often reach full equilibrium with in-situ values and must usually be corrected for two major effects, the thermal disturbance to the borehole and surrounding formation by drilling and circulation (e.g., Bullard, 1947; Jaeger, 1961), and the transient approach of probe temperature to sediment temperature (Bullard, 1954). The latter condition is the result of either the decay of frictional heating of the probe on penetration into the sediments (if they are relatively cool) or the rise in probe temperature toward equilibrium (if the sediments are warm). Borehole disturbance is mentioned only briefly, as it usually affects openhole temperature logs measured shortly after drilling, which are not normally attempted using the ODP tools. The gradual approach of probe temperatures to in-situ values is clearly seen in data measured in sediments with the WSTP or APC tool, and the methods and shipboard computer programs required to extrapolate the measured temperatures to in-situ values are briefly summarized. More detailed treatments of these topics can be found in the WSTP and APC tool cookbooks available on board the JOIDES Resolution.

\section{B. Temperature Measurements with the WSTP}

Most of the tools used to measure temperatures during the early stages of DSDP were similar in concept to the present WSTP (Figure III-1; see Erickson et al., 1975), which also incorporates a fluid sampler (see Chapter II). Yokota et al. (1980) and Uyeda and Horai (1982) described the temperature recorder for the first push-in tool, which they developed before DSDP Leg 60. In combination with the case, batteries, bulkhead, and the temperature probe itself, this tool was known during DSDP and early ODP as the "Uyeda probe" or "Tokyo T-probe"; until recently, this tool was still used on JOIDES Resolution. When combined with an early generation of the Barnes pore-fluid sampler, the resulting temperature and fluid-sampling tool was called the Barnes-Uyeda probe. In its latest iteration, we refer to this tool as the WSTP. Both the Uyeda tool and WSTP employ battery-powered recorders with electronic memories to monitor the resistance of one or more thermistors in a probe that protrudes about $1 \mathrm{~m}$ ahead of the bit (Figure III-1). 


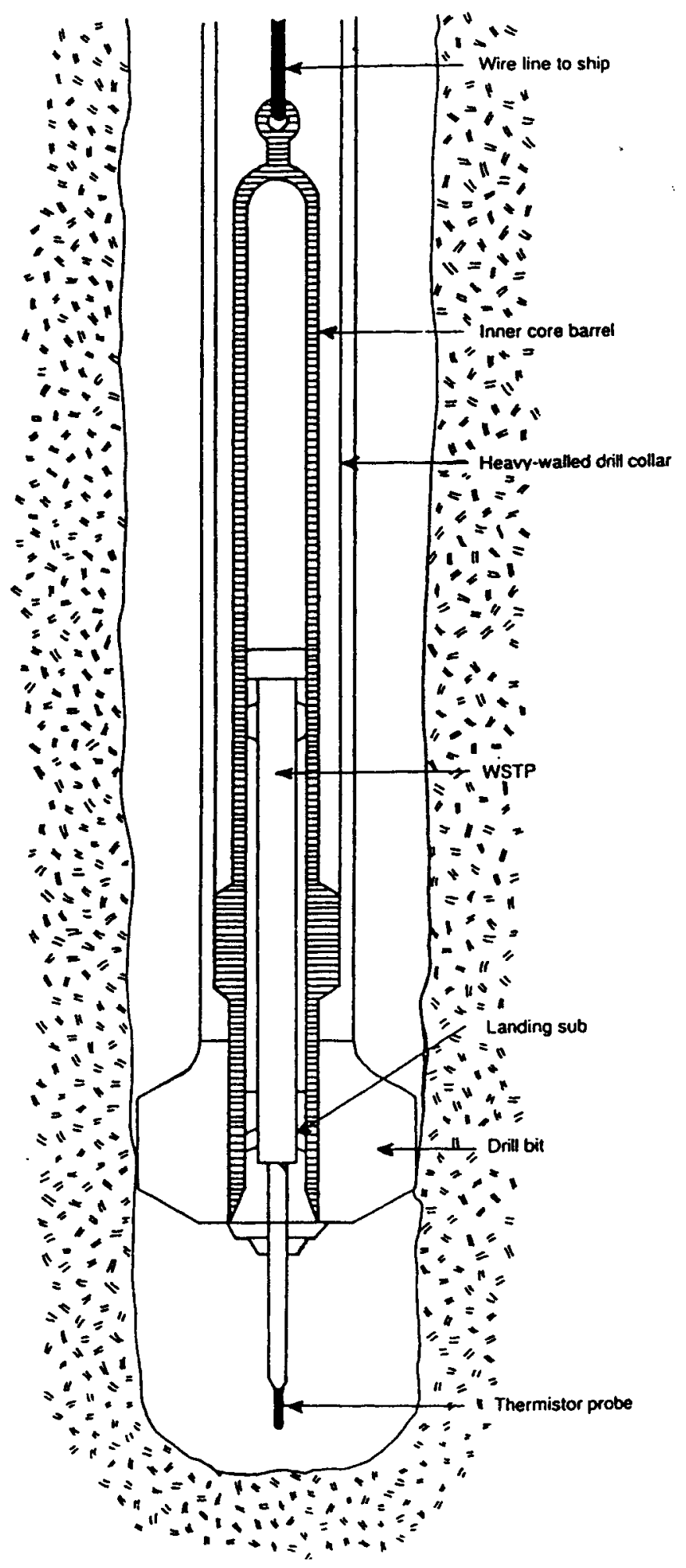

Figure III-1. WSTP downhole deployment schematic, not to scale (Hyndman et al., 1987). 


\section{WSTP geometry, structure, and recording capabilities}

The original Uyeda temperature tool had a thin, stainless-steel probe. The second-generation tool had a slightly thicker probe tip which extended past the end of a pore-fluid filter block. The newest generation (Leg 139) WSTP includes a temperature-probe tip which is slightly longer and wider overall, but still ends with the same 1.3-cm diameter (Fig II-2). Because the filter assembly was also made longer to improve fluid-sampling performance while tool length was kept constant, the new WSTP probe tip extends just $3.5 \mathrm{~cm}$ past the end of the sampling filter. During Leg 139, a 2.7-cm-diameter, solid sleeve was fabricated to fit over the temperature probe for use when the tool was to be run without fluid sampling (Fig. II-2). This sleeve is run instead of the filter assembly, to reduce the time constant of the probe and improve the geometry of the measurement so that 1) the frictional heating (or cooling) pulse associated with insertion of the probe can be assumed to approximate more closely a line source, and 2) insertion of the instrument is less likely to fracture semilithified sediments. In either configuration, the probe has a time constant in sediments on the order of 2-3 minutes, and it must be held in position for at least 10 minutes to obtain enough data to reliably extrapolate to in-situ sediment temperature.

The temperature-measuring systems of the WSTP and original Uyeda tool are similar in concept but differ primarily in their electronic capabilities. The Uyeda recorder was limited to storing 128 values of thermistor resistance, and could be programmed to read these values at 1- or 2-minute intervals during stations that lasted 2 or 4 hours, respectively. The second-generation WSTP recorder sampled 16,000 values from three channels (temperature plus two pressure transducers) at an interval of up to about 5 seconds. Unfortunately this recorder proved to be unreliable. The present WSTP digital recording package is referred to as the "double-Current data-logger" (DCDL). The DCDL records a single data channel (i.e., temperature from a single thermistor), and can store up to 2048 values sampled at a fixed time interval of $4.369 \mathrm{~s}$, using a 12-bit A/D converter. For Leg 139, when two thermistors were run in the WSTP, two DCDLs were mounted into a single frame and run in tandem, with each recorder monitoring a separate circuit (Fig. III-2). The DCDL has also proven unreliable on recent legs and adaptation of a commercial data logger is now under way. 
Technical Note No. 10

Page 32

Because Leg 139 included operations immediately adjacent to high-temperature hydrothermal vents, it was necessary to "harden" the WSTP for use in high-temperature and reactive fluids. Part of this upgrade included extending the temperature range of the data logger and sensing thermistors. DCDL components were upgraded to military specifications $\left(125^{\circ} \mathrm{C}\right.$ operating temperature), and two thermistor circuits were run with overlapping ranges (Fig. III-2). Hightemperature pass-throughs were designed for the WSTP's lower bulkhead (to allow the thermistor cables to reach the data logger), and Kalrez o-rings were used for the pressure case. Additional WSTP modifications included complete rewiring with high-temperature conductors and connectors. These upgrades allow measurements of in-situ temperatures up to $200^{\circ} \mathrm{C}$ as long as there is a high-temperature thermistor installed in the probe tip and the electronics are cooled by continuous circulation around the tool during penetration.

\section{WSTP preparation and deployment}

Once the WSTP is prepared for general use during a leg (by ODP marine specialists), collecting temperature data is relatively simple. It is advisable to check the thermistor calibration and electronic circuits throughout the leg by verifying the bottom-water reading of the thermistorrecorder circuit and by substituting a decade box for the thermistor before and after stations; the DCDL data-dumping software now available on the downhole-tools PC provides a dedicated "Calibration" function to assist with this operation. A fully charged battery pack should be used for each run, particularly if extensive instrument testing or calibration is conducted immediately before deployment and/or if a long station is planned.

As described in the WSTP cookbook and excerpted in Chapter II, the WSTP can be used in several deployment modes. The instructions directed toward obtaining a good water sample generally apply to measuring temperatures as well. The standard deployment methods described in Chapter II include latched-in (RCB) and colleted (APC/XCB) delivery operation, each requiring about 1-3 hours between cores (depending on water depth). Normally, the tool is lowered on the coring line and latched into the bit held just above the bottom of the hole. As the tool is lowered to the bit, a 5- to 10-minute pause to check recorder performance and water temperatures should be made just above the mud line, where the temperatures inside the pipe should be close to (but possibly slightly warmer than) the stable bottom-water temperature. Once the tool is lowered and 


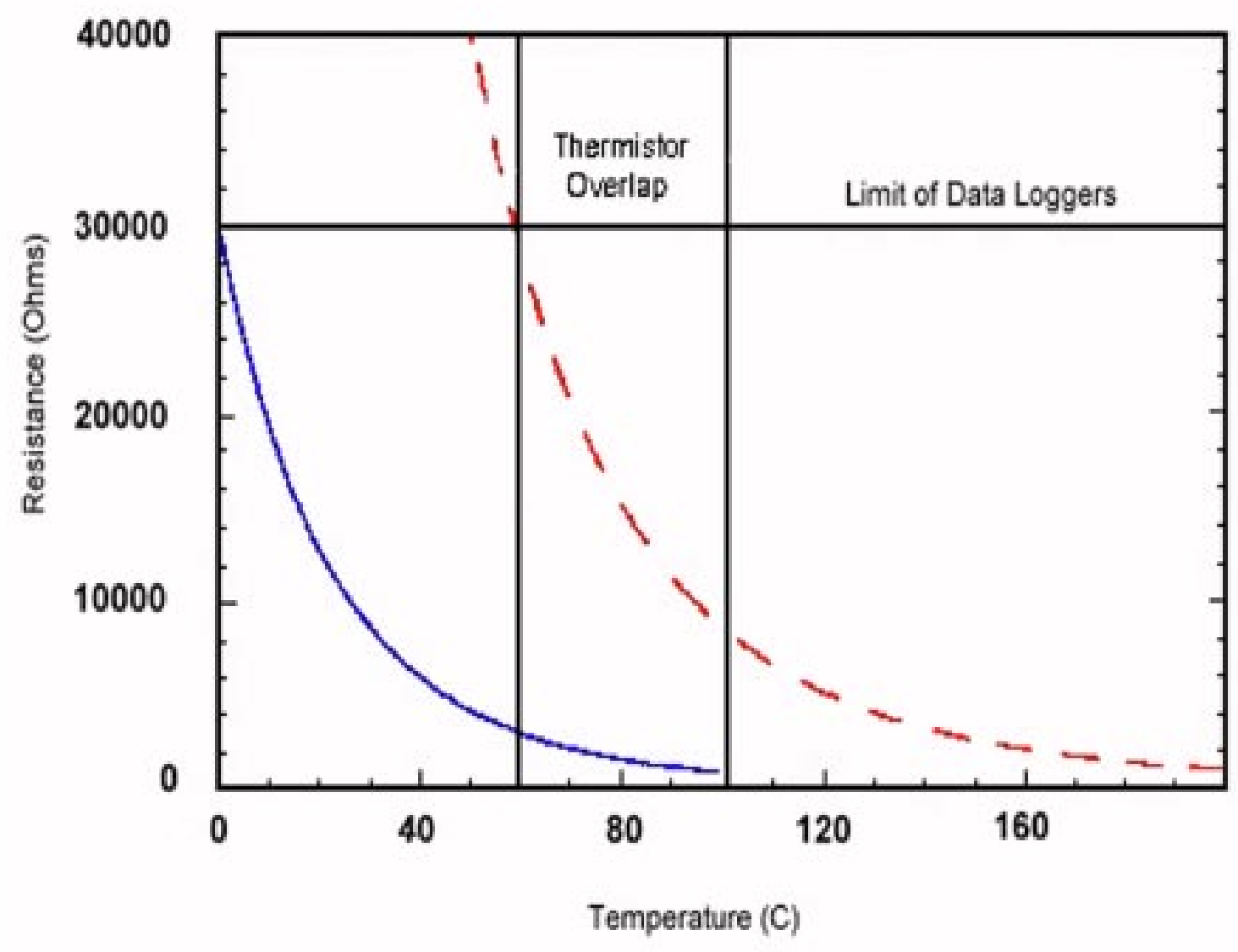

Figure III-2. Performance curves for two typical WSTP thermistors, as configured for high- temperature work during Leg 139. The two circuits allow nominal resolution of $0.1^{\circ} \mathrm{C}$ over a temperature range of about $0-200^{\circ} \mathrm{C}$. The low-temperature thermistor (solid line) reads about 10k ohms at room temperature, while the high-temperature thermistor reads about $100 \mathrm{k}$ ohms at room temperature. The upper limit of the data logger is $30 \mathrm{k}$ ohms, making the low-temperature thermistor is usable over a temperature range of about $0-70^{\circ} \mathrm{C}$, while the high-temperature thermistor is usable over a range of about $60-200^{\circ} \mathrm{C}$. Overlap of the two thermistor ranges allows some intercalibration of the two sensors. Both thermistors were calibrated at the factory over their working ranges. Each thermistor is on a separate recorder circuit, with two data independent loggers run in a single recorder frame inside the WSTP. There is plenty of power in a standard WSTP battery pack to support two recorders. 
latched into the bit, the pipe is then lowered, pushing the probe to the measurement depth in undisturbed sediments ahead of the hole. As described previously, the driller should continue circulation at least until the probe is pushed into the sediments, to keep the bottom of the hole clear of fill. The driller can also "clean up" the bottom of the hole with a few seconds of rotation and pumping, if necessary, before the probe is inserted. Calculations made following Leg 110 indicate that so long as the WSTP is inserted $60 \mathrm{~cm}$ or more below the bottom of the hole, within 2-4 hours after drilling stops, the thermal effects of circulation on sediment temperature measurements are negligible (Fisher and Hounslow, 1990).

Once pressed into the sediments, the WSTP is held stationary using the heave compensator (for latched-in, RCB deployment) or decoupled from the drill string (for colleted delivery, APC/XCB deployment). With RCB deployment, the heave compensator will be effective at maintaining the position of the bit and probe only when the amount of weight that will be held by the bit is greater than the sensitivity of the heave compensator, about $5000 \mathrm{lb}$. Thus measurements using the RCB BHA should be taken at depths only where sufficient weight can be maintained to hold the probe stationary. Unfortunately these depths may not be ideal for scientific purposes. In particular, it is difficult to measure temperatures with the WSTP deployed through an RCB BHA in very shallow sediments, which are often not competent enough to support the minimum weight required for heave compensation.

Keeping the probe stationary for about 10 minutes in undisturbed sediments is the primary consideration in obtaining good temperature data with the WSTP. The weight required to penetrate the sediments (for all deployments) and to hold the probe in place (for RCB deployments) will depend on sea conditions and the strength of the sediments, and will generally increase deeper in the section. If too little weight is applied, the probe may be allowed to move, degrading the data through two possible factors, additional frictional heating on probe movement and leakage of borehole fluids around the probe. On the other hand, if too much weight is placed on the bit, the probe may be slowly pushed ever deeper, resulting in continuous frictional heating, and the formation may even be fractured, allowing borehole fluids to leak around the probe and disturb the measurement. 
Technical Note No. 10

Page 34

When the measurement time has expired, the WSTP is pulled from the formation and retrieved with the coring line. Downhole-tools scientists may wish to have the WSTP pause again at mud line to check for recorder drift, although mud-line temperatures measured after a temperature station often are somewhat higher than those measured before a station, as warmer fluids can be swabbed up the pipe by the WSTP and core barrel.

\section{WSTP data recovery, processing, and archiving}

When the WSTP is recovered, it is extracted from its pressure case on the rig floor, carried up to the Downhole Tools Lab, and placed on the counter. The rig crew may need to be reminded to clean off the probe tip with a high-pressure water line before the tool is brought up to the lab. The tip is often packed with mud (particularly if a water sample was collected) and is very difficult to clean when dry.

WSTP data must be uploaded from the DCDL, converted from resistances to temperatures, and extrapolated to equilibrium to determine the in-situ temperature. Prior to Leg 139, downhole-tools scientists and marine specialists were required to learn the operating systems and file structures of at least two (and potentially four) different computers in order to download, convert, process, and store WSTP data. Each of these tasks is now considerably easier, and downhole-tools operators deal mainly with an IBM-compatible PC running DOS and Windows. Data are uploaded from the recorder to the PC, and automatically archived on the VAX. Conversion and processing are accomplished within a separate Windows program, with which scientists can also produce plots for their shipboard reports. Each of these specific tasks is described in the following sections.

Once the WSTP is returned to the lab, the stainless-steel shell is opened, and the DCDL is connected to the $\mathrm{PC}$ with a ribbon cable. The operator then runs the DCDL data-dumping program on the PC, which (1) uploads the data; (2) creates a header file of core, depth, and thermistor information; and (3) places archive copies of data and header files on the VAX. If the network is down, archive copies of these files are stored on a second hard drive on the PC. Working copies of the files also remain on the PC for processing. Data should be recovered from the DCDL as soon as possible after the WSTP is brought back on deck, as the data are stored in volatile memory and could be lost if the power supply to the recorder is interrupted. 
Up until Leg 139, VAX-based programs were available to convert data from resistances to temperatures, and to provide a simple temperature-time plot of each station, but it was up to individual shipboard scientists to create their own programs and procedures for processing WSTP data. In 1989, K. Becker supplied the ODP with several PC-based programs (written in Fortran, with system calls to separate text-editing and graphics programs) which enabled scientists to interactively process pressure data collected during formation testing using a drill-string packer. During Leg 139, Becker modified one of these programs, along with a VAX program for analyzing APC-tool data, to produce two hybrid programs for processing WSTP and APC tool temperature data. These programs were similar in that they both matched real data to theoretical curves and extrapolated to infinite time to obtain "equilibrium" temperatures. During the fall of 1991 and spring of 1992, A. Fisher assisted M. Sun (ODP/TAMU) with developing an objectoriented Windows program to support conversion and processing of WSTP temperature data. This new program is rooted in the methods used by the Leg 139 software, but is easier to use and features a fully graphical implementation, on-line help and advice, and an array of plotting options.

The downhole-tools scientist should be concerned with at least two stages of WSTP data processing: first, possibly correcting the raw data according to the results of calibrations before or after the station or at mud line during the station; and second, extrapolating the corrected temperatures to the in-situ value. A rigorous theory describes the approach of a cylindrical probe to in-situ temperature after penetration (Bullard, 1954; Jaeger, 1956), and the in-situ temperature should be determined by fitting the measured values to Bullard's (1954) F-function (tabulated by Lister, 1979; see also Hyndman et al., 1979). See the shipboard WSTP cookbook for more detailed instructions regarding data processing. Good-quality temperature vs. time records for a WSTP temperature run are shown in Figure III-3, along with examples illustrating the relationship between measured and extrapolated temperatures.

\section{APC Temperature Tool}

With the development of the hydraulic piston corer during the late stages of DSDP, R. Von Herzen developed a miniature recorder designed to fit in the cutting shoe and measure sediment 

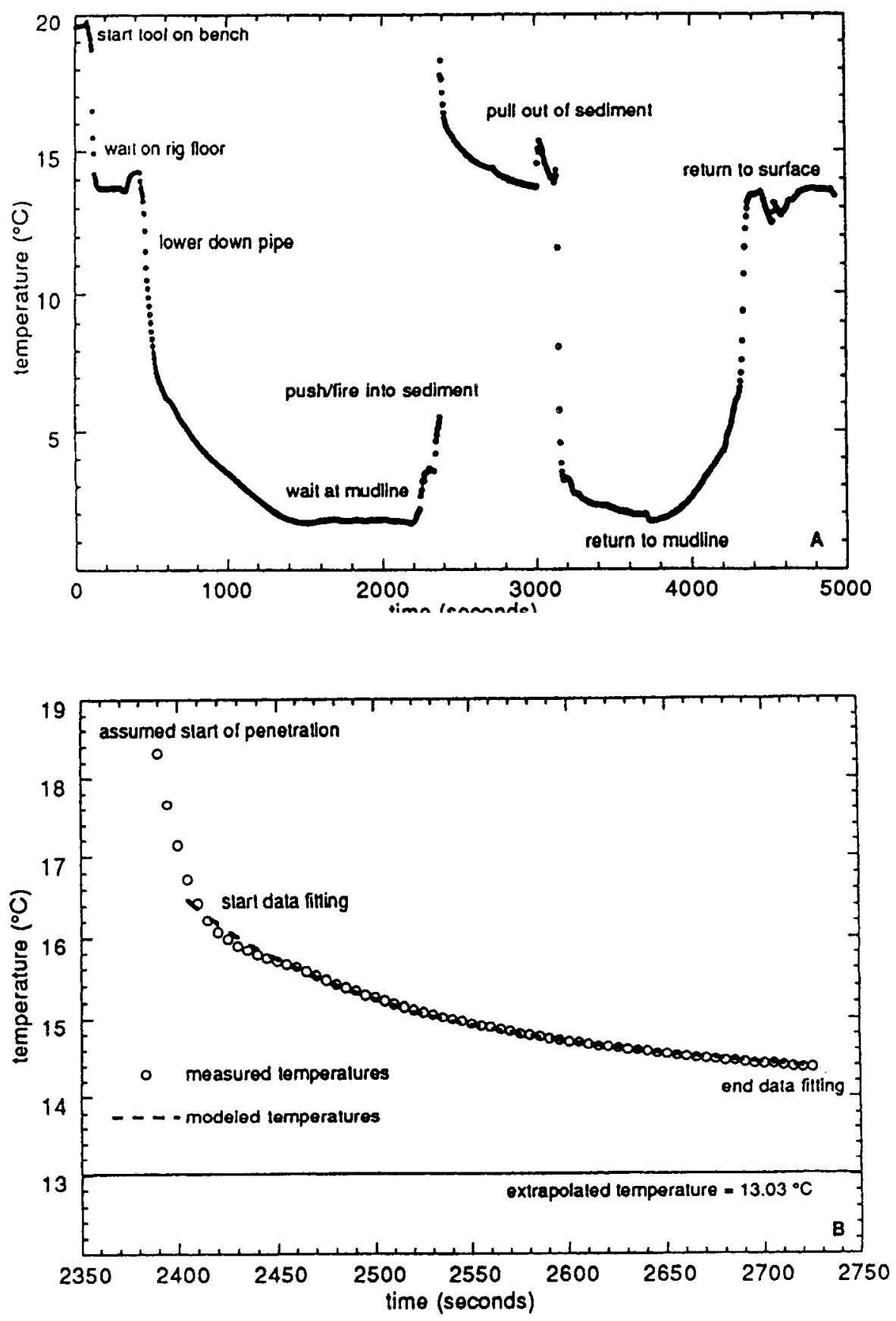

Figure III-3a. Typical records from good in-situ sediment temperature stations with the WSTP and APC tool. The APC tool tends to give smoother, more ideal data curves, as this tool has a more stable data logger and penetrates more deeply into the sediments at the bottom of a hole, thus remaining more stationary. A. Example record from a complete station in relatively cool sediments. The frictional spike associated with tool insertion is generally greater for the APC tool, which is fired hydraulically into the sediments. B. Example comparing measured and modeled temperature decay from the same run as in (A). Note that the extrapolated final temperature is considerably lower than the lowest value measured while the probe was in the sediments. The shape of the decay curve varies as a function of the thermal properties of the sediments and tool, and the shape of the tool. 

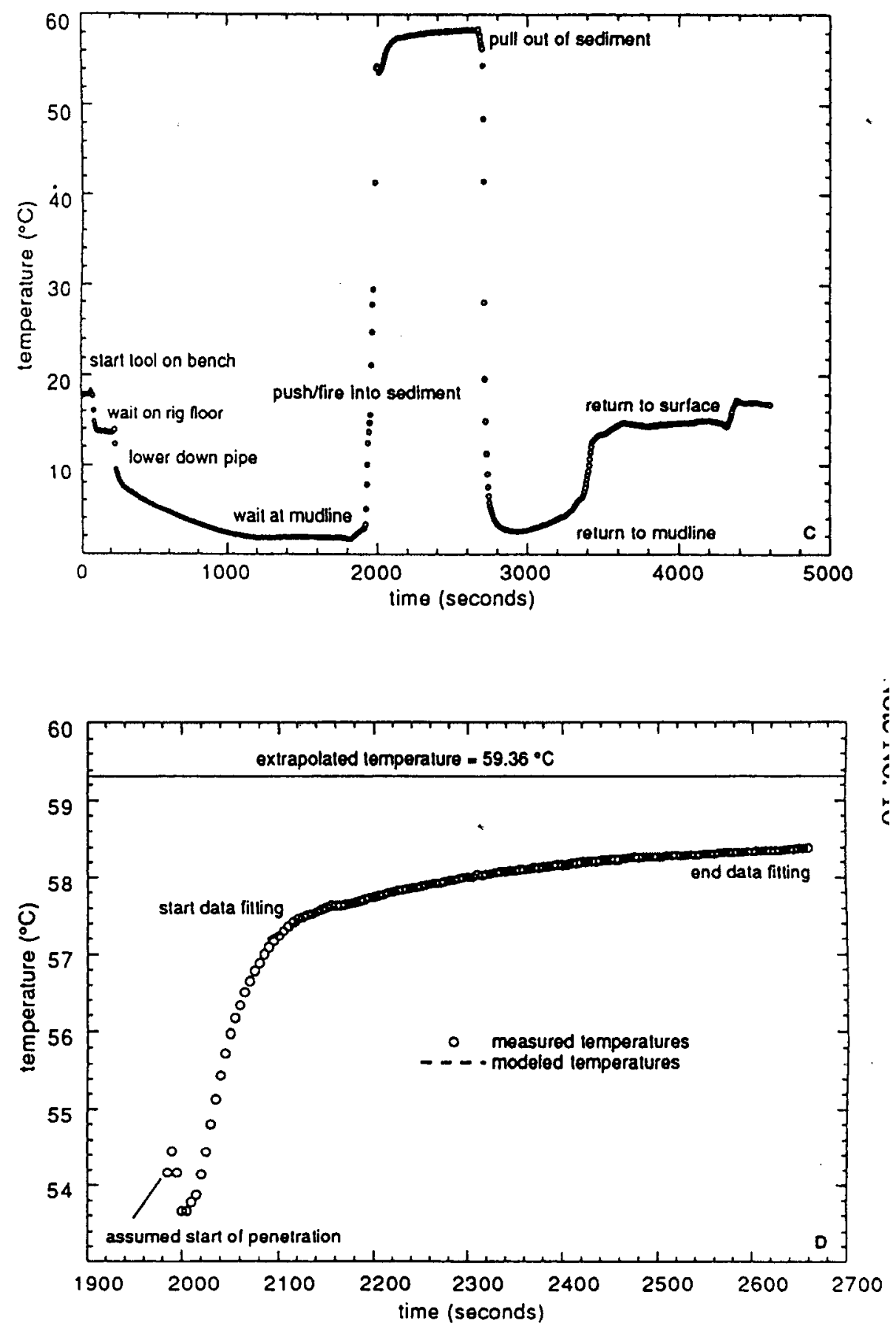

Figure III-3b. C. A good temperature vs. time record for a measurement in warm sediments. The frictional heat pulse associated with insertion is barely apparent. D. Example comparing measured and modeled temperature decay from the same run as in (C). 
Technical Note No. 10

Page 36

temperatures as a core was taken (Horai and Von Herzen, 1985; Koehler and Von Herzen, 1986). The Von Herzen tool was extremely successful, but the eight instruments purchased by ODP in

1984 became damaged, one by one, until none was left by Leg 117. It took several years to develop a replacement tool, but this was finally accomplished in time for ODP Leg 139. In the winter of 1990-91, ODP contracted with Adara (a small geotechnical company in British Columbia) for the design and construction of 10 new tools. The Adara development included interface boxes (to allow the tools to communicate with an IBM-compatible PC), connector cables, deployment and data-analysis software, documentation, and assorted battery packs, retaining rings, and spare parts. Four of the tools were delivered in time for Leg 139, and the rest have been delivered since then. One tool remains at TAMU/ODP in College Station for training and testing purposes, and the other nine tools and all the necessary hardware and software are routinely available on board JOIDES Resolution as of Leg 146.

\section{APC tool design and components}

Like the original Von Herzen instrument, the Adara temperature tool (APC tool) is designed to measure sediment temperatures as a piston core is taken. Each tool comprises a series of circuit boards, battery packs, a temperature sensor, and assorted retaining hardware (Fig. III-4). The programmable recorder and battery packs are built into a cylindrical frame, designed to fit in the cutting shoe of the advanced hydraulic piston corer. At the base of the APC tool frame are two stainless-steel prongs which fit into holes at the bottom of the annular cavity in the cutting shoe. These prongs help to stabilize the instrument in the cavity, and one of the prongs also contains a platinum resistance temperature device (RTD) which is used to monitor formation temperature during a station. The wall thickness of the cutting shoe outside the annular cylinder is about 1.5 $\mathrm{cm}$, giving it an effective time constant of roughly 2-3 minutes in sediments. Thus the APC must be held in place for at least 10 minutes (and preferably 15) to record enough data to reliably extrapolate to in-situ sediment temperature.

The APC tool is run with two battery packs, each of which contains seven ordinary "camera" batteries. The tool was originally designed to draw primary power off one of the battery packs, and clock power off the second. A diode has been added to the APC tools to allow the instruments to 


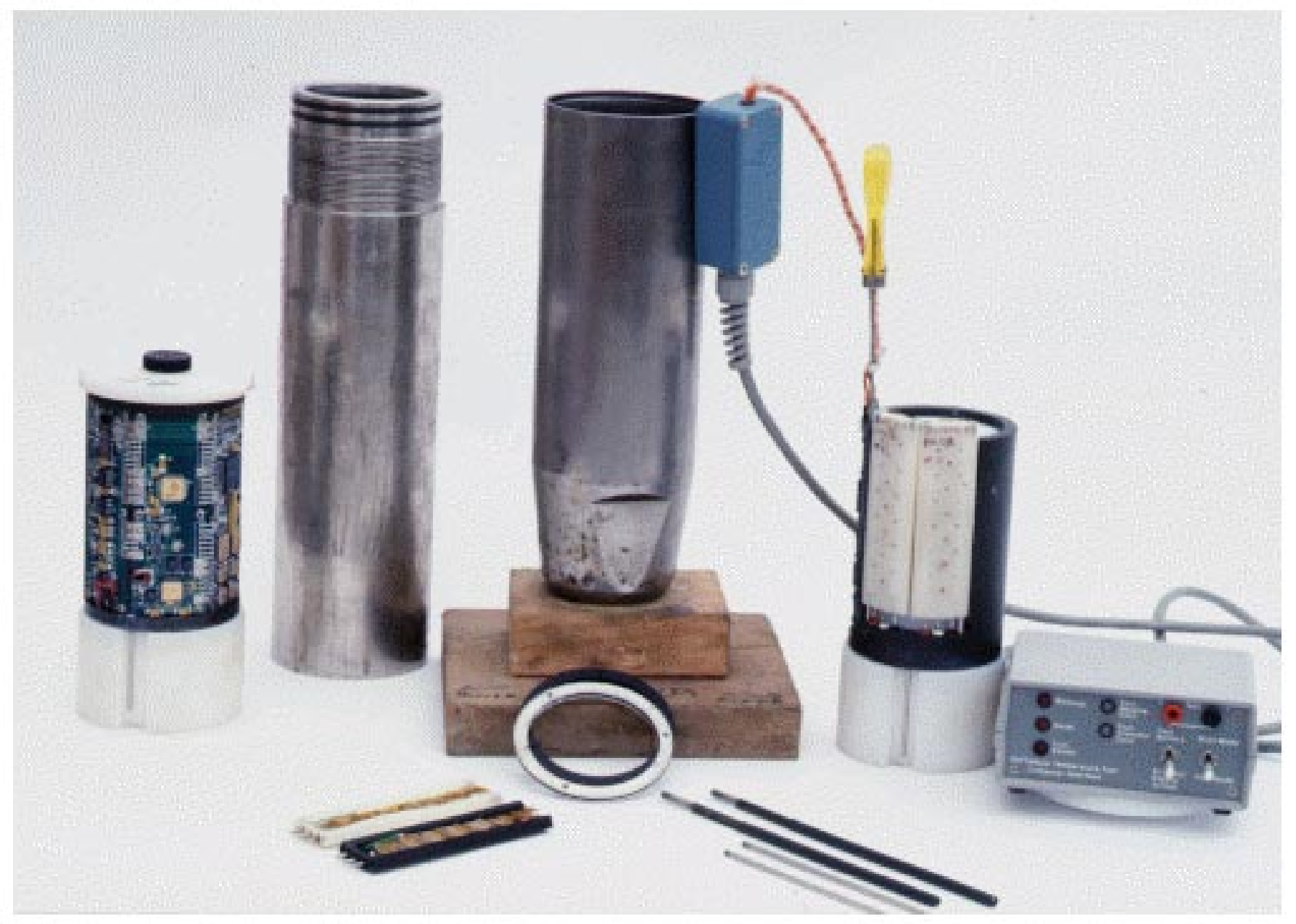

Figure III-4. Photograph of APC tool components (left to night background): APC tool on cylindrical holder, APC Landing Sub, APC coring shoe (with intemal annular cavity), interface cable attached to another APC tool (tumed to show battery packs), and interface box. (Left to right foreground): battey packs, tool retaining rings, and extraction tools. 
draw clock and main instrument power from both battery packs at the same time, which helps increase overall battery life and reduces the chances of running out of power during a station. In contrast to the WSTP, data storage in the APC tool recorder is nonvolatile, meaning that previously collected data are retained in memory even if power is lost during a station. The APC tools are calibrated over a temperature range of $-20^{\circ}$ to $100^{\circ} \mathrm{C}$, and will operate at temperatures up to $125^{\circ} \mathrm{C}$. The latter limit was verified during Leg 139 when an APC tool functioned perfectly until the

recorded temperature reached $127^{\circ} \mathrm{C}$ ! The tool might actually have operated to higher temperatures, but the battery packs began to deform, and the tool lost power. At higher temperatures there is also danger of damage to the tool's o-ring's, which could cause catastrophic flooding.

\section{APC tool preparation and deployment}

As noted above, the major advantage of the APC tool over the WSTP is that the APC tool is used to measure temperatures as a piston core is taken, with very little time required in addition to that needed to take the core. On the other hand, use of the APC tool is limited to depths at which the force required on pullout is within safe limits, generally the upper $120 \mathrm{~m}$. This depth limit is somewhat less than the limit for regular APC coring, because the sediments will "grip" the corer more tightly during a 10-15-minute station to measure temperatures than during the much shorter time required simply to collect a core.

The APC tool is normally used on selected cores in a sequence of APC cores in the upper sediments, with allowable depths of measurement determined by the lengths of the cored intervals, usually $9.5 \mathrm{~m}$. (If offset APC holes are cored at the same site, staggering of APC-tool deployments in two or more holes can increase sampling density.) The selection of temperature stations and preparation of the recorder must be carefully coordinated to avoid disrupting the coring routine, which can be surprisingly rapid-fire in a typical APC hole, particularly in shallow water. Interested scientists must consult in advance with the ODP lab officer and downhole-tools specialist to specify the cores on which the APC tool is to be run and the sampling sequence to be used. APC tools were run on successive cores during Legs 139 and 146 (i.e., Cores 3H, 4H, 5H, 
Technical Note No. 10

Page 38

etc.); this mode of operation requires extremely careful planning and at least two tools and two dedicated personnel.

Each APC tool contains a microprocessor and can be programmed to operate with a variety of functions and sampling intervals. Programming is accomplished with a spreadsheet-like interface on a PC, and the test sequence is downloaded to a tool which has been preloaded into a coring shoe. The shoe is then made up to a core-barrel cross-over sub and handed to the ODL core techs for deployment.

If the APC tool and cutting shoe are ready at the appropriate time, the station will proceed like a normal piston core, with one obvious exception: after the corer is hydraulically fired into the sediment, it must be held in position to record enough data to allow the in-situ temperature to be determined. The corer is then retrieved in normal fashion. It may also be desirable to pause with

the tool at mud line during tool retrieval to check the bottom-water temperature. When it is brought on deck, the cutting shoe is broken off and given to the downhole tools-scientist or specialist before the core is removed from the core barrel.

\section{Data retrieval and processing}

As with the WSTP, the downhole-tools marine specialist is responsible for dumping the raw data from the APC tool to the downhole-tools PC and uploading archived data to the VAX. The APCtool software is easy to run and includes automatic conversion of recorded resistances to temperatures and plotting on the computer screen. Processing of the data to determine the equilibrium sediment temperature requires running a separate program on the $\mathrm{PC}$. To determine the best estimate of true (equilibrium) sediment temperature, the measured temperatures must be fit to a function that describes the approach of the APC cutting shoe after penetration to true temperature. This function was formulated in two dimensions by K. Horai (in an unpublished manuscript titled "A theory of processing down-hole temperature data taken by the hydraulic piston corer (HPC) of the DSDP.") The data-reduction procedure is summarized by Horai and Von Herzen (1985). Copies of these papers are available in the shipboard reprint collection (see Appendix A). The procedure for data reduction is somewhat interactive and subjective, and must 
be conducted carefully, because (1) Horai's formula probably does not apply at very short times after penetration, and (2) the thermal properties of the cutting shoe introduce an ambiguity in assigning an effective time origin in treating the data.

Just before Leg 146, a new graphically interactive program was provided by Adara for processing data collected with the APC tool. This APC tool program is based on the original Horai programs which ran on the VAX. The new program is similar in format to the program developed at ODP for WSTP data processing, with the following differences: (1) the APC tool program runs under DOS rather than Windows, (2) the APC tool program does not allow direct access to the data (although the data can be accessed through DOS by exiting or shelling out of the processing program), and (3) the APC tool program does not provide the ability to make hard-copy of plots. The program is very fast, however, allowing shipboard scientists to determine equilibrium temperatures quite easily. Figure III-3 shows examples of excellent data recorded with the APC tool during Leg 139, and the fit of the data to a theoretical cooling curve, calculated with the revised programs presently available.

\section{Use of ODP Temperature Tools for Discrete Temperature "Logs"}

The previous sections in this chapter concerned the deployment of the ODP temperature recorders in their normal mode, to determine a single equilibrium sediment temperature per tool lowering during the process of coring a sediment hole. It is also possible to use these tools to obtain readings of temperatures at multiple depths during a single lowering, either in open boreholes or in sections of sediment that are not cored. For such stations, the procedures for tool preparation and data processing are basically the same as discussed above, although somewhat longer recording periods may be required. Only the methods of deployment are different, as are discussed here.

To obtain such discrete temperature "logs", either the APC tool or the WSTP can be used, although the APC tool is often preferable for reasons discussed below. During these stations, the tool is lowered to the bit, and the pipe is moved in stages so that the temperature sensor is held for about 10 minutes at each of the measurement depths. The tool can be lowered to the bit either on the coring line or by freefall, but if it is run on the coring line, the range of measurement depths is 
Technical Note No. 10

Page 40

limited to about $20 \mathrm{~m}$ because it will not be possible to add or remove pipe over the coring line. Twenty meters corresponds to the approximate length of drill pipe that can be drawn up in the derrick before the station and then lowered into the hole with the coring line once the tool is run to the bit at the beginning of the station. Thus, deployment by freefall is necessary if it is desired to measure temperatures over a depth range that is greater than about $20 \mathrm{~m}$.

\section{Logging sediment temperatures without coring}

If the temperature profile is to be measured in sediments, the tool must be latched into the bit. The pipe is then pushed and washed through the sediments to just above each of the measurement depths; the pumps are then shut off and the tool is pushed into place and held stationary for 10-15 minutes using the drill-string heave compensator as described in section (B). It is preferable to use the APC tool for this kind of station because (1) less sediment must be displaced in penetrating with the annular APC cutting shoe than with the larger-profile WSTP, and (2) the APC can be free-fall deployed more safely. As illustrated by the example in Figure III-5 (from Bryan, Juteau, Adamson, et al., 1988, at a low heatflow site), the resulting temperature record will clearly show the effects of fluid circulation and frictional heating as the probe is moved between measurement points, but good data can still be collected at the measurement depths if the probe can be held stationary.

\section{Logging open-hole temperatures}

Upon returning to a reentry hole in which the borehole fluids have reequilibrated with the geothermal gradient, it is usually critical to log borehole temperatures and sample fluids before any other operations disturb the borehole. Ideally, a continuous temperature log should be obtained using a lightweight tool on the logging cable, as was done when Leg 111 revisited Hole 504B (Becker, Sakai, Merrill, et al., 1988). However, this will not be allowed if the hole is not expected to be completely free of bridges or obstructions. In that case, true logging will not be permitted until the hole has been cleaned out by running the pipe and bit to hole bottom, but this cleanout pipe trip will disturb the thermal equilibrium of the borehole fluids.

Nevertheless, a temperature log and fluid samples can still be obtained by deploying a WSTP to the bit as this cleanout trip is made. To minimize disturbances to the borehole fluids, the pipe 


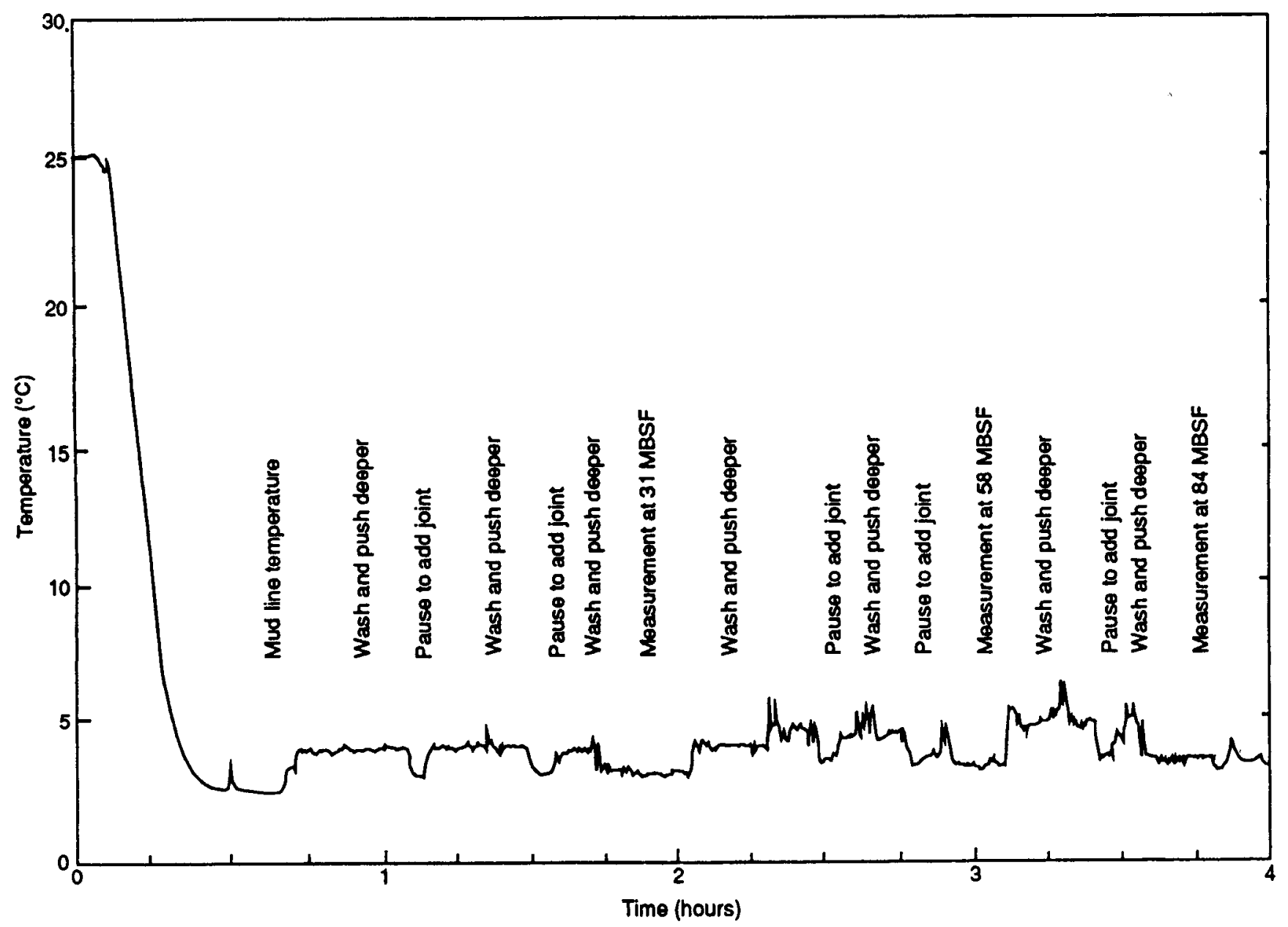

Figure III-5. Temperatures measured with the APC tool during Leg 139 in the uncored sediments of "Hole" 395C. The tool was mounted on a core barrel, which was latched in ahead of the bit, then pushed ahead into a sediment pond, pausing periodically to get more stable readings. 
should be run very slowly and carefully into the hole, avoiding circulation and rotation unless absolutely necessary to clear an obstruction. Pauses can be made during this cleanout pipe trip at nearly any depth, to measure temperatures, sample fluids, or retrieve and re-deploy the tool. It is even possible to configure the WSTP and APC tool together, and run them simultaneously to assure recovery of equilibrium temperature data in the event of a tool failure. Note that a strict temperature limitation of $125^{\circ} \mathrm{C}$ applies to this kind of WSTP deployment, as it will not be desirable to circulate around the electronics to keep them cool in the event higher temperatures are encountered. Figure III-6 shows the data obtained with the APC tool during this kind of station when Leg 92 reentered Hole 504B (Leinen, Rea, et al., 1986); the WSTP was run simultaneously to sample fluids and record backup temperature data, which are not shown.

In addition to the ODP temperature tools described in detail above, there are two specialty tools presently maintained or being developed by the ODP logging contractor, the Borehole Research Group of LDEO. These tools are the temperature-pressure memory tool (TLT), that can be run as part of a conventional logging string, and a high-temperature logging tool run as a separate tool deployment. These tools are different from the ODP-TAMU tools described above, in that the ODP-TAMU tools are run on the coring line, while the LDEO tools are run on a logging line, either as part of a conventional logging run, or on a dedicated logging run.

The TLT is a self-contained instrument for use at temperatures up to $125^{\circ} \mathrm{C}$ and pressures up to 10,000 psi. The TLT measures 3.25" in diameter and 36" in length. A personal computer is used to initiate data acquisition before logging and to retrieve the temperature data after logging, via a modem in the tool. TLT data acquisition is activated downhole by pre-selecting a trigger pressure. The TLT will then measure the time gap between measurements, for later data merging. The TLT can be attached to the bottom end of most conventional (Schlumberger) logging strings and provides temperature information with essentially no associated "time-cost." The TLT records one channel of pressure data, and two channels of temperature data, one from an extremely accurate, slow-response thermistor, and another from a less accurate, fast-response thermistor. After the TLT is recovered and the data are uploaded to a shipboard computer, the user must merge the TLT temperature records with a time record of wireline depth, or transform the pressure channel into a 


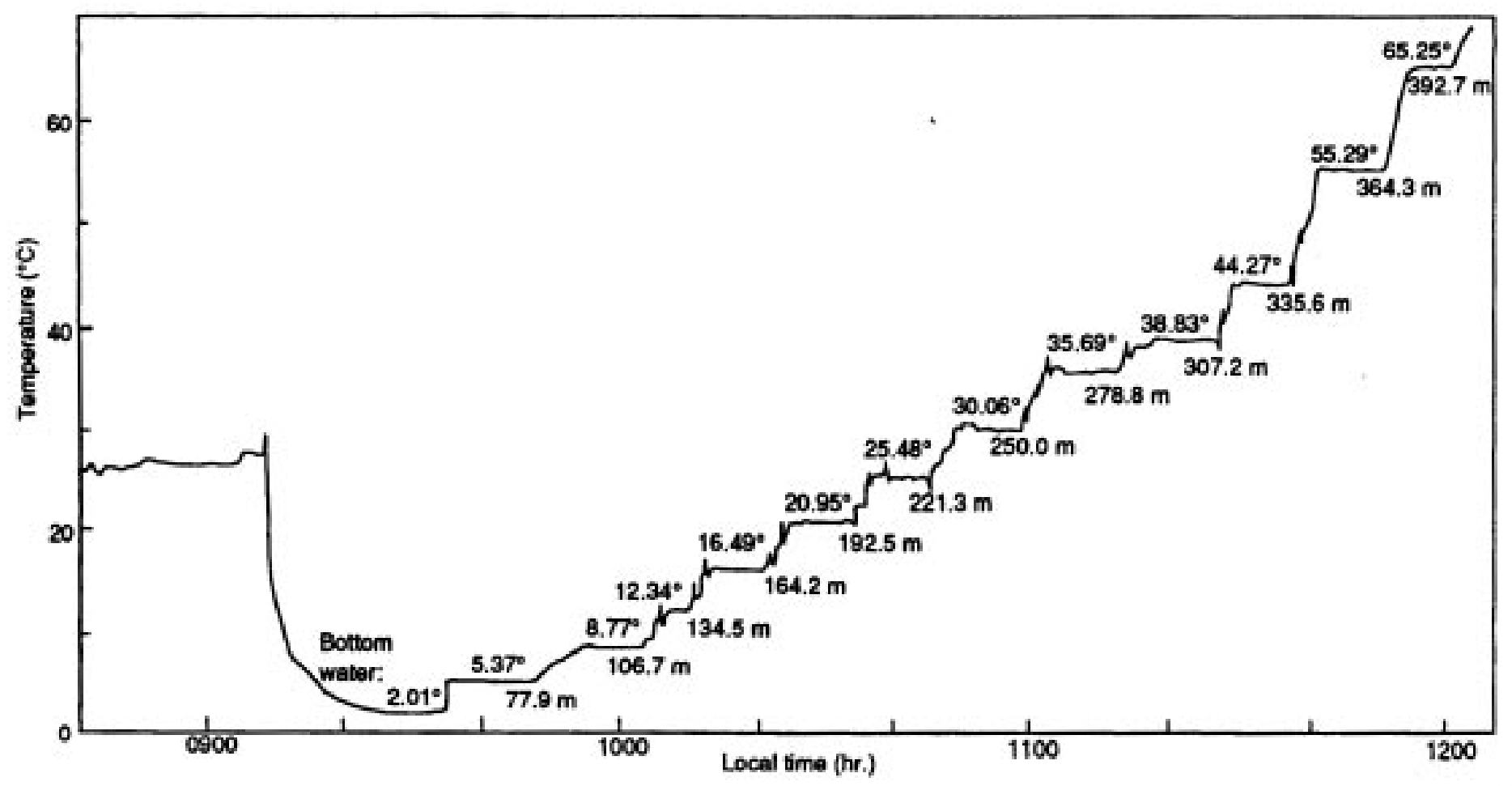

Figure III-6. Temperatures measured with the APC tool during DSDP Leg 92 in Hole 504B. The tool was landed at the bit, and sections of pipe were added, one stand at a time, to log a large interval of the open hole. 
Technical Note No. 10

Page 42

depth record. The latter procedure is tricky, since the fluid in the borehole may contain some component of logging mud or cuttings, and its density is unknown.

The second LDEO temperature instrument (now under development following field testing) is a high-temperature, slim diameter $(60 \mathrm{~mm})$ logging tool capable of recording temperatures in excess of $300^{\circ} \mathrm{C}$. Because this is a wireline tool, however, its temperature range is limited to that of the high-temperature wireline. The high-temperature wire presently onJOIDES Resolution is rated to $260{ }^{\circ} \mathrm{C}$. In addition, cable heads are notorious flaky at high temperatures; several cable head designs are now being explored. The high temperature tool is $3 \mathrm{~m}$ long and weighs $50 \mathrm{~kg}$. The temperature sensors are accurately calibrated thermistors housed in a 5-mm-diameter tube at the lower end of the tool. Temperatures are determined from the resistance of two thermistors that can be monitored individually or in series for maximum sensitivity across the entire logged interval. The control unit uses a programmable precision voltmeter and a custom interface panel monitored with a personal computer. The computer records depth, two resistance values, and the calculated temperature approximately every $10 \mathrm{~cm}$. Data are output to standard ASCII files. 


\section{DRILL-STRING PACKERS}

\section{A. Introduction}

A packer is defined as a device that produces a hydraulic seal in a borehole (Fig. IV-1). If the integrity of this hydraulic seal is properly maintained, the hydrologic properties of the formation can be tested by applying differential fluid pressures to the isolated section. Formation properties that can be measured using a packer include pore pressure, transmissivity, from which permeability can be derived, and (less accurately) storage coefficient, which is related directly to formation porosity. In addition, it may be possible to sample fluids from the section of borehole isolated by a packer; if the formation is permeable enough, the sample may contain a component of formation fluids.

A drill-string packer is designed to be part of the BHA; the wireline packer deployed on Leg 133 was a separate tool lowered on a conducting cable into open hole, like a logging tool. A drillstring packer or a wireline packer can be configured as a straddle packer, which incorporates two hydraulic seals and allows the zone between the seals to be tested or sampled. In contrast, a singleelement packer isolates the zone between the packer seal and the bottom of the hole.

One packer is presently available in ODP: a nonrotatable drill-string packer that can be configured as a single packer or a straddle packer, originally supported by an NSF grant to K. Becker and now maintained and run by ODP/TAMU. This packer was used successfully during Legs 109, 111, $118,139,144,146$, and 148 and is available for use in reentry holes that penetrate stable formations.

At various times, three additional packer tools have been deployed from the Resolution, although none was run successfully. Like the successfully deployed straddle packer, these three unsuccessful packer tools were manufactured by TAM International of Houston, Texas. The first of these tools was a rotatable drill-string packer built and operated by ODP and intended for use in less stable formations where a rotational capability may be required for safety reasons. This packer was tested during Leg 110, subsequently modified, and run again during Legs 123 and 131. It was sometimes called the TAM drilling packer, or "TDP." The third packer-type tool run from the 


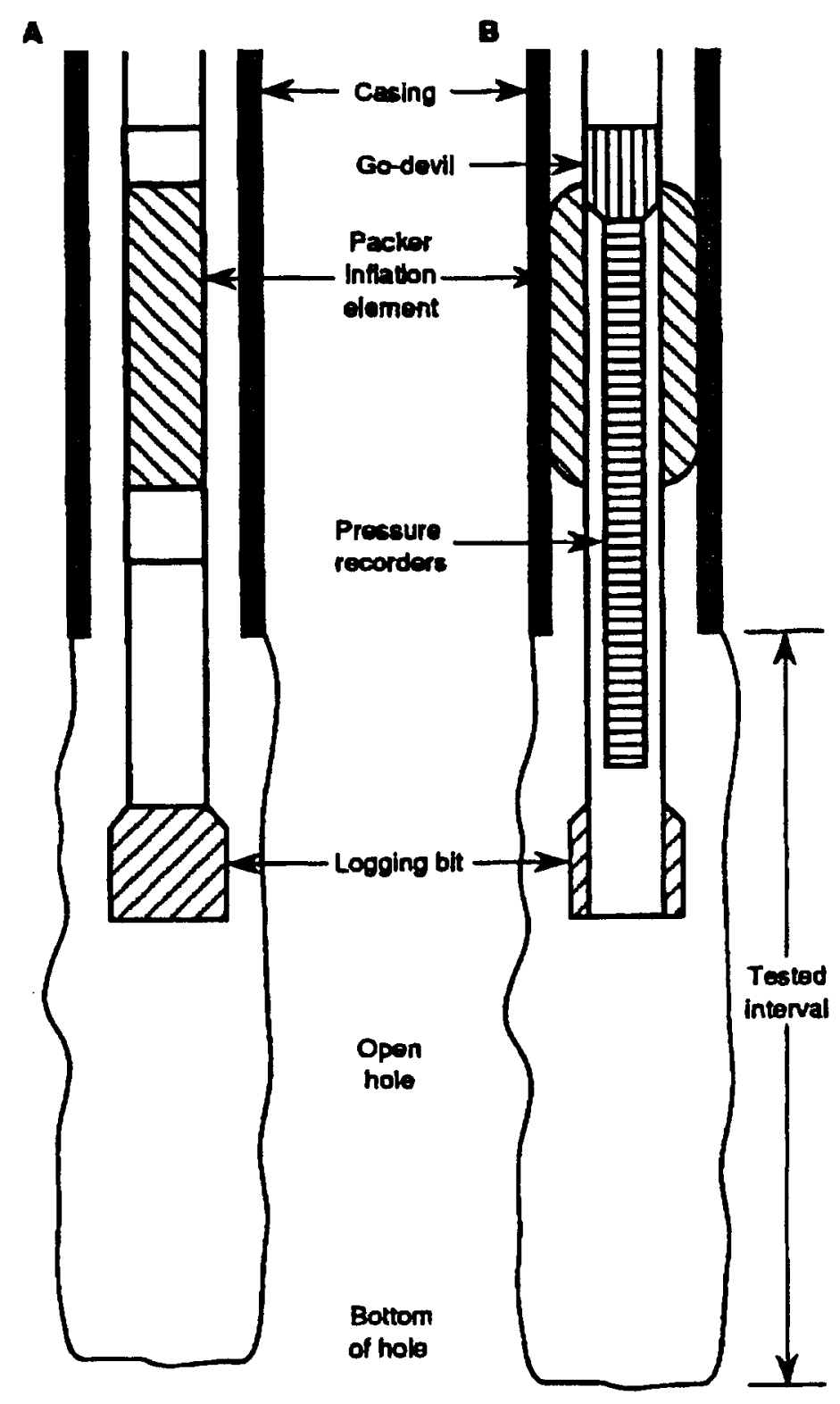

Figure IV-1. Sketch of the inflatable drill-string packer as deployed during most ODP legs, with a single packer element incorporated into the bottom-hole assembly. A. Packer and drill string before inflation or after deflation. B. Cut-away view of the inflated packer showing go-devil, pressure recorders, and tested interval between the casing shoe and the bottom of the hole. During inflation of the packer, the go-devil directs fluids pumped from the rig floor into the inflation element; once the packer is inflated, a sleeve is shifted such that fluids pumped from the rig floor are directed into the tested formation. Sometimes, two elements are configured as a "single-seal" packer to give the packer assembly greater holding capabilities (for example, against the relatively smooth walls of casing). The ODP straddle packer can also be configured to test an interval between two elements. 
Technical Note No. 10

Page 44

Resolution was the wireline sampler built and operated by the Borehole Research Group at LDEO. As the name suggests, this instrument was built primarily for fluid sampling but also was intended to be capable of limited formation testing. The wireline packer was deployed once during Leg 133 but suffered from several design and construction flaws. The fourth packer tool was called the Geoprops probe, a third-party tool initially funded and developed with an NSF grant by D. Karig; Geoprops was deployed for the first time for field testing during Leg 146.

The failures of the rotatable packer, wireline sampler, and Geoprops probe are revealing in terms of the effort required for downhole-tool development and the nature of drilling in ODP. All three tools were intended for use in less than optimal borehole conditions (open, possibly large holes, semi-stable formations) and suffered from fundamental design flaws (see Chapter VIII for more details). These tools have all been retired for now, and none is presently scheduled for use or available during ODP cruises as part of regular operations.

The use of the drill-string straddle packer is discussed briefly in this chapter. A more complete treatment of packer testing is available as Technical Note 14 (Becker, 1990a).

\section{B. ODP Drill-string Straddle Packer}

\section{Packer elements}

The packer used in ODP is inflatable and seals the borehole using hybrid rubber/steel elements that are pressurized with seawater pumped down the drill string from the rig floor. Each of these elements consists of an internal rubber bladder, which is bonded to an expandable steel strength member, which in turn is bonded to an outer rubber cover. The outer rubber and the steel serve to 'grip' and seal against the borehole wall and to protect the inner bladder, which must remain unpunctured for the packer to remain inflated.

The proprietary TAM design uses a tight weave of stainless steel wire rope as the internal strength member of the element (Fig. IV-2). This has the advantage that good bonds can be maintained between the woven cable and both the inner and outer rubber during expansion and contraction of the element. However, this type of element may be weak at very high degrees of inflation, if the 


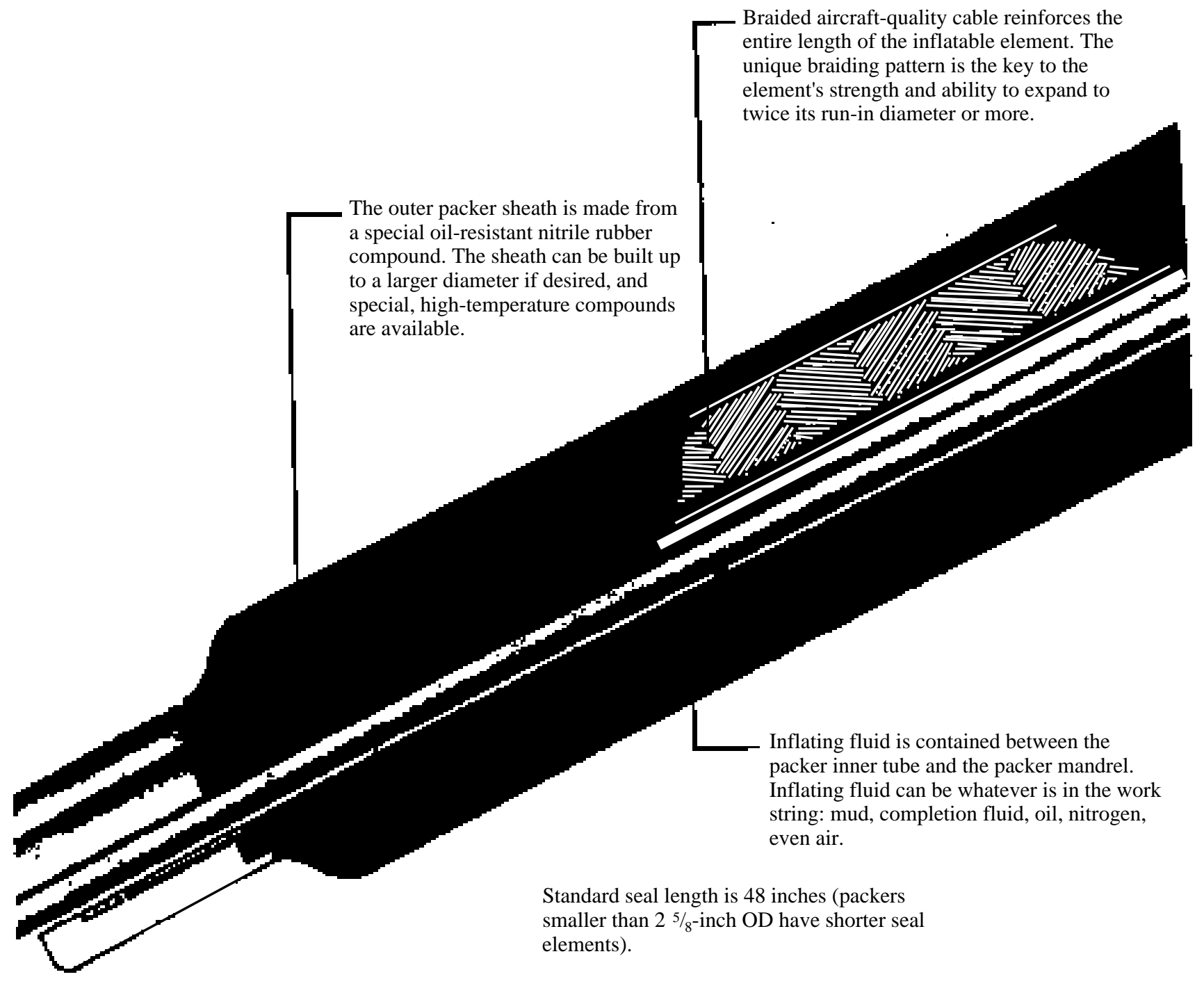

Figure IV-2. Anatomy of the rubber elements used on the ODP drill-string packer manufactured by TAM International. The elements of the developmental rotatable packer, wireline packer, and Geoprops probe (none of which is presently functional) had a similar design. 
cables separate to the extent that the rubber in the gaps must bear too much of the inflation pressure.

\section{Inflation of packer elements using go-devils}

The TAM packer elements can safely be inflated to as much as twice their uninflated diameters. However, a greater degree of inflation requires more time for full deflation and produces a weaker hydraulic seal that can withstand a lesser range of test pressures (Fig. IV-3). Thus, effective formation testing requires that the element(s) be positioned in zones where the borehole is in good condition and in gauge, where the degree of packer inflation can be kept reasonable. Such zones are usually apparent in logs that should be run before packer tests are begun, such as caliper, resistivity, density, and sonic.

After the drill-string packer is positioned in the desired zone, inflation of the element(s) is accomplished by pumping seawater from the ship down the pipe. Before pumping, the inflation mechanism is enabled by free-falling a retrievable go-devil, which keys into the packer plumbing system. A properly seated go-devil will perform several functions, including (1) forming a hydraulic seal within the packer to direct the fluids pumped from the rig either into the elements for inflation or into the formation for testing, (2) carrying the pressure recorders that monitor the data needed to determine pore pressure and permeability, and possibly (3) carrying a sample chamber. Because the go-devils are retrievable with the coring line, multiple sets of the ODP drill-string packers can be made with a single pipe trip as long as the elements hold pressure and seal the borehole.

\section{Temperature limitations of the ODP drill-string packers}

The temperatures to which the drill-string packers can be used are limited by the temperature ratings of the rubber compounds that make up the packer elements and inner seals. Standard nitrile o-rings and elements are rated to about $100^{\circ} \mathrm{C}$. Commercially available o-rings made of special elastomers are effective to temperatures as high as $300^{\circ} \mathrm{C}$. However, the combination of elasticity, strength, and resetability required of the rubber in the inflation elements is difficult to achieve at high temperatures. Packer elements made with high-temperature rubber compounds will probably be effective to $200-250^{\circ} \mathrm{C}$, but only at limited test pressures and limited degrees of expansion 


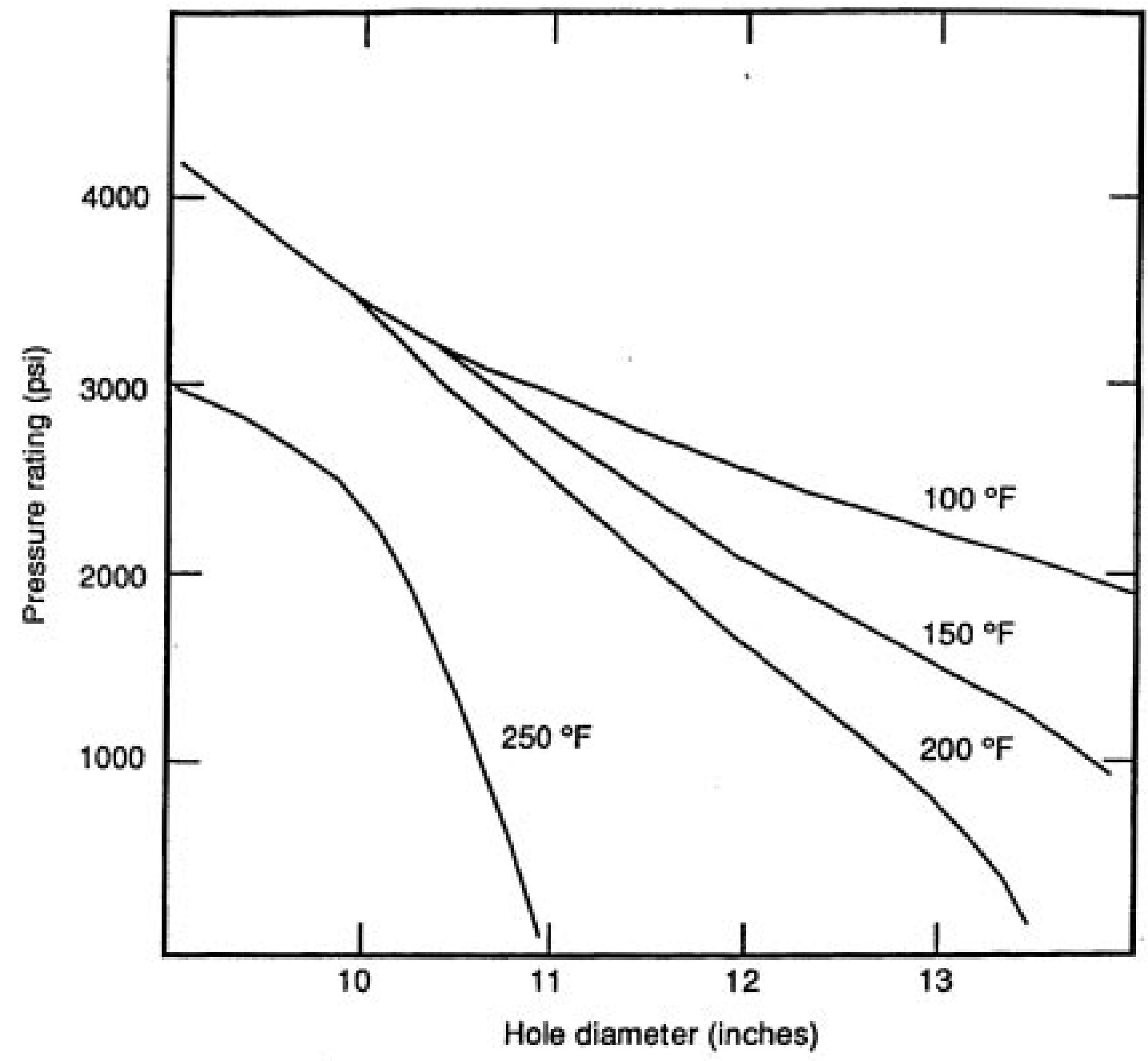

Figure IV-3. The burst pressure of standard drill-string packer elements at various temperatures and inflation diameters. High-temperature elements are also often available on board the JOIDES Resolution. 
Technical Note No. 10

Page 46

( $<10 \%-20 \%)$, and such elements may last only for single settings. During Leg 111, two special elements rated to $120^{\circ} \mathrm{C}$ were successfully used at temperatures of $120^{\circ}-145^{\circ} \mathrm{C}$ in Hole $504 \mathrm{~B}$, but lasted for only one setting each. During Leg 139 in active hydrothermal fields at Middle Valley, northern Juan de Fuca Ridge, packer work was confined to casing, so that high-temperature components were not needed. TAM International is continuously refining their packer-element materials and construction techniques; they now claim that their moderate and high-temperature elements are nearly as expandable and strong as their lower temperature elements.

\section{Compatibility of ODP drill-string packer with logging}

The non-rotatable drill-string packer should be kept in tension, like the drill pipe above the BHA, and should not be included as part of a coring, rotating BHA. Thus, formation testing with the drill-string packer will require separate pipe trips into reentry holes that have already been cored. As described below, the packers are compatible with logging, and it may be possible to accomplish logging and packer measurements during a single pipe trip.

All the standard logging tools will pass through the drill-string straddle packer, unless a packer godevil is in place. (A newly designed go-devil may also be compatible with one or more logging tools; see Chapter VIII-B.4.) Packer measurements are usually run after the completion of wireline logging, because of the chances of a go-devil getting stuck in the pipe or of rubber from the packer elements stripping off in the hole. Also, the logs are usually important in locating formations in which to set the packer.

In some situations, it may be better for operational reasons to run a separate pipe trip for packer measurements. For example, the packer BHA may require more drill collars than an optimal logging BHA to balance the upward force on pressurizing the zone isolated below the packer. It may be necessary that most or all of the BHA be in the hole below seafloor during logging, and a heavier, longer packer BHA would limit the shallowest depth to which logs could be run. Thus, if it is essential to log the upper $50 \mathrm{~m}$ of a reentry hole, separate pipe trips might be required for logging and packer measurements. 


\section{TAM straddle Packer design}

The design of the TAM straddle packer is quite simple, as it has no rotational capability and is intended primarily for measurements in reentry holes that penetrate stable formations. By assembling it in the BHA with or without a few essential parts, this packer can be used in four resetable modes, all of which are fully compatible with logging:

(a) as a single-element packer,

(b) as a double-element (double-seal) single packer,

(c) as a straddle packer,

(d) as a straddle packer allowing the option to separately test the straddled interval or the interval below the packer.

The minimum I.D. is 3.94-in. for a single packer configuration, or 3.84" for a straddle packer configuration.

When a straddle configuration is used, the straddle interval can be as small as $1 \mathrm{~m}$ and can be changed by spacing sections of drill pipe between the elements. Hydraulic continuity is maintained between the elements by connecting them with 3/8-in.-diameter stainless-steel tubing external to the spacing drill pipe. Thus, if either element or the tubing fails to hold pressure, neither element can be inflated. This is a good safety feature in that once the packers are inflated, a hydraulic failure anywhere in the system will result in the deflation of both elements, not permitting an element to remain locked in an undeflatable position.

Depending respectively on whether a single or a straddle configuration is deployed, the first or both of two go-devils assembled from common parts will be used:

(a) a go-devil with 3.99-in.-diameter seals and stop rings that seals above the single packer (or the upper straddle element) and keys into the subassembly that controls inflation and deflation of the single (or entire straddle) packer; 
Technical Note No. 10

Page 48

(b) a go-devil with 3.89-in.-diameter seals and stop rings that passes through the control sub and seals the drill pipe at the lower straddle packer, allowing the straddled interval to be tested.

Self-contained pressure recorders are attached to the upper go-devil to record pressures in the isolated section, whether it be between a single packer and the bottom of the hole or between the two inflated elements of the straddle configuration. During operations with the straddle packer, a single pressure recorder can also be hung below the lower go-devil to test for leakage from the straddled interval. ODP maintains several mechanical Kuster pressure gauges which can record pressures up to 15,200 psi. At present neither go-devil can sample formation fluids, but it should be feasible to develop this capability.

Each go-devil must be retrieved with a standard overshot on the coring line. The use of the singlepacker configuration is fairly straightforward, requiring just one free fall/retrieval round-trip of a single go-devil, whereas use of the straddle configuration requires a more complex and timeconsuming sequence of go-devil operations, as follows. First, the upper go-devil must be dropped to allow inflation of both packers and possibly testing of the zone below the lower packer. Second, to test the straddled interval, the upper go-devil must be retrieved, the lower go-devil dropped into place, and the upper go-devil dropped a second time. Third, at the end of the experiment, two trips of the coring line are required to retrieve both go-devils.

To enable inflation, the upper go-devil must seal properly in the packer control sub. This assembly incorporates one principal moving part that can shift vertically by about $20 \mathrm{~cm}$, controlling whether or not the inflate/deflate port to the elements is open. This control tube is directly connected to the drill string, and its position is controlled from the rig floor using the drill-string heave compensator. When the drill string is freely suspended, both the flow paths into the elements and down the pipe up the annulus are open, so that pressure in the elements will remain the same as in the borehole. Thus the elements will remain uninflated until the upper go-devil is in place and the rig pumps are used to pressurize the elements. When the elements are fully inflated against the borehole wall, the heave compensator is adjusted to put some weight on the packer, shifting the control tube so that the inflate/deflate ports are closed and the packer elements are locked in the 
inflated position. Then, after the completion of formation testing, the packers can be deflated by simply pulling up on the drill string at the rig floor, opening the inflate/deflate port whether or not the go-devil is in place. Technical Note 14 contains full schematics and gives detailed instructions for:

(a) assembling the nonrotatable drill-string packer as a single packer or as a straddle packer,

(b) testing the assembled packer before deployment, and

(c) deploying and operating the packer and go-devil(s).

\section{Formation Testing Using the Straddle Packer}

Several hydrologic parameters of the formation can be determined in various types of tests with the packer that involve controlled pumping of seawater from the rig floor into the isolated interval. In all of these tests, the critical parameter that is actually measured and from which the formation properties are derived is fluid pressure in the isolated section of the borehole. During testing it is also important to measure fluid pressure at the rig-floor pumps as well as the volume and rate at which fluid is pumped into the isolated zone.

On JOIDES Resolution, two powerful pumps are available for inflating the packer and testing the formation: the "cement" pump and the "mud" pump. The mud pump is directly controlled at the rig floor by the driller and is more convenient, particularly for setting the packers. The cement pump is controlled below the rig floor and is thus much less convenient but may be more appropriate when accurately-measured, smaller volumes of higher pressure fluid are required.

\section{Downhole pressure recorders}

Downhole pressures can be measured using several kinds of recorders. At present, ODP maintains four self-contained mechanical model K-3 recorders made by Kuster Co. (Fig. IV-4). These are calibrated for pressure ranges of 0-9900 to 0-15,200 psi, and can be configured with Kuster clocks to record for 3, 6, or 12 hours. (An additional University of Miami clock presently available aboard JOIDES Resolution allows recording of 9, 18, or 36 hours as well.) The pressure records 
Figure IV-4. Schematic cutaway drawing of the Kuster K-3 mechanical pressure gauge for use with the drill-string packer.

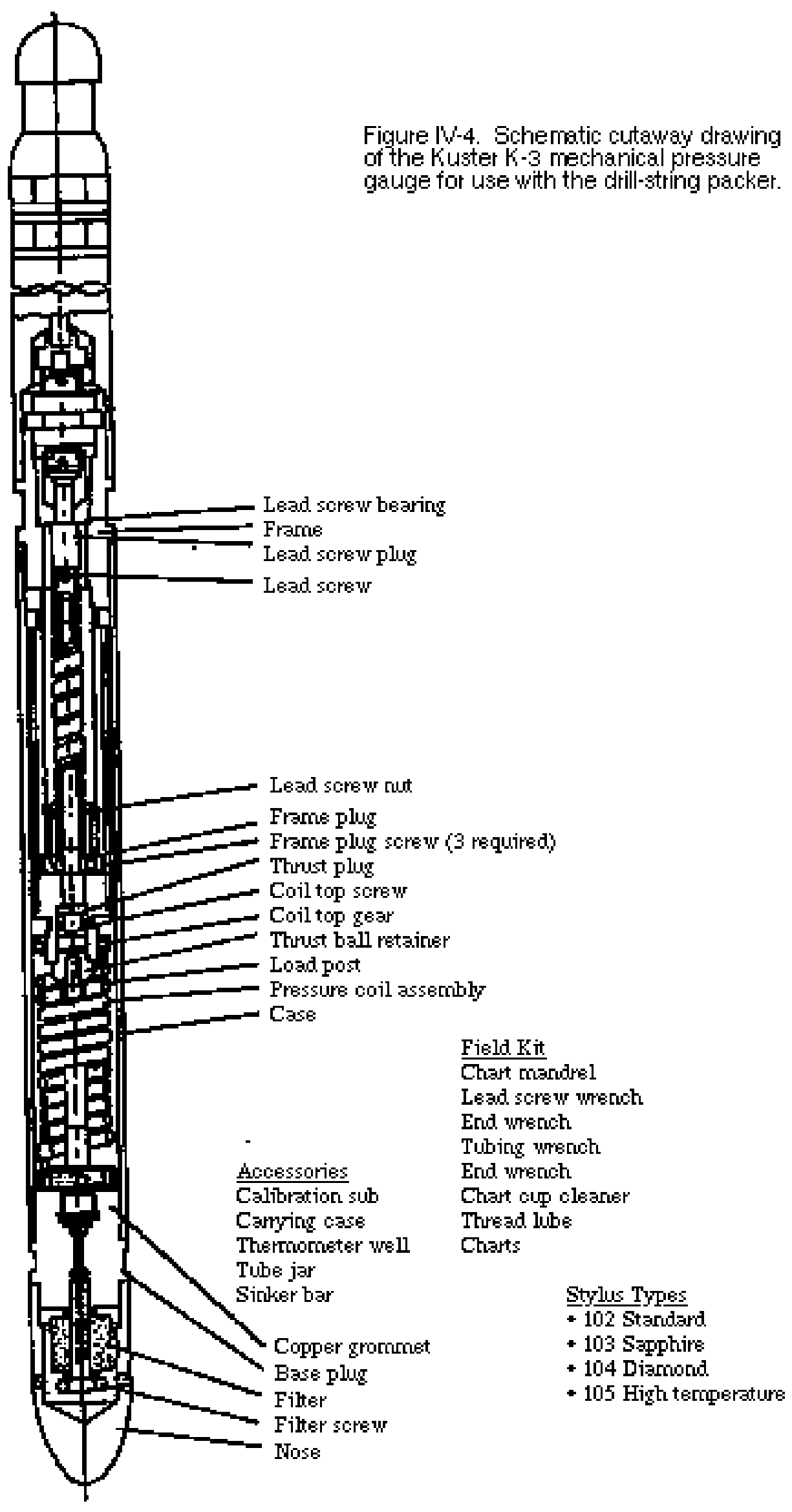


Technical Note No. 10

Page 50

are scratched quite accurately onto small coated brass charts. As only one size of chart is produced, some resolution is lost if a longer recording time is chosen; in recent practice, the recorders have been set for 3 or 6 hours. The charts must be read using a calipered, microscopic chart reader, one of which is kept at the University of Miami.

During Legs 139, 146, and 148 packer scientists used electronic gauges instead of, or along with, the conventional mechanical Kuster gauges. These electronic gauges are also owned by K. Becker at the University of Miami. The electronic recorders are effectively interchangeable with the Kuster recorders, except that the electronic data are accessible immediately after the go-devil is retrieved.

The pressure gauges/recorders are housed in special carriers that attach to the go-devil. Normally, two K-3 recorders are attached to the go-devil to provide redundant data in case one recorder malfunctions. Like the Kuster recorders, the University of Miami electronic recorders are housed in special carriers attached to the go-devil. The electronic gauges have slightly different dimensions, however, so a separate set of gauge carriers must be used. ODP may consider purchase of additional electronic gauges at a later time.

\section{Pressures measured during formation testing}

In testing the formation using a packer, it is important to control carefully the packer inflation pressure. This is defined as the pressure (relative to hydrostatic) at which fluid is pumped into the packer element(s) when inflated, and is measured at the rig-floor pumps. The inflation pressure must be chosen carefully, based on anticipated hole conditions, formation properties, and test pressures. Given good open-hole conditions, the elements should be inflated to about 500-1000 psi, or to roughly half the planned test pressures if higher pressures are planned. If the inflation pressure is improperly chosen (either too high or too low), a "leaky" packer seal may result, which will certainly affect any measurements but will not necessarily be recognizable in the pressure data. Care must be taken not to inflate the element(s) to a pressure high enough to actually fracture the formation and thereby invalidate any testing. This upper limit on inflation pressure will depend on the lithostatic pressure and strength of the formation. 
It is critical to measure and distinguish three different pressure values in the isolated section of the borehole: hydrostatic pressure, in-situ pore pressure, and test pressures. This necessity dictates the overall sequence in the testing procedure at each isolated zone:

(a) Hydrostatic pressure must be measured first, before the packer is inflated, both to check the recorder calibrations and to provide a reference baseline to compare the measurements of in-situ pore pressure and test pressures. The hydrostatic-pressure baseline is usually obtained by waiting 10-20 minutes after the go-devil lands in the packer before pressuring up to inflate the packer.

(b) When the packer is inflated, fluid pressure in the isolated section of the borehole will slowly approach in-situ pore pressure of the formation, which may differ from the borehole hydrostatic pressure. If it is critical to determine pore pressure, as much as 2-3 hours (or more) of passive recording may be required before active testing to provide sufficient pressure data to extrapolate accurately to in-situ pressure.

(c) In active testing, permeability can be estimated from the transient behavior of pressure in the borehole in response to controlled pumping from the rig floor through the go-devil and into the formation. Two principal kinds of tests have been used in previous DSDP/ODP permeability measurements, pulse or "slug" tests and constant-rate injection tests, which are described in detail below.

\section{Active formation testing}

The permeability of a formation that is isolated by a packer can be determined by any number of methods. The simplest and most direct of these are pulse tests and constant-rate injection tests, both of which involve applying controlled fluid pressure to the isolated zone using the rig-floor pumps. Figure IV-5 reproduces a Kuster pressure record from Leg 118 that illustrates both kinds of tests.

In a pulse test, the downhole recorders monitor the decay of a short, effectively instantaneous pressure pulse applied by the rig-floor pumps. In a relatively impermeable formation, the decay of such a pulse will be long compared to the duration of the pulse, and the pressure data can be treated with the theory for an instantaneous pulse (Cooper et al., 1967; Papadopulos et al., 1973; 


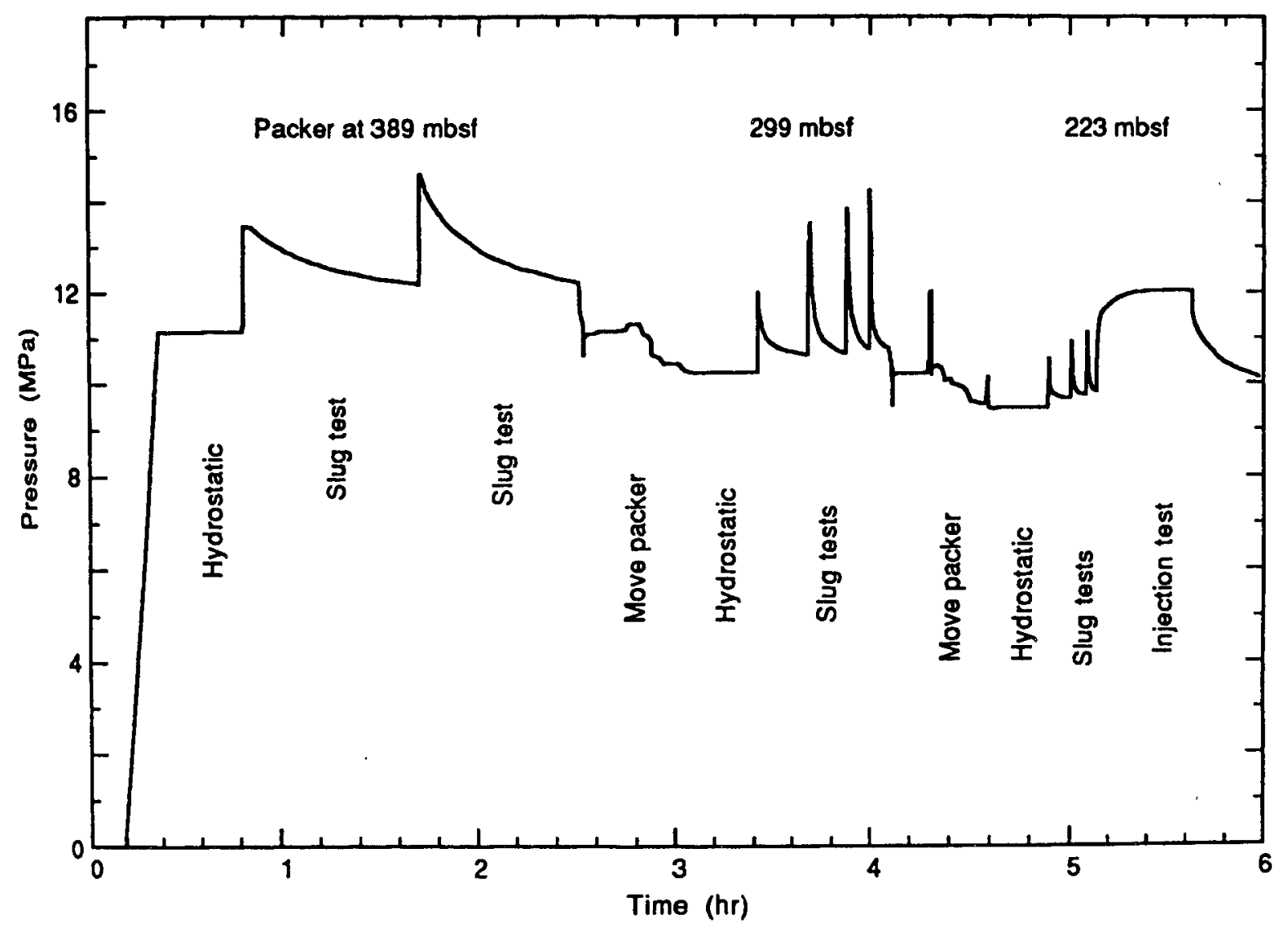

Figure IV-5. Example of Kuster K-3 gauge record from a packer experiment during Leg 118. This record illustrates the pressure vs. time history of the experiment during one of three packer element inflations in Hole 735B (Becker, 1991). The record shows good responses during both slug and injection testing. 
Technical Note No. 10

Page 52

Bredehoeft and Papadopulos, 1980). The decay of an instantaneous pulse is described by a complicated integral involving two dimensionless parameters, which depend respectively on "transmissivity" (a function of permeability and the thickness of the permeable zone) and "storage coefficient" (a function of porosity). Fitting pulse-test pressure data to this function generally resolves transmissivity much better than storage coefficient, yielding estimates of permeability but not necessarily of porosity.

In a relatively permeable formation, a pressure pulse will decay too rapidly to allow resolution of transmissivity, and constant-rate injection tests are appropriate. These involve pumping into the formation from the rig floor at a known constant rate, and monitoring the change in downhole pressure with time. The associated rate of pressure increase within the isolated zone, when plotted against log time, is proportional to permeability (Horner, 1951; Matthews and Russell, 1967). The pressure rise is analogous to the rise in temperature associated with thermal-conductivity measurements (Jaeger, 1958; Von Herzen and Maxwell, 1964). After pumping is stopped and the hole is shut in, the subsequent pressure drop can be used independently to estimate permeability, with the method of analysis closely following that for injection testing.

In oceanic sediments and crust, the ranges of permeabilities over which pulse tests and constantrate injection tests yield reasonable permeability estimates overlap, and it is often not possible to determine before testing which type of test will be more appropriate. As injection tests disturb the pressure field in the isolated formation to a greater degree than pulse tests, it is advisable to attempt pulse tests before injection tests. If several pulse and/or injection tests are to be attempted in a single formation, the pressurized system should not be allowed to "flow back" between tests and the pressure should be allowed to decay naturally as much as possible between tests. If the hole is kept "shut-in" (at the wellhead or downhole), the effects of the individual tests will be superimposed in a straightforward manner, and it will be possible to correct for the effects of previous tests.

As with temperature measurements using the WSTP or APC tool, processing pressure data from packer tests involves fitting of imperfect field data to theoretical curves. In practice, this means that data from early in the test periods tend to diverge from idealized curves due to imperfections in the 
test equipment and system geometry. Interpretations of transient pressure responses during formation testing generally require the assumption that the borehole is a "line-source," i.e., that the borehole is infinitely thin, while the formation extends radially to infinity. In addition, the potential complications of leaky seals, superimposed decay curves (from repeated testing in the same hole), and other factors mean that processing of packer test data requires considerable care and experience.

The programs of testing will vary from hole to hole, depending on the formation permeability. Further guidance can be gleaned from several good examples: the work done during DSDP in Hole 395A by Hickman et al. (1984) and in Hole 504B by Anderson and Zoback (1982) and Anderson et al. (1985), and the measurements made during ODP Legs 109, 111, 118, and 139 in Holes 395A, 504B, 735B, 857D and 858G (Becker, 1989; 1990a; 1991). (For the ODP work, see also relevant sections in Bryan, Juteau, Adamson, et al., 1988, Becker, Sakai, Merrill, et al., 1988, and Robinson, Von Herzen, et al., 1989; Davis, Mottl, Fisher et al., 1992, as well as ODP Technical Note 14). 
Technical Note No. 10

Page 54

\section{CORE ORIENTATION}

\section{A. Introduction}

Core orientation involves two primary components, rotation about an axis parallel to the core barrel, and translation along this axis. Tools are routinely available aboard JOIDES Resolution to assist with orientation of APC cores for paleomagnetic studies of sediments; additional developmental tools assist with translation and rotation of RCB cores for hard-rock core orientation and general data integration. Orienting APC cores is easier than orienting RCB cores for several reasons. First, APC cores are collected rapidly in soft sediments. Recovery is often close to $100 \%$, and it is likely that the APC core barrel maintains its rotational orientation during the few seconds that a core is collected. In addition, each APC core retains its orientation relative to the core barrel after the core is collected. Thus only one downhole tool is needed for APC orientation: a "multishot" compass which records the rotational orientation of the core barrel before, during, and after the barrel is fired into the sediments. Orientation of RCB cores requires that several additional data types be collected and combined, and that individual pieces of core be oriented separately.

\section{B. APC Orientation}

ODP operates two different magnetic multishot cameras to measure orientation of nonrotary cores taken with the APC. The analog (Eastman-Christensen) magnetic multishot provides a photographic record of a magnetic reference azimuth, the deviation of the core from vertical determined with a pendulum, and the magnetically determined azimuth of that deviation. The analog tool continuously records images of its compass/pendulum "angle unit" on 10-mm movie film at preselected intervals. A digital multishot was recently developed for ODP use by Tensor, Inc. The Tensor tool uses two accelerometers and three orthogonal magnetometers to provide coreorientation information. The tool records hole inclination (drift), azimuth, and magnetic tool face (core alignment) direction, either in single-shot or continuous modes. Tool specifications for the digital multishot are listed in Table V-I. As with other tools used with the APC, the use of a 
Table V-I. Digital multishot specifications.

Length

Diameter

Weight (with batteries)

Temperature limitiations

Shock limitations

Vibration limitations

Accuracy

Shot capacity

Hold-off time

Shot interval

Battery voltage

Operating life per battery pack
$71.4^{*}$

$1.38^{\prime \prime}$

$5 \mathrm{lb}$

Storage: $\quad-20$ to $150^{\circ} \mathrm{C}$

Operation: $\quad 0$ to $125^{\circ} \mathrm{C}$

$1000 \mathrm{~g}, 0.5 \mathrm{msec}$

$167 \mathrm{~g}, 3 \mathrm{msec}$

5 to $20 \mathrm{~Hz}, 1.0^{\prime \prime}$ amplitude

$20-200 \mathrm{~Hz}, 30 \mathrm{~g}$ peak-to-peak

Orientation: $\pm 0.2^{\circ}$

Temperature: $\pm 1.5^{\circ} \mathrm{C}$

Single shot: 15

Multishot: $\quad 1023$

1 to $533 \mathrm{~min}$

5 to $32,000 \mathrm{sec}$

15.5 to $18 \mathrm{~V}$

50 to 60 hours 
multishot with piston cores is limited to depths at which the force required on pullout is within safe limits, typically 100-300 mbsf.

To fully utilize the magnetic orientation capabilities of either multishot tool, a special, 30-ft nonmagnetic drill collar must be included in the BHA just above the lowermost drill collar (also known as the outer core barrel). Therefore the decision to obtain oriented cores at a given site must be made before the BHA is made up and the pipe is run into the hole. The multishot is housed in a nonmagnetic pressure case that is installed between two nonmagnetic sinker bars in the assembly used to connect the coring line to the APC core barrel. When coring commences, handling the multishot will add 5-10 minutes per core to normal coring times.

The ODP downhole-tools specialist is responsible for all phases of operating the multishot tools. For the analog tool, these tasks include tool preparation for each core, removing and developing the film after the run, interpreting the film record, and recording the relative azimuth angle, deviation from vertical, and direction of deviation on special envelopes in which the developed film is stored. The azimuth orientation angle is recorded as the clockwise angle (when looking down) between magnetic north and the double lines drawn on the core liner. The physical alignment between the double line on the core liner and the reference "lubber" line that is superimposed over the compass image on the multishot pictures is accomplished using a series of mechanical devices built into the equipment. The total error in the azimuth orientation reading introduced by these mechanical devices should not exceed $3^{\circ}$. Running the electronic tool involves checking battery power, arming the tool, handing it over to the core techs for deployment, retrieving the data after the station, and archiving raw data in the shipboard database.

Even if the nonmagnetic drill collar is not installed in the BHA, the multishot can be used to measure the deviation from vertical without any determination of orientation, also known as "drift" of the hole. The analog multishot angle unit determines the verticality using a pendulum suspended over a bull's-eye, while the digital tool uses two accelerometers. The amount of drift can be read from the developed film, although the orientation of deviation from vertical is meaningless when the multishot tool is used in the presence of a magnetic drill collar. The electronic multishot can also be used to determine hole drift without orientation. 
Technical Note No. 10

Page 56

\section{RCB Orientation}

As with APC cores, orientation of RCB cores includes running a multishot tool inside a nonmagnetic drill collar to record continuously the orientation of the core barrel. RCB cores tend to be cut in short pieces, however, with centimeter- to meter-long pieces of core breaking off from formation when the torque transferred from the cutting surface to the core exceeds the rotational strength of the rock. Thus two additional tools are needed to determine the orientation of each core piece while it is being cut, before the piece can brake off and rotate independently within the core barrel. These two tools are the sonic core monitor (SCM) and the scribing core-catcher. The entire hard-rock (RCB) core-orientation system is illustrated in Figure V-1.

The SCM is a battery-powered electronic tool that monitors and records core height relative to the core catcher. The SCM is programmed via an IBM-compatible PC, and mounted above the core receptacle inside the top of a corebarrel, which is then lowered or dropped down the pipe to the BHA. The SCM monitors the height of a core as it is cut by transmitting ultrasonic waves down the barrel at a target, which rides atop incoming core. As more core enters the barrel, the time for the reflected ultrasonic wave to be returned to the SCM receiver is reduced. At present, the rate of bit penetration is recorded at the rig floor with the same computer used to program and operate the SCM. This is done by having the driller record drilling and pipe progress manually, as sections of pipe pass through the Kelly bushing at the rig floor. When the core barrel and SCM are returned, bit depth and core height are merged to indicate the depth of origin (relative to the rig floor) of each part of the core.

The scribingcCore-catcher (Figure V-2) uses three asymmetrically arranged carbide blades to mark the orientation of hard rock as it enters the core barrel. Three knives are used to prevent pieces of core from becoming eccentrically loaded and jamming in the core catcher; they are arranged asymmetrically to allow the "primary" scribe mark to be determined. The primary scribing knife is aligned mechanically with a magnetic reference on the electronic multishot, thus allowing relative core orientation to be tied to the absolute orientation of the barrel. Individual pieces of core 




Figure V-1. Schematic illustration of the complete hard-rock (RCB) orientation system including electronic multishot, swivel, sonic core monitor, and core scriber. 


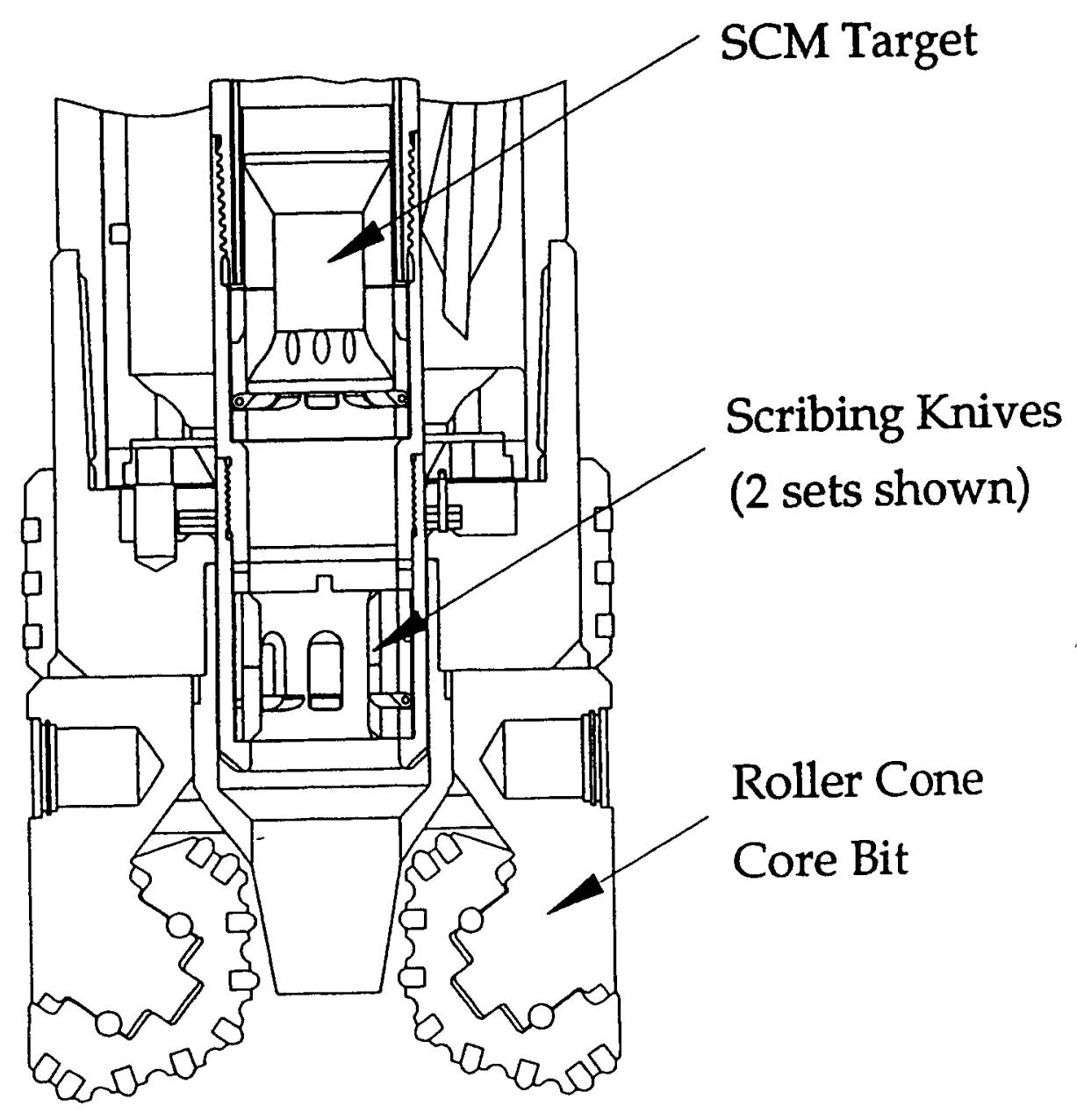

Figure V-2. Cutaway illustration of the scribing core-catcher and SCM target in the RCB coring system. 
tend to rotate relative to each other once the pieces enter the core barrel; each of these pieces must be individually reoriented after the core is recovered on deck.

In order to orient a piece of hard-rock core, the interested scientist must merge four distinct data sets: bit depth, core height, core-barrel orientation (relative to magnetic north), and core-piece orientation (relative to the core barrel). Bit depth and core height are presently merged within the same program used to operate the SCM, but this prototype system, like the rest of the hard-rock core-orientation system, is still in development. Example records from preliminary SCM deployments are shown in Figure V-3. The hard-rock orientation system is compatible only with the rotary core barrel. There are no plans at present to adapt hard-rock orientation to XCB cores. 
A B

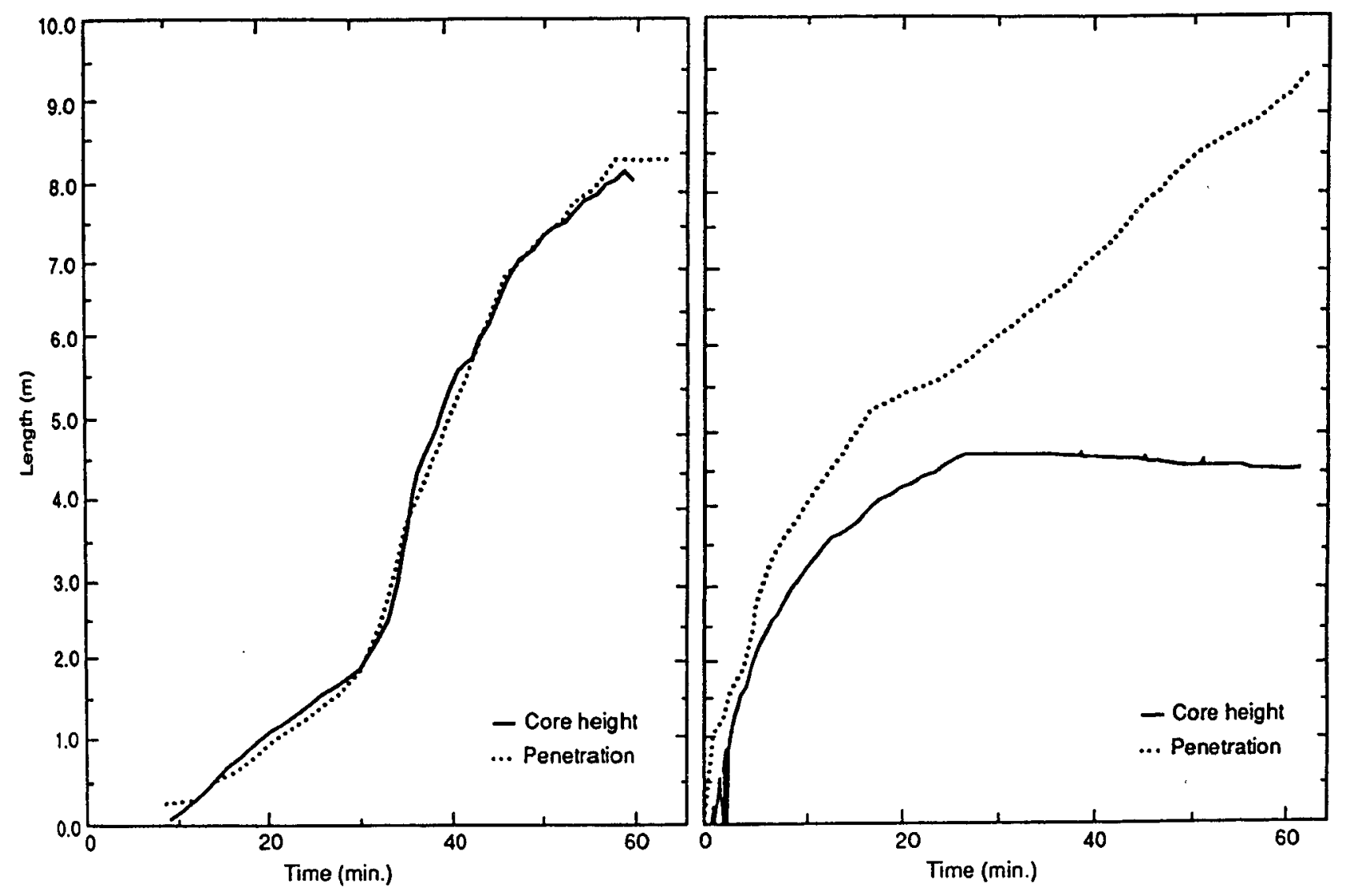

Figure V-3. Example sonic core monitor records. A. This record reveals almost full recovery, as core height closely follows bit penetration. B. This record reveals incomplete recovery. Recovery stopped when the bit penetrated about $4.5 \mathrm{~m}$, after just 26 minutes of coring. Thus the recovered core came from the upper part of the cored section. 
Technical Note No. 10

Page 58

\section{CORK}

\section{A. Introduction}

The CORK is a long-term, seafloor observatory intended to allow a monitored and accessible borehole to return to its pre-drilling state. The reprinted manuscript following this section, which appeared in the Leg 139 Initial Reports volume (Davis, Mottl, Fisher, et al., 1992), describes CORK development, deployment, and interpretation of preliminary data in some detail. A more complex treatment of CORK post-emplacement operations and data interpretation will appear in the Leg 139 Scientific Results volume, due for publication in the summer of 1994. Additional CORK operations conducted during Leg 146 are summarized briefly below, and in Table VI-I.

\section{B. Leg 146 CORK Operations}

Two new CORK systems were deployed during Leg 146, one in Hole 889C on the Vancouver margin, and one in Hole 892B on the Oregon margin. Site 889 is located on a 15-20-km-wide zone of low-gradient slope off Vancouver Island. The site was positioned to allow penetration and sampling of a gas hydrate zone and bottom-simulating reflector (BSR); CORK emplacement at this site is hoped to elucidate the geothermal, geochemical, and hydrogeological conditions conducive to BSR and hydrate formation. Hole 889C was drilled to $384.5 \mathrm{mbsf}$, with $259.5 \mathrm{~m}$ of casing, and a perforated, closed-end 5-in. liner extending to $322.9 \mathrm{mbsf}$. Deployment of the CORK data logger and thermistor/sampling string was hampered by poor weather and obstructions within the liner, apparently due to infilling of sediment through the $3 / 8$-in. liner perforations. The fluid-sampling tube was damaged during initial deployment attempts and was eliminated from the experiment, and a shortened 240-m thermistor string was installed.

Site 892 is located on the seaward flank of the second landward ridge at the toe of the Oregon accretionary margin. The site was positioned to intersect both a BSR and an apparently hydraulically active, landward-dipping fault at 68 and 105 mbsf, respectively. Hole 892B was drilled to a total depth of $178.5 \mathrm{mbsf}$, with casing to $93.6 \mathrm{mbsf}$, and a perforated, closed-end 5-in. liner extending to $146.1 \mathrm{mbsf}$. Once again, sediment appears to have flowed in through perforations in the liner, reducing the amount of available open hole. Because this hole was 
Table VI-I. Summary of CORK deployments through Leg 146.

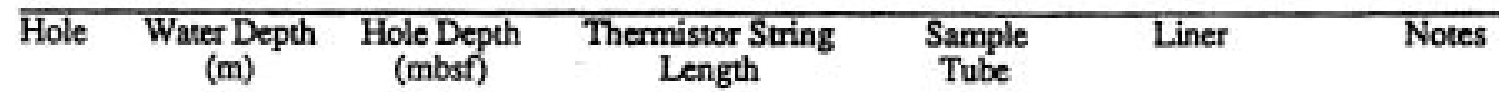

\begin{tabular}{|c|c|c|c|c|c|c|}
\hline \multirow[t]{2}{*}{ 857D } & 2432 & 936 & 325 & $\mathbf{Y}$ & $\mathrm{N}$ & $\begin{array}{l}\text { Installation visited by DSR/V ALVIN } \\
\text { September } 1991 \text {, data logget } \\
\text { downloaded and reprogrammed, } \\
\text { borehole found underpressured. }\end{array}$ \\
\hline & & & & & & $\begin{array}{l}\text { Cork damaged during attempted } \\
\text { replacement of thermistor string } \\
\text { during Leg } 146 \text {. }\end{array}$ \\
\hline $858 \mathrm{G}$ & 2426 & 432 & 425 & $\mathbf{Y}$ & $\mathbf{N}$ & $\begin{array}{l}\text { Installation visited by DSR/V ALVIN } \\
\text { September 1991, data logger } \\
\text { downloaded and reprogrammed, } \\
\text { borehole found underpressured. }\end{array}$ \\
\hline
\end{tabular}

Installation visited summer 1992 by Canadian ROV, data logger downloaded and reprogrammed.

$\begin{array}{lllllll}889 \mathrm{C} & 1326 & 323 & 238 & \mathrm{~N} & \mathrm{Y}\end{array}$

Hole has apparently filled in through perforated liner to total depth of $\sim 260$ mbsf.

Sampling tube left off due to installation problems.

$\begin{array}{llllll}892 B & 684 & 146 & 127 & \text { N } & \text { Y }\end{array}$

Hole has apparently filled in through perforated liner to total depth of $\sim 136$ mbsf.

Sampling tube left off due to size of $500 \mathrm{~m}$ thermistor string doubled back to shorten to $127 \mathrm{~m}$. 
significantly shallower than originally intended for CORK emplacement at the Oregon margin, a long thermistor string had to be doubled over upon itself several times to shorten it to $127 \mathrm{~m}$. This overlap in the thermistor string significantly thickened the string, requiring that the fluid-sampling tubing be omitted from the second Leg 146 CORK deployment.

During Leg 146 it was also intended that the thermistor string hanging beneath the CORK emplaced in Hole 857D (on Leg 139) would be replaced. The original thermistor string was too short because Hole 857D ended up being deeper, and the cased section longer, than originally planned. Poor weather during Leg 146, in combination with the delicate nature of CORK recovery operations, resulted in the Hole 857D CORK being severely damaged. A skirted running tool was lowered to the seafloor and latched on to the upper end of the CORK, which projected above the reentry cone. A series of large heaves while the heave compensator was being adjusted resulted in application of excessive weight to the CORK, driving the data-logger down through the CORK mandrel. The CORK running tool then disengaged from the CORK and dragged across the ROV platform and off the reentry cone to the seafloor. The exposed data logger and failed mandrel remain in the reentry cone, and were observed leaning at an angle against the ROV platform opening. The data-logger case may still be intact, as may be the primary CORK seal. An attempt to extract data from the logger at Hole 857D will be made from a submersible in August 1993.

The Leg 146 experience illustrates that the successful deployment of CORK seafloor observatories is weather and formation dependent. Scientists considering emplacement of CORKs on upcoming legs should alert ODP as early as possible in the planning process so that these and other factors can be considered. One significant modification which is now being planned by CORK PI's is the addition of an acoustic link to allow logger integration and reprogramming from a conventional surface vessel. 
Technical Note No. 10

Page 60

\section{PRESSURE CORE SAMPLER}

\section{A. Introduction}

The pressure core sampler (PCS) is fully described in ODP Technical Note 17 (Pettigrew, 1992), from which the following material was excerpted. The PCS was developed by T. Pettigrew at ODP as a replacement for the pressure core barrel designed during the Deep Sea Drilling Project (DSDP). Development of the PCS resulted largely from interest in improving recovery and maintaining stability of gas hydrates. The stated goal for Phase I of the PCS was to develop a prototype that could demonstrate and test the concept of improved techniques for obtaining pressurized core, gas, and water samples at near in-situ pressure. This effort has been partially successful, as revealed most recently during Leg 146, but additional refinement is needed.

\section{B. PCS Technical Description and Deployment Method}

The pressure core sampler is a free-fall-deployed, hydraulically actuated, wireline-retrievable pressure coring tool capable of retrieving core samples maintained at bottom-hole pressures. The PCS utilizes both current conventional oil-field pressure-coring technology and technology developed by DSDP. The PCS is completely compatible with the existing ODP bottom-hole assemble (BHA) used for the advanced piston corer (APC) and extended core barrel (XCB). The PCS is not compatible with the ODP rotary core barrel (RCB) BHA.

The PCS is completely interchangeable with the APC and XCB coring tools, thus allowing a pressurized core sample to be taken at any time from the mud line down to indurated formations and/or into basement. The PCS is free-fall deployed and lands in the BHA. The PCS latches into the BHA and is rotated with the BHA during coring operations similar to the XCB. The PCS recovers a nominal 42-mm (1.65-in.)-diameter core sample $86 \mathrm{~m}$ (34 in.) long at pressures up to 690 bar (10,000 psi). A schematic of the PCS (Fig. VII-1) illustrates its operation.

The PCS contains six main components, or subassemblies: latch subassembly, actuator subassembly, accumulator subassembly, manifold subassembly, ball-valve subassembly, and detachable sample chamber. 


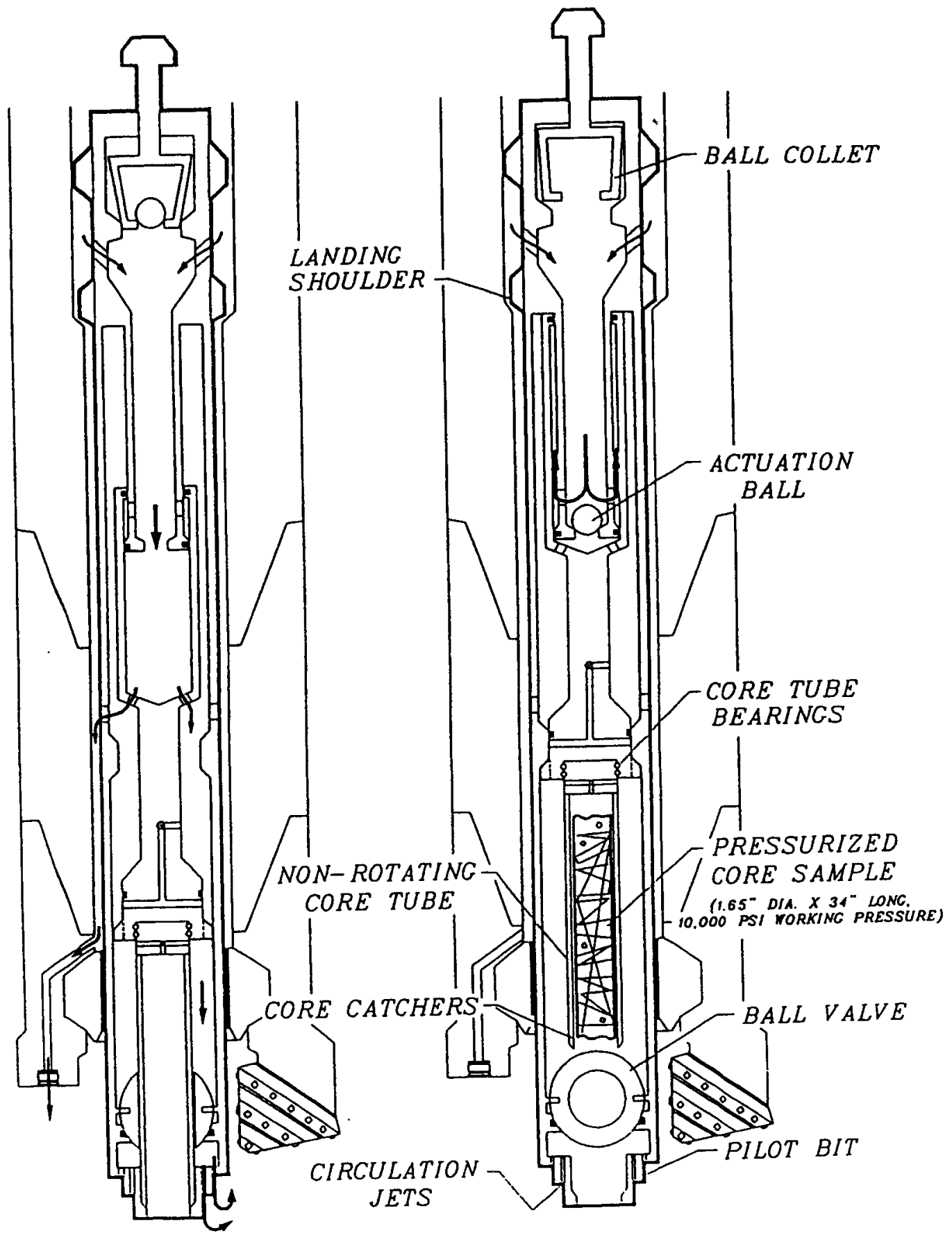

Figure VII-1. Cutaway drawing of the pressure core sampler.

A. PCS while cutting ahead. B. PCS with sample chamber closed. 


\section{Latch subassembly}

The PCS latch subassembly is a modified XCB latch. The latch subassembly contains the landing point for the PCS when free-fall deployed, and transmits torque from the BHA to the PCS. The PCS cutting shoe is rotated with the BHA, trimming the core sample to proper size for entry into the sample chamber. The latch subassembly also diverts all flow down the drill string through the inside of the PCS, and holds the actuation ball during deployment and coring operations. When the latch subassembly is engaged by the coring wireline and an upward force is applied, the actuation ball is automatically released, dropping into the actuator subassembly. Finally, the latch subassembly provides a receptacle for attachment of the coring wireline during retrieval of the PCS.

\section{Actuator subassembly}

The PCS actuator subassembly has a dual latch system which latches the ball valve open during coring operations and closed after actuation. The actuator subassembly catches the actuation ball when released by the latch subassembly, and diverts all flow through the PCS to the actuation piston. After the actuation ball has been released and pressure is applied to the PCS, the actuator subassembly automatically unlatches and strokes through itself, pulling the core tube through the ball valve and into the sample chamber. As the core tube is pulled through the ball valve it mechanically rotates the ball valve closed. During actuation, seals at the top of the core tube are pulled into a seal sub, thus closing the sample chamber at both ends. When the actuator subassembly reaches the end of its stroke, it automatically latches once again, holding the sample chamber closed.

\section{Accumulator subassembly}

As the name implies, the accumulator subassembly contains an accumulator. As the ball valve closes, a small change in volume occurs. To offset the volume change, the accumulator forces fluid into the sample chamber, thus maintaining bottom-hole pressure. The accumulator also compensates for any fluid loss due to weeping seals as the differential pressure increases inside the sample chamber during retrieval of the PCS. The PCS accumulator subassembly also contains a 
Technical Note No. 10

Page 62

pressure-relief mechanism. An integral back-pressure valve relieves pressure from the gas-charged side of the accumulator in the event of overpressurization of the sample chamber.

\section{Manifold subassembly}

The PCS manifold subassembly contains integral valves that enable the sample chamber to be isolated and removed. Two sample ports for collecting gas and/or fluid samples also controlled by integral valves are contained in the manifold subassembly. The sample ports have separate flow paths into the sample chamber; one flow path leads to the inside of the core tube, and the other flow path leads to the annular volume surrounding the core tube. The manifold subassembly also contains a burst disk which vents all pressure from the sample chamber should the internal pressure exceed the designed working pressure of 690 bar (10,000 psi). (This burst disk was deactivated during Leg 146 and will likely be eliminated in future designs.) An optional pressure transducer can also be installed in the manifold subassembly, enabling monitoring of the sample chamber internal pressure.

\section{Ball-valve subassembly}

The PCS ball-valve subassembly forms the sample chamber lower seal when actuated. The ball valve is mechanically closed as the actuation subassembly pulls the core tube through the ballvalve subassembly. The ball-valve subassembly also serves as the connection point for the PCS cutting shoe.

\section{Detachable sample chamber}

The PCS detachable sample chamber consists of the manifold subassembly, ball-valve subassembly, and pressure case. The sample chamber when detached from the PCS is $92.2 \mathrm{~mm}$ (3.75 in.) in diameter and $1.8 \mathrm{~m}$ (6 ft) long. When the sample chamber is stroked closed and removed from the core barrel, the two sampling ports and their associated integral valves as well as the integral pressure transducer are easily accessible. A sampling manifold can be attached to either or both sampling ports for sampling fluids and/or gases. 


\section{PCS Operation and Plans for Additional Development}

The PCS is free-fall deployed and is rotated with the BHA similar to the XCB. Once the core sample has been cut, the rig pumps are shut off, and the coring wireline is attached to the PCS. The PCS is picked up off the BHA landing shoulder to release the actuation ball, then lowered back onto the BHA landing shoulder. The rig pumps are reengaged to pressurize the drill string, which actuates the actuator subassembly, stroking the sample chamber closed. The PCS is then retrieved via the coring wireline. Once on deck, the detachable sample chamber is removed and placed in a temperature-controlled bath. A sampling manifold can be attached, and gas and/or fluid samples extracted.

Recovering a pressurized sample from the seafloor is only half the battle. As concluded by the participants at an ODP workshop on pressure core sampling, "the most important improvement to be made remains in the design of a system that subsamples gas, interstitial waters, and sediments without depressurizing the sample." At present there is no mechanism for extracting a solid (sediment or hydrate) sample under pressure from the PCS; solid core samples must be depressurized to access. Enhanced capabilities for accessing fluid, gas, and solid samples under pressure, and for conducting laboratory tests of these materials at in-situ conditions, constitute Phase II of PCS development. This level of PCS development has been put on hold pending funding of a scientific proposal by third-party investigators to develop a pressurized laboratory chamber. 
Technical Note No. 10

Page 64

\section{THIRD-PARTY AND DEVELOPMENTAL TOOLS}

\section{A. JOIDES Policy for Third-Party Tool Development}

Downhole measurements form an integral part of the technology that is routinely used in ODP. In addition to the standard downhole tools that are available on all ODP scientific legs, ODP has historically drawn upon tools developed outside the framework of its primary contractors. These tools are known as "third-party" tools.

Support for the development of third-party tools can come from a variety of sources. In the United States, third-party tool development has generally been supported by the National Science Foundation, using funds earmarked for ODP and allocated to highly ranked, unsolicited proposals. International partners operate a similar procedure.

Tools that are developed with this type of funding are specifically intended for deployment in ODP. However, ODP sometimes wishes to use existing tools that have been developed externally for different purposes. In both cases, it is important that third-party tools are certified as satisfying all the operational and safety criteria that ODP applies to its own in-house tools.

Third-party tools are required to make a transition from the development stage to certification for deployment downhole in ODP, under the management of either the ODP Logging Contractor (for wireline "logging" tools) or the Science Operator (for all others). To facilitate this transition, a set of guidelines has been formulated for the overall process of bringing the third-party tools to the development stage. The aim is to improve communications between ODP and those outside investigators who wish to develop a third-party tool, with the object of preserving ODP's safe, secure, and scientifically beneficial operations.

The following guidelines for third-party tool development were written by the JOIDES Downhole Measurements Panel and approved by the Planning Committee. These guidelines indicate a general progression through which new tools are introduced to ODP operations. More detailed technical specifications are available from the ODP Science Operator and Logging Contractor. 


\section{Classification of tools}

ODP defines three types of third-party tools: development tools, certified tools, and mature tools. A Development Tool is either a tool that is under development externally for use specifically in ODP or a tool that has been developed outside ODP for other purposes and is being considered for ODP deployment. A Certified Tool is a tool that has been developed outside ODP, either for specific ODP application or for other purposes, and is now deemed to satisfy all the criteria for scientific deployment in ODP. Where there is likely to be a long-term requirement for the data provided by a Certified Tool, it may be a candidate to become an ODP Mature Tool. A Mature Tool is an established tool that has become part of the range of ODP tools operated routinely by the Science Operator or the Logging Contractor. Such a tool will effectively be owned by ODP and will no longer be a third-party tool.

\section{Development tools}

For a tool to be considered an ODP Development Tool, several criteria must be satisfied.

(1) There must be an identified Principal Investigator who is the primary proponent for the use of the tool in ODP.

(2) The Principal Investigator should formulate a Development Plan in consultation with the Science Operator or the Logging Contractor, as appropriate.

(3) The Development Plan should:

- indicate the usefulness of the proposed measurements and the financial and technical feasibility of making them;

- include a brief description of the tool, schematic diagram(s), details of the operational procedure, and technical specifications such as dimensions, weight, temperature and pressure ratings, cable-length restrictions, cable type, etc.;

- identify development milestones in terms of both the level and the timing of technical achievements;

- make provision for initial testing on land; 
Technical Note No. 10

Page 66

- satisfy safety considerations;

- specify shipboard requirements such as the data processing necessary to make the information accessible on board ship, any special facilities (emphasizing areas where the tool is not compatible with existing hardware and software), and appropriate technical support;

- make provision for transporting tools for shipboard testing, in terms of both cost and time; and

- contain a signed (pro forma) statement of (a) agreement with these requirements and (b) intent that the tool would be available for post-development deployment in ODP.

(4) The Development Plan must be submitted for approval to the ODP Downhole Measurements Panel (DMP). This submission should be made by the Science Operator or the Logging Contractor, as appropriate, on behalf of the Principal Investigator, who may be invited to present the Development Plan to the Panel in person.

(5) If DMP endorses the Development Plan, the Panel will appoint a coordinator to monitor on behalf of the Panel the tool's progress through the Development Plan. The Panel monitor will receive reports from the Principal Investigator on request and will present these to DMP. Day-to-day liaison with the Principal Investigator will be the responsibility of the Science Operator or the Logging Contractor.

(6) An ODP Development Tool can be scheduled for testing during an upcoming leg. Development tools must be deployed in test mode. (By their very definition they are not certified or mature tools, and therefore the scientific success of a leg should not be contingent upon the proper functioning of such a tool.)

(7) Where it becomes apparent that the Development Plan is seriously behind schedule and that the tool is unlikely to have satisfied all the above criteria prior to its planned deployment, the shipboard test should be canceled and agreement reached on a revised 
schedule. In particular, if a Development Tool has failed to satisfy all the above criteria 6 months before the start of the test leg, the tool should be withdrawn immediately from that leg.

(8) It is incumbent upon the Principal Investigator to ensure that the Science Operator or Logging Contractor, as appropriate, is fully advised of the tool's status before the 6 month deadline.

(9) A tool cannot be regarded as an ODP Development Tool, and therefore cannot be scheduled for testing in future legs, if the above procedure has not been followed. A Development Tool cannot be deployed on an ODP leg unless the ODP Science Operator or the Logging Contractor are fully satisfied that the terms of the Development Plan have been fully met.

\section{Certified tools}

For a tool to be considered an ODP Certified Tool, the following criteria must be met.

(1) The tool must have satisfied all the requirements for an ODP Development Tool.

(2) The tool must have been tested at sea during ODP legs and performed satisfactorily in the opinion of the Science Operator or Logging Contractor.

(3) The Principal Investigator should formulate a Request for Certification in consultation with the Science Operator or Logging Contractor, as appropriate.

(4) The Request for Certification should:

- indicate the cost of routine operations including shipboard data processing;

- outline the operational requirements for routine deployment and data processing;

- detail the availability of spare components;

- provide information on adequate maintenance facilities;

- include an operating and maintenance manual; 
Technical Note No. 10

Page 68

- satisfy safety considerations; and

- confirm the long-term usefulness of the data.

(5) The Request for Certification must be submitted for approval to the ODP Downhole Measurements Panel. This submission should be made by the Science Operator or the Logging Contractor on behalf of the Principal Investigator, who may be invited to present the Request for Certification to the Panel in person.

(6) If DMP endorses the Request for Certification, a certificate confirming the satisfactory conclusion of tests and the compliance with all other requirements will be issued to the Principal Investigator by the Science Operator or the Logging Contractor. A copy of this certificate should be forwarded to the DMP Chairman.

(7) An ODP Certified Tool remains in the charge of the third party. It can be scheduled for deployment during an upcoming leg and would be expected to contribute to the scientific success of the leg.

(8) Tools that do not possess a certificate cannot be programmed for scientific deployment on future legs.

\section{Mature tools}

For a tool to be considered an ODP Mature Tool, the following criteria must be met.

(1) The tool must satisfy all the requirements for an ODP Certified Tool.

(2) A Mature Tool Proposal should be submitted for approval to the ODP Downhole Measurements Panel. This submission should be made by the Science Operator or the Logging Contractor, as appropriate. DMP will advise on the long-term scientific benefits of the proposal. 
(3) If DMP proposes and the Planning Committee endorses the Mature Tool Proposal, the Science Operator or Logging Contractor will proceed toward the acquisition of the tool for ODP.

(4) When several Certified Tools are competing for the same Mature Tool slot, DMP will require the appropriate contractor to evaluate all these tools and to submit their multiple-tool evaluations to DMP for Panel consideration. DMP will advise on the most suitable $\operatorname{option}(\mathrm{s})$.

(5) Tools that have not undergone this process cannot be adopted by ODP as Mature Tools and will therefore remain third-party tools.

\section{Protocol for development}

Prospective proponents of third-party tools are requested to contact the ODP Logging Contractor (for wireline tools) or the ODP Science Operator (for all other downhole tools) at the earliest possible stage of their projects. Proponents will receive a detailed, current list of specifications with which third-party tools must comply. Proponents will also be further informed of the protocol governing the development and deployment of ODP third-party tools.

\section{B. Examples of Recent Third-Party Tool Developments}

The following examples should give interested scientists an idea as to the creative range of possibilities for tool development, and the complexity and difficulty of deploying such tools successfully. The examples range from tools developed for other settings that have been "borrowed" by the program (borehole-fluid samplers), to tools developed for general oceanographic use, with an eye toward ODP deployment (LAST I and II), to tools developed specifically for ODP use (spinner flowmeter), often with considerable assistance from ODP engineering and technical staff (Geoprops). It should be noted that even in the case of proven technology, it is usually necessary that a dedicated operator sail on JOIDES Resolution to run a third-party tool, or that significant pre-cruise training be undertaken so that shipboard staff are prepared for use of a nonstandard instrument. 
Technical Note No. 10

Page 70

\section{Borehole-fluid samplers}

Pristine formation fluids have never been retrieved successfully from a DSDP or ODP hole drilled into igneous basement or other hard formation. Recovering formation fluids from soft materials is relatively easy and routine during most ODP cruises: whole-round samples of cores are cut and squeezed in the shipboard laboratory. Hard (particularly igneous) rock does not yield pore fluids by squeezing, in part because hard rocks are difficult to squeeze but also because porosity in these materials tends to be fracture dominated and therefore not represented in recovered core. One means of obtaining samples of fluids from boreholes that penetrate igneous rock (fluid that may reflect the composition of pristine pore waters at some distance from the borehole) is to return to a reentry hole months or years after the last operations, after seawater pumped into the hole has had time to react with the surrounding rock, and gently lower a passive sampler into the open hole (Mottl and Gieskes, 1990). Eight such samples were obtained from DSDP/ODP Hole 504B at the start of Leg 137, using two customized samplers developed for geothermal applications.

Leakage is a common problem with sampling fluids in high-temperature wells. Once the hot sample has been collected and isolated in a chamber, the sampler must be drawn up through the cold-water column. Close to the seafloor, the sampler and fluid sample experience a rapid change in temperature with a relatively small change in hydrostatic pressure. Reductions in fluid specific volume associated with this change in temperature can create a vacuum inside the chamber, causing valves to leak, and allowing the sampler to take on additional (borehole or water-column) fluids. The intake of an unknown quantity of fluid of unknown composition can change drastically the chemistry of materials in the sampler (through mixing, reaction, dissolution, and precipitation). Designing leak-proof valves is probably the primary challenge in borehole-fluid sampling today.

The tools ODP used during Leg 137 were a mixture of established technology and developments by scientists and technicians working at Los Alamos National Laboratory (LANL) and the Lawrence Berkeley Laboratory (LBL). The tools were provided for this specific leg through special arrangement with the individual government laboratories, with ODP covering costs for shipping, maintenance, and technician time. Technicians from each lab sailed with the tools to handle preparation, maintenance, and sampling operations. Both tools employ a flow-through design, 
which allows flushing of the samplers as they are lowered through the water column (Fig. VIII-1). The design also prevents steam "flashing" of sampled fluids as they are drawn into an evacuated sample chamber, a problem with other sampling designs such as the WSTP. Titanium versions of both tools were available during Leg 137, hardened with special o-rings and other components to operate in temperatures greater than $300^{\circ} \mathrm{C}$ (Table VIII-1).

The two tools take different approaches toward overcoming the "shrinkage and leaking" problem associated with sampling high-temperature fluids: the LANL sampler has a collet (or notch) on each valve, intended to prevent it from moving significantly once the sampler is sealed; the LBL sampler includes an expandable-bellows pressure compensator. Both systems have advantages and disadvantages, and neither worked perfectly during Leg 137.

While the bellows in the LBL tool appears to have compensated sample shrinkage in several cases, it also restricted free flow through the tool, allowing it to entrain seawater as it was lowered into the hole. The LANL valves probably opened during tool ascent on at least one of the deeper runs in the hole, but this resulted in part because the upper colleted valve was incompatible with a screen needed to keep the valve free of rust, and so was not used. Another important difference between the tools is that the LANL sampler is a mechanical tool which runs on the coring line. The valves on the LBL tool are operated electrically, requiring a single or multiconducting cable. While the mechanical clock on the LANL has distinct advantages at high temperatures (where logging lines, connections, and terminations tend to fail), having the LBL tool run off a logging line also allows direct control over triggering time and therefore sample location. In contrast, there is no way to be positive as to when (and where) the LANL mechanism triggers. An additional problem with fluid sampling during Leg 137 was that of accessing the samples under pressure once they were returned to the surface. Extraction manifolds were provided along with the LANL and LBL tools, but these components were complex and could not be mated directly to shipboard analytical instruments in the chemistry laboratory.

An additional borehole-fluid sampling development is now under way. This effort is being led by P. Lysne (Sandia) and J. Edmund (MIT), who are working on the sampling apparatus, and K. Von Damm (New Hampshire), who is overseeing design and construction of a manifold and 


\begin{tabular}{|c|c|c|c|}
\hline Clock & Vatvo & Sample chamber & Vilve \\
\hline & $\Longrightarrow$ & 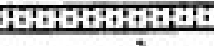 & B:HWE \\
\hline $1.625 \mathrm{ln}$ & Exit port & * & Flow \\
\hline
\end{tabular}

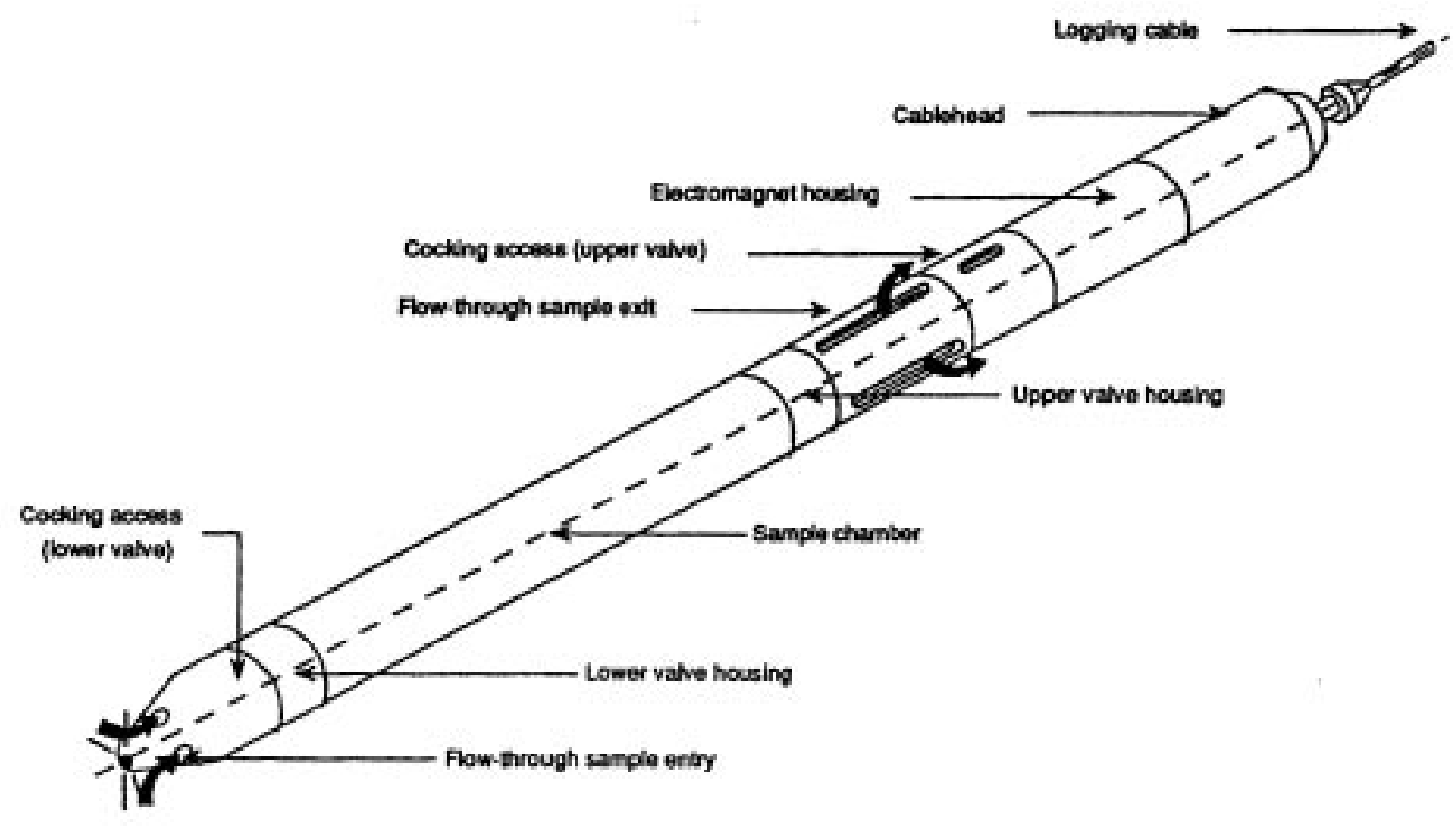

Figure VIII-1. Diagrams of two third-party high-temperature borehole-fluid samplers used during Leg 137. Specifications for these samplers are listed in Table VIII-1. A. LANL borehole sampler. B. LBL fluid sampler. 
Table VIII-1. Specifications of LANL and LBL fluid samplers run during Leg 137.

\begin{tabular}{|c|c|c|}
\hline Parameter & LANL Samplers & LBL Sampler \\
\hline Material & $\begin{array}{l}\text { 1. Stainless steel (316) } \\
\text { 2. Titanium }\end{array}$ & MP35N alloy \\
\hline Length & $108^{\prime \prime}$ & $110^{\prime \prime}$ \\
\hline Outer diameter & $\begin{array}{l}\text { 1. } 1.50^{\prime \prime} \\
\text { 2. } 1.63^{\prime \prime}\end{array}$ & $2.25^{\prime \prime}$ \\
\hline Weight & $\begin{array}{l}1.40 \mathrm{lb} \\
2.30 \mathrm{lb}\end{array}$ & $75 \mathrm{lb}$ \\
\hline Sampler volume & $\begin{array}{l}1.1000 \mathrm{ml} \\
2.990 \mathrm{ml}\end{array}$ & $2000 \mathrm{ml}$ \\
\hline Clock Type & Mechanical & Electrical \\
\hline Deployment wire type & Coring line & Logging line \\
\hline Temperature limit & $>300^{\circ} \mathrm{C}$ & $350^{\circ} \mathrm{C}$ \\
\hline Leakage prevention method & Colleted valve & Internal bellows \\
\hline
\end{tabular}

1 Los Alamos National Laboratory and Lawrence Berkeley Laboratory 
Technical Note No. 10

Page 72

associated uphole plumbing for the tool. This tool is intended to be a high-temperature, slim-hole sampler, capable of running on a wireline and maintaining sample integrity during tool ascent. This tool is also intended to provide borehole temperature and pressure information. Later versions of this tool may also contain nuclear-logging capabilities.

\section{Geoprops}

The Geophysical Properties tool (Geoprops) was intended to provide information on the in-situ mechanical and hydrogeological properties of sediments in accretionary complexes. In 1987 D. Karig (Cornell) obtained NSF funding for a feasibility study of tool design. The 1988 feasibility study (authored by Karig and E. Taylor) described a tool comprising two inflatable, instrumented packers and a sampling apparatus, to be deployed through a conventional ODP coring bit into a previously drilled pilot hole. The pilot hole would be approximately 4 in. in diameter and drilled with a developmental coring system then being developed by ODP. Geoprops would provide information on formation temperature, pore pressure, permeability, in-situ horizontal stress, and pore-fluid composition (by sampling). Development and testing was intended to be completed in time for a scheduled leg to the Nankai accretionary complex in late 1989.

Funding for construction of Geoprops was obtained through NSF, and a contract was let with TAM International, the same company that had designed and built the successful ODP straddle packer. Unfortunately, TAM had little experience with the kind of development associated with Geoprops, and was also busy at the same time with design and construction of a wireline sampler for LDEO, so work on Geoprops was delayed. Problems also developed with the Navidrill coring system, which tended to stall; eventually this latter system was abandoned, and a new design was prepared for a motor-driven core barrel (MCDB) to replace the Navidrill. The Nankai leg was also delayed for 4 months, but the Geoprops probe was still not ready; Leg 131 to the Nankai accretionary complex sailed without Geoprops.

Two Geoprops tools were made available for land testing several months after the Nankai leg, in August 1990. Problems were soon discovered with the valve and shear-pin systems used to actuate different Geoprops functions, and some redesign was needed. A second series of bench tests was completed in June 1991, revealing additional valve, seal, and shear-pin problems. 
Additional recommendations from ODP engineers included redesign of the shock-absorbing system (necessary for intended free-fall deployment), compilation of electronics drawings and a list of spare parts, more extensive bench testing of individual components, and considerations of design upgrades affecting the sampling mechanism, materials of construction, and ease of operation. TAM felt they had fulfilled their obligation to the project and did not take part in these additional developments.

Karig decided not to pursue funding for these developments, but B. Carson (Lehigh) was supported by NSF to complete an additional phase of development and testing in time for ODP Leg 146 to the Cascadia margin. ODP engineer S. McGrath was assigned to oversee this new phase of development and testing, and a contract was let to an engineering consultant to do the actual work. Additional modifications and testing continued through the summer of 1992, and two modified Geoprops tools were sailed for "field testing" during Leg 146. Geoprops was finally deployed at Site 889 on the Cascadia margin, but the tool would not fully penetrate the MDCB pilot hole, so the packer could not be inflated. The tool was later dropped into the BHA and flow tested in the water column at Site 892 to learn more about its behavior under pressure. During this test, the Geoprops thermistors and shock sub failed. Additional modifications to the plumbing configuration and deployment method have also been recommended, although it is unclear at this time whether or not work with this tool will continue.

\section{LAST I and II}

Two generations of the lateral stress tool (LAST) have been developed for ODP use by K. Moran of the Atlantic Geoscience Centre, Geological Survey of Canada. LAST I is a passive coring device (Figure VIII-2) which is pressed into the sediments about $5 \mathrm{~m}$ ahead of the bit. The tool is configured similar to a standard APC coring shoe, except that the shoe's taper is on the inside rather than the outside of the cutting edge. While this disturbs the sampled core more than regular piston coring, it also presents the formation with the flat cylindrical face of the outside of the shoe. The tool is left in the formation for about 30 minutes, during which time strain is measured with three gauges mounted in the wall of the tool. The gauges are oriented $120^{\circ}$ apart in a single horizontal plane. Pore pressure and temperature at the wall of the tool are also measured. 


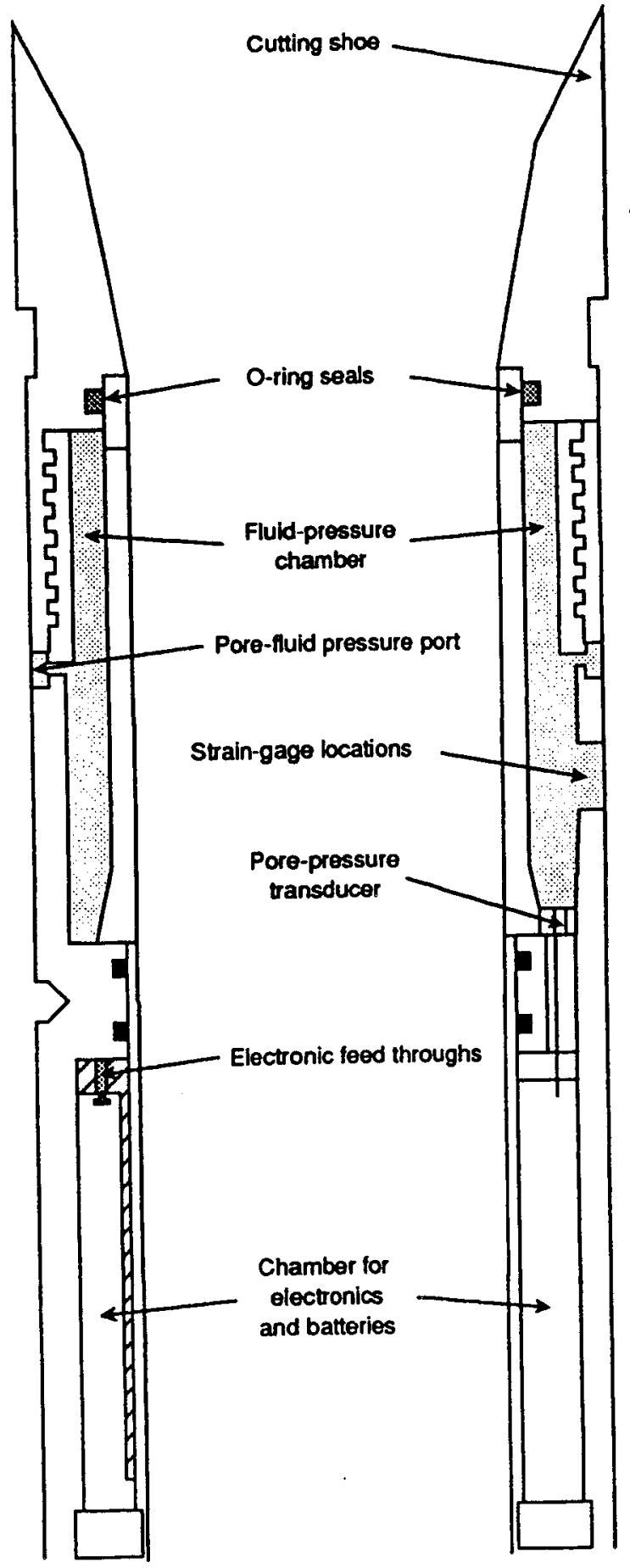

Figure VIII-2a. Schematic of lateral stress tool, LAST I. This tool is a passive instrument. 
Technical Note No. 10

Page 74

The strain gauges are bonded to the inside of thinned sections of the tool wall, which act as diaphragms that differentially deflect under lateral load. The outside of the diaphragm is intended to measure total lateral lithostatic stress, while the inside of the diaphragm experiences ambient pore pressure. Thus the deflection of each diaphragm should reflect the effective lateral stress. Like the APC temperature tool described in Chapter III, LAST I is entirely self-contained and programmed with an IBM-compatible PC. Measurements are made at user-defined time intervals, typically every 5 seconds while the tool is in the formation. The tool is powered by six AA batteries that are changed for each run. LAST I was first fielded at sea during ODP Leg 131, and was run again during Leg 146.

LAST II is an active measurement device intended to determine in-situ lateral stress, strength, elastic modulus, and pore-pressure response. The measurement element is a radially expanding bladder with two pressure sensors. One sensor measures expansion pressure, and the other measures formation pore pressure. The bladder is expanded using a motor-driven piston. Piston displacement is calibrated with bladder expansion to determine radial displacement of the bladder.

The tool is deployed with the same colleted delivery system used for the WSTP (Chapters II and III). The tool is pushed into the formation about $2.6 \mathrm{~m}$ ahead of the bit, and left in place during operation. Lateral stress is determined from the lift-off pressure of the stress-strain curve. Shear modulus and strength are determined directly from the stress-strain curve. Pore pressure is measured independently. The tool is programmed using a bench-top computer, then disconnected and sent down the pipe. The tool cycles through its test sequence via downhole computer control. LAST II can be programmed for several loading and unloading cycles; the tool was first fielded at sea during Leg 146.

LAST I apparently functioned properly during two of five initial deployments on ODP Leg 131, although there were minor glitches related primarily to shipboard protocols and tool programming (Moran et al., 1993). Data from LAST I and LAST II runs during Leg 146 have yet to be analyzed to determine if they are scientifically useful. 


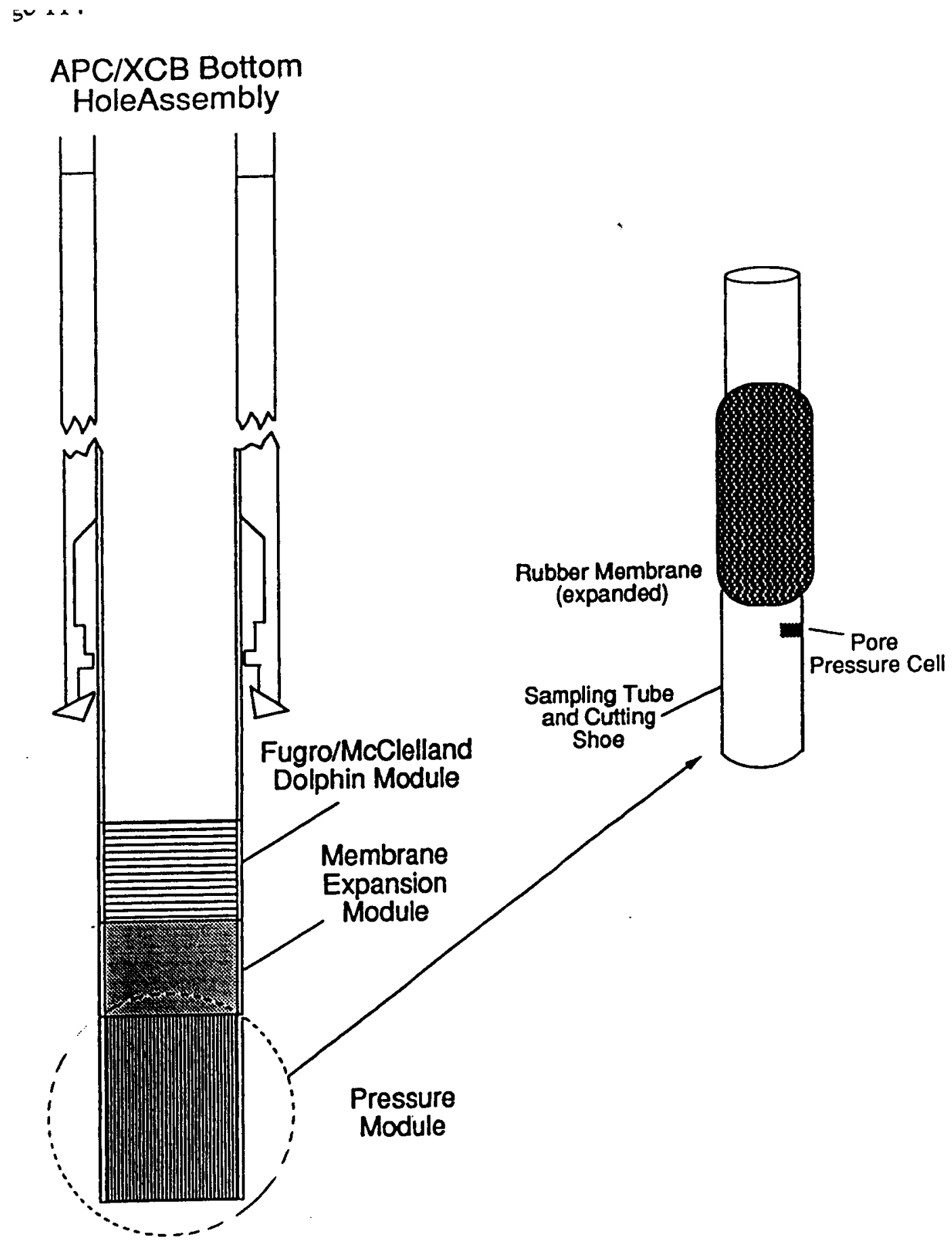

Figure VIII-2b. Schematic of lateral stress tool, LAST II.

This active instrument was run during Leg 146. 


\section{Flowmeter Experiment and Logging Cable Go-Devil}

As described in Chapter IV, measurements of bulk permeability in the upper oceanic crust have been conducted successfully using drill-string packers in the DSDP and ODP. These measurements reveal the equivalent "bulk" or average Darcian permeability of the zone between an inflated

packer and the bottom of open hole. However, permeability in the oceanic basement and other settings such as accretionary complexes is likely to be dominated by fractures and irregular networks of inter-connected porosity, as suggested by many logs and the discrepancies between bulk permeabilities measured downhole and laboratory permeabilities of competent samples. The flowmeter experiment was intended to assess the detailed permeability structure in a borehole, using constant-rate fluid injection into a zone sealed by the drill-string packer, with concurrent logging of borehole pressure and flow velocity in the isolated zone. Thus, this experiment involves both a logging tool and the drill-string packer, and it required careful coordination among the third-party investigators, LDEO wireline personnel, and ODP engineers.

An NSF grant to K. Becker (Miami) and R. Morin (Miami and USGS) provided funding for the design and construction of the flowmeter, a spinner tool made by Comprobe. In addition, ODP engineer T. Pettigrew designed a new packer go-devil to accomodate the experiment, and this go-devil may have application to any logging tool intended to be run in a section of hole sealed by the drill-string packer. Before the development of this go-devil, logging or other experiments were not permitted through an inflated drill-string packer, because this would have involved unsafe procedures on the rig floor, as follows: When the packer is inflated and gripping the borehole wall, the BHA is immobilized and the drill-string heave compensator must be engaged to avoid tearing the packer loose. With the drill-string compensated, the upper end of the pipe will move relative to the heaving rig floor, and it would normally be very difficult and unsafe to attempt to "stab" a logging tool into the end of the pipe before running it down into the isolated section of hole.

The new go-devil is initially attached to the logging cable above the cablehead connected to the flowmeter (or other) tool, and the flowmeter, logging cable, and new go-devil are deployed before the packer is inflated and the drill-string heave compensator is engaged. When the go-devil lands in 
Technical Note No. 10

Page 76

the packer, it enables packer inflation in the standard way. After the packer is inflated and the drill-string heave compensator is engaged, additional pumping then allows the logging line to detach from the go-devil, and the flowmeter can be lowered into the isolated section of the borehole. This approach allows the logging tool to be introduced into the isolated zone before the drill string becomes heave compensated, and thus avoids the potential safety problems described above. Although there are presently no plans to run other logging or sampling tools in combination with the drill-string packer, in principle it should now be possible to do so.

Funding for the flowmeter was granted about one year prior to its first intended use on Leg 137. Comprobe was able to build the tool in time for land-based field testing prior to the leg at the Palisades sill test well, with the assistance of LDEO personnel. The flowmeter experiment was not successful during Leg 137, because the packer lost inflation pressure and inadvertently deflated. However, flowmeter experiments were successfully completed during Leg 139, as described in Becker et al. (in press).

\section{5. "Active" fluid sampling}

The WSTP and Kuster tools are described as "passive" samplers (Mottl et al., 1983, 1985) in that the fluids sampled are those that are in the immediate vicinity of the sampler, whether in sediments penetrated by a probe or in open hole. In some situations it may be more desirable to actively draw a sample from the formation, particularly in semilithified or lithified sediments that cannot be penetrated by the WSTP probe, or in open basement holes where the borehole fluids have not had time to equilibrate with pore fluids. During Leg 111, a Schlumberger repeat formation tester (RFT) was run in Hole 504B as the primary sampling tool to extract a pore-fluid sample from the wall of the borehole. The RFT is a "doughnut" sampler run on the logging line, with a circular sealing port that is pressed against the side of the borehole using a mechanical arm. The RFT failed to obtain a formation sample, returning borehole fluid instead, and the mechanical sampling arm broke off in the hole. Subsequent analysis of RFT sampling technology suggests that this design will not return a scientifically useful sample from a hole through a fractured formation if the borehole wall does not include a mud cake (common in commercial petroleum wells), as fluid drawn into the RFT will simply bypass the rubber seal from the open hole (R. Desbrandes, pers. comm., 1992). 


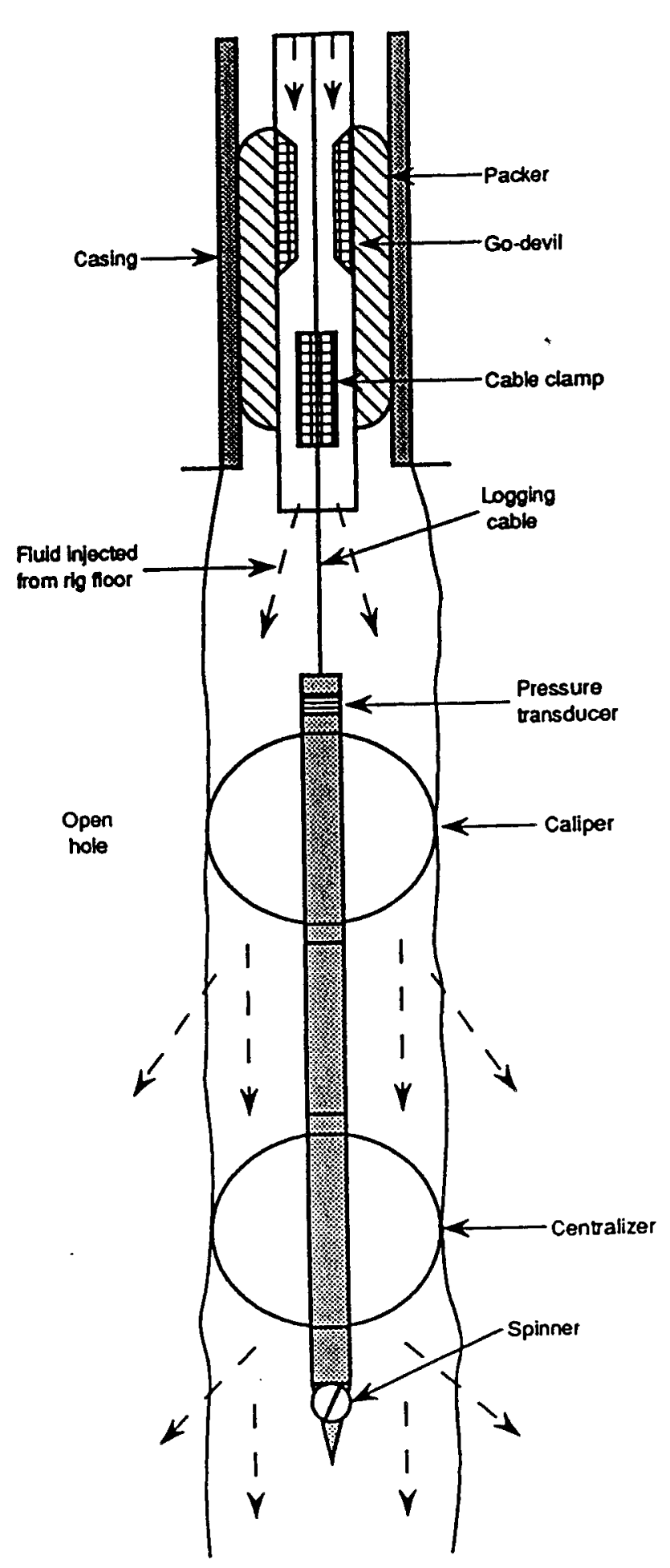

Figure VIII-3. Schematic of spinner flowmeter experiment conducted during Leg 139. The dashed lines with arrows illustrate flow paths for fluids pumped from the rig floor, down the pipe, through the inflated packer and go-devil, and into permeable sections of the isolated formation. 
The Borehole Research Group at LDEO later undertook to develop and test a wireline sampler for active pore-fluid sampling during ODP. The original intent was to produce an instrument that could be deployed through the pipe and bit over any zone of interest, like a conventional logging tool. The tool was designed and built by TAM International, the same company that produced the successful ODP straddle packer described in Chapter IV. Wireline-sampler development extended over several years, and the tool was finally deployed during Leg 133.

The wireline sampler consisted of a short straddle packer, four sample bottles, downhole pumps and valves to inflate the packers or pump fluids from the formation to the sample bottles, and electronic sensors to monitor key properties of the fluids to be sampled, such as pressure, temperature, $\mathrm{pH}$, and concentrations of $\mathrm{Na}$ and $\mathrm{Ca}$. The tool was intended to be deployed in open hole, with elements that would inflate from the 3.9-in. minimum internal diameter of a regular BHA to 10-13-in. in the borehole. The tool would begin a pumping sequence, with real-time surface readout of fluid properties to allow the operator to assess when some component of "pristine" pore fluids was being pumped past the sensors. The operator would then trap one to four samples of fluid, either in time series at a single level, to allow extrapolation of pure pore-fluid composition, or at several different levels within the hole during the same deployment.

Unfortunately, the main filter assembly became clogged and collapsed under pressure during deployment in Hole 816C on Leg 133 (Davies, McKenzie, Palmer-Julson, et al., 1991). In addition, the inflatable packer elements did not return to a small enough diameter upon deflation to pass back up through the BHA. Analysis of the wireline packer design after Leg 133 led those involved in its development to recommend numerous design modifications, requiring a substantial investment of time and money. As it was not clear that it would be physically possible to obtain a scientifically useful sample from a hard formation disturbed by drilling, the wireline packer project was tabled pending the outcome of the "Request for Proposals" for assessment of active fluidsampling technologies, as described below.

Without a riser system (which would allow the use of heavy mud to avoid circulation loss) and a long-term, stable well-head facility (which would allow well "production" for days or weeks), it may not be possible to draw formation fluids from the wall of an ODP borehole that are 
Technical Note No. 10

Page 78

undisturbed enough to be of scientific use. In some ways, the borehole CORK was intended to address this need. The CORK isolates a borehole and allows the borehole fluid to equilibrate with the surrounding formation; unfortunately, the CORK also requires considerable time, money, and effort for installation. Also, reacted borehole fluids are not exactly the same as formation pore fluids.

In response to requests from the community, PCOM in 1992 convened a Fluid-sampling Working Group to produce a Request for Proposals (RFP) for a feasibility study of available and developmental technologies for pore-fluid sampling in hard rock and lithified sediments. The RFP also requests an assessment of the hydrogeological state around an ODP borehole to determine under what conditions there is a good chance for successful fluid sampling. PCOM has deferred distribution of this RFP, due to a lack of available funds, until the Spring of 1993. Depending on the results of this RFP, and the resulting feasibility study (which could indicate that formation sampling in hard rock is beyond the reach of ODP operations), some form of active sampling technology may become available in the next 2-3 years.

\section{Additional Developments}

Additional tools are presently available or are being developed through LDEO for upcoming legs. These tools include: slimline (Diamond-coring compatible) natural gamma-temperature-caliper and Kuster mechanical temperature tools; a high-temperature, digital borehole televiewer; a slimhole, digital borehole televiewer; a multichannel, shear sonic tool; and high-temperature resistivity and sonic tools. Another third-party development presently underway is a slimline, pressure-temperature-flowmeter-conductivity-caliper tool. Contact the science operator or logging contractor for up-to-date information on availability and specifications of these instruments. 


\section{REFERENCES}

Anderson, R.N. and Zoback, M.D., 1982. Permeability, underpressures, and convection in the oceanic crust near the Costa Rica Rift, eastern equatorial Pacific. J. Geophys. Res., 87:28602868.

Anderson, R.N., Zoback, M.D., Hickman, S.H., and Newmark, R.L., 1985. Permeability versus depth in the upper oceanic crust: in situ measurements in DSDP Hole 504B, eastern equatorial Pacific. J. Geophys. Res., 90:3659-3669.

Barnes, R., 1979. Operation of the IPOD in-situ porewater sampler. In Sibuet, J.-C., Ryan, W.B.F., et al., Init. Repts DSDP, 47, Pt. 2: Washington (U.S. Govt. Printing Office), 19-22.

1988. ODP in-situ fluid sampling and measurement: a new wireline tool. In Mascle, A., Moore, J.C., et al., Proc. ODP, Init. Repts., 110: College Station, TX (Ocean Drilling Program), 55-63.

Becker, K., 1986. Special report: development and use of packers in ODP. JOIDES Journal, 12(2):51-57.

1989. Measurements of the permeability of the sheeted dikes in Hole 504B, ODP

Leg 111. In Becker, K., Sakai, H., et al., Proc. ODP, Sci. Results, 111: College Station, TX (Ocean Drilling Program), 317-325.

, 1990a. Measurements of the permeability of the upper oceanic crust at Hole 395A, ODP Leg 109. In Detrick, R., Honnorez, J., Bryan, W.B., Juteau, T., et. al., Proc. ODP, Sci. Results, 106/109: College Station, TX (Ocean Drilling Program), 213-222.

, 1990b. A Guide to Formation Testing Using ODP Drill-string Packers. College Station, TX (Ocean Drilling Program), Tech. Note 14. 
Technical Note No. 10

Page 80

, 1991. In-situ bulk permeability of oceanic gabbros in Hole 735B, ODP LEg 118. In Von Herzen, R.P., Robinson, P.T., et al., Proc. ODP, Sci. Results, 118: College Station, TX (Ocean Drilling Program), 333-347.

Becker, K., Langseth, M.G., and Von Herzen, R.P., 1983a. Deep crustal geothermal measurements, Hole 504B, Deep Sea Drilling Project Legs 69 and 70. In Cann, J.R., Langseth, M.G., Honnorez, J., Von Herzen, R.P., White, S.M., et al., Init. Repts. DSDP, 69: Washington (U.S. Govt. Printing Office), 223-235.

Becker, K., Langseth, M.G., Von Herzen, R.P., and Anderson, R.N., 1983b. Deep crustal geothermal measurements, Hole 504B, Costa Rica Rift. J. Geophys. Res., 88:3447-3457.

Becker, K., Langseth, M.G., Von Herzen, R.P., Anderson, R.N., and Hobart, M.A., 1985. Deep crustal geothermal measurements, Hole 504B, Deep Sea Drilling Project Legs 69, 70, 83, and 92. In Anderson, R.N., Honnorez, J., Becker, K., et al., Init. Repts. DSDP, 83: Washington (U.S. Govt. Printing Office), 405-418.

Becker, K., Morin, R., and Davis, E., in press. Permeabilities in the Middle Valley hydrothermal system measured with packer and flowmeter experiments. In Mottl, M., Davis, E., Fisher, A., et al., Proc. ODP, Sci. Results, 139: College Station, TX (Ocean Drilling Program).

Becker, K., Sakai, H., et al., 1988. Proc. ODP, Init. Repts., 111: College Station, TX (Ocean Drilling Program).

Bredehoeft, J.D. and Papadopulos, S., 1980. A method for determining the hydraulic properties of tight formations. Water Resour. Res., 16:233-238.

Bryan, W.B., Juteau, T., et al., 1988. Site 395. In Detrick, R., Honnorez, J., Bryan, W.B., Juteau, T., et al., Proc. ODP, Init. Repts., 106/109: 175-202. 
Bullard, E.C., 1947. The time necessary for a bore hole to attain temperature equilibrium. Monthly Notices Roy. Astron. Soc., Geophys. Suppl., 5:127-130.

, 1954. The flow of heat through the floor of the Atlantic Ocean. Proc. Roy. Soc. London, A 222:408-429.

Cooper, H.H., Bredehoeft, J.D., and Papadopulos, I.S., 1967. Response of a finite-diameter well to an instantaneous charge of water. Water Resour. Res., 3:263-269.

Davies, P.J., McKenzie, J.A., Palmer-Julson, A., et al., 1991. Proc. ODP, Init. Repts., 133: College Station, TX (Ocean Drilling Program).

Davis, E.E., Mottl, M.J., Fisher, A.T., et al., 1992. Proc. ODP, Init. Repts., 139: College Station, TX (Ocean Drilling Program).

Erickson, A.J., Von Herzen, R.P., Sclater, J.G., Girdler, R.W., Marshall, B.V., and Hyndman, R., 1975. Geothermal measurements in deep-sea drill holes. J. Geophys. Res., 80:2515-2528.

Fisher, A.T. and Hounslow, M.W., 1990. Heat flow through the toe of the Barbados accretionary complex. In Moore, J.C., Mascle, A., et al., Proc. ODP,Sci. Results, 110:345-363.

Gieskes, J.M., Kastner, M., Erzinger, J., Boulègue, J., and Hart, S.R., 1986. Geochemical studies in Hole 504B, Leg 92. In Leinen, M., Rea, D.K., et al., Init. Repts. DSDP, 92: Washington (U.S. Govt. Printing Office), 547-562.

Hickman, S.H., Langseth, M.G., and Svitek, J.F., 1984. In situ permeability and pore-pressure measurements near the Mid-Atlantic Ridge, Deep Sea Drilling Project Hole 395A. In Hyndman, R.D., Salisbury, M.H., et al., Init. Repts. DSDP, 78B: Washington (U.S. Govt. Printing Office), 699-708. 
Technical Note No. 10

Page 82

Horai, K., and Von Herzen, R.P., 1985. Measurement of heat flow on Leg 86 of the Deep Sea Drilling Project. In Heath, G.R., Burckle, L.H., et al., Init. Repts. DSDP, 86: Washington (U.S. Govt. Printing Office), 759-777.

Horner, D. R., 1951. Pressure build-up in wells. Proc., Third World Pet. Cong., II:501.

Hyndman, R.D., Davis, E.E., and Wright, J.A., 1979. The measurement of marine geothermal heat flow by a multipenetration probe with digital acoustic telemetry and in situ thermal conductivity. Mar. Geophys. Res., 4:181-205.

Hyndman, R.D., Langseth, M.G., and Von Herzen, R.P., 1987. Deep Sea Drilling Project geothermal measurements: a review. Rev. Geophys., 25:1563-1582.

Jaeger, J.C., 1956. Conduction of heat in an infinite region bounded internally by a circular cylinder of a perfect conductor. Aust. J. Phys., 9:167-179.

, 1958. The measurement of thermal conductivity and diffusivity with cylindrical probes, Trans. Am. Geophys. Union, 39:708-710.

, 1961. The effect of the drilling fluid on temperatures measured in bore holes. $J$. Geophys. Res., 66:563-569.

Koehler, R., and Von Herzen, R.P., 1986. A miniature deep sea temperature data recorder: design, construction, and use. Technical Report WHOI-86-3, Woods Hole Oceanographic Institution.

Leinen, M., Rea, D.K., et al., 1986. Site 504. In Leinen, M., Rea, D.K., et al., Init. Repts. DSDP, 92: Washington (U.S. Govt. Printing Office), 187-214.

Lister, C.R.B., 1979. The pulse-probe method of conductivity measurement. Geophys. J. R. Astr. Soc., 57:451-461. 
Matthews, C.S., and Russell, D.G., 1967. Pressure buildup and flow tests in wells. SPE Monograph v.1: Dallas (Society of Petroleum Engineers of AIME).

Moran, K., Brückmann, W., and Feezer, V., 1993. In-situ stress conditions at Nankai Trough, ODP Site 808. In Hill, I., Taira, A., Firth, J., et al., Proc. ODP, Sci. Results, 131: College Station, TX (Ocean Drilling Program), 283-291.

Mottl, M.J., Anderson, R.N., Jenkins, W.J., and Lawrence, J.R., 1983. Chemistry of waters sampled from basaltic basement in Deep Sea Drilling Project Holes 501, 504B, and 505B. In Cann, J.R., Langseth, M.G., Honnorez, J., Von Herzen, R.P., White, S.M., et al., Init. Repts. DSDP, 69: Washington (U.S. Govt. Printing Office), 475-483.

Mottl, M.J., Druffel, E.R.M., Hart, S.R., Lawrence, J.R., and Saltzman, E.S., 1985. Chemistry of hot waters sampled from basaltic basement in Hole 504B, Deep Sea Drilling Project Leg 83, Costa Rica Rift. In Anderson, R.N., Honnorez, J., Becker, K., et al., Init. Repts. DSDP, 83: Washington (U.S. Govt. Printing Office), 315-328.

Mottl, M., and Gieskes, J., 1990. Chemistry of waters sampled from oceanic boreholes, 19791988. J. Geophys. Res., 95:9327-9342.

Papadopulos, S.S., Bredehoeft, J.D., and Cooper, H.H., 1973. On the analysis of "slug test" data. Water Resour. Res., 9:1087-1089.

Pettigrew, T. L., 1992, The Design and Preparation of a Wireline Pressure Core Sampler, College Station, TX (Ocean Drilling Program), Tech. Note 17.

Robinson, P.T., Von Herzen, R., et al., 1989. Proc. ODP, Init Repts ., 118: College Station, TX (Ocean Drilling Program).

Salisbury, M. H., Scott, J. H., Auroux, C. A., et al., 1986 Proc., Init. Repts. (Pt. A), ODP, 102. 
Technical Note No. 10

Page 84

Snow, D.T., 1968. Rock fracture spacing, openings and porosities. J. Soil Mech. Foundation Div., ASCE Proc., 94.

Speiss, F.N., and Boegeman, D.E., 1990. Fly-in reentry - past and future. Trans. Am. Geophys. Union - EOS, 71:1408.

Uyeda, S., and Horai, K., 1982. Heat flow measurements on Deep Sea Drilling Project Leg 60. In Hussong, D.M., Uyeda, S., et al., Init. Repts. DSDP, 60: Washington (U.S. Govt. Printing Office), 789-800.

Von Herzen, R.P., and Maxwell, A.E., 1964. Measurements of heat flow at the preliminary Mohole site off Mexico. J. Geophys. Res., 69:741-748.

von Huene, R., 1985. Direct measurement of pore fluid pressure, Leg 84, Guatemala and Costa Rica. In von Huene, R., Aubouin, J., et al., Init. Repts. DSDP, 84: Washington (U.S. Govt. Printing Office), 767-772.

Worthington, P., Anderson, R.N., Bell, J.S., Becker, K., Jarrard, R.D., Salisbury, M.H., and Stephen, R.A., 1987. Downhole measurements for the Ocean Drilling Programme. In Report of the Second Conference on Scientific Ocean Drilling (COSOD II), Strasbourg: European Science Foundation, 131-136.

Worthington, P., Fisher, A. T., and Golovchenko, X., 1992, Downhole Measurements in the Ocean Drilling Program: A Scientific Legacy, College Station, TX (Ocean Drilling Program).

Yokota, T., Kinoshita, H., and Uyeda, S., 1980. New DSDP (Deep Sea Drilling Project) downhole temperature probe utilizing IC RAM (memory) elements. Univ. Tokyo Earthquake Res. Inst. Bull., 55, Pt.1:75-88. 


\title{
APPENDIX A. SELECTED REPRINTS FOR ODP DOWNHOLE MEASUREMENTS
}

\author{
(Shelved in Logging section, shipboard library)
}

\section{A. Theory of heat conduction (and, by analogy, decay of borehole pressures)}

(See also Carslaw, H.S., and Jaeger, J.C., 1959. Conduction of Heat in Solids, second edition, London: Oxford Univ. Press, available in shipboard library)

(1) Jaeger, J.C., 1965. Application of the theory of heat conduction to geothermal measurements. In Lee, W.H.K. (ed.), Terrestrial Heat Flow, AGU Monograph, Washington: Amer.Geophys.Union, 8:7-23.

\section{B. Approach of a cylindrical probe to in-situ temperature}

(2) Bullard, E., 1954. The flow of heat through the floor of the Atlantic Ocean. Proc. Roy. Soc. London, A 222:408-429.

(3) Table of Bullard's F(2,tau), calculated by Lister, C.R.B., 1979. The pulse-probe method of conductivity measurement. Geophys. J. Roy. Astr. Soc., 57:451-461.

(4) Hyndman, R.D., Davis, E.E., and Wright, J.A., 1979. The measurement of marine geothermal heat flow by a multipenetration probe with digital acoustic telemetry and in-situ thermal conductivity. Mar. Geophys. Res., 4:181-205.

\section{Approach of the APC shoe to in-situ temperature}

(5) Horai, K., unpublished manuscript. A theory of processing down-hole temperature data taken by the hydraulic piston corer (HPC) of the DSDP. 
Technical Note No. 10

Page 86

(6) Horai, K., and Von Herzen, R.P., 1985. Measurement of heat flow on Leg 86 of the Deep Sea Drilling Project. In Heath, G.R., Burckle, L.H., et al., Init. Repts. DSDP, 86:Washington (U.S. Govt. Printing Office), 759-777.

\section{Thermal-conductivity measurements}

(7) Jaeger, J.C., 1958. The measurement of thermal conductivity and diffusivity with cylindrical probes. Trans. Am. Geophys. Union, 39:708-710.

(8) Von Herzen, R.P., and Maxwell, A.E., 1959. The measurement of thermal conductivity of deep-sea sediments by a needle-probe method. J. Geophys. Res., 64: 1557-1563.

\section{E. Borehole temperatures -- theory}

(9) Bullard, E.C., 1947. The time necessary for a bore hole to attain temperature equilibrium. Monthly Notices Roy. Astron. Soc., Geophys. Suppl., 5:127-130.

(10) Jaeger, J.C., 1961. The effect of the drilling fluid on temperatures measured in bore holes. J. Geophys. Res., 66:563-569.

(11) Lesem, L.B., Greytok, F., Marotta, F., and McKetta, J.J., 1957. A method of calculating the distribution of temperature in flowing gas wells. Petrol. Trans. AIME, 210:169-176.

\section{F. Borehole temperatures -- DSDP, review and examples}

(12) Erickson, A.J., Von Herzen, R.P., Sclater, J.G., Girdler, R.W., Marshall, B.V., and Hyndman, R., 1975. Geothermal measurements in deep-sea drill holes. J. Geophys. Res., 80:2515-2528. 
(13) Hyndman, R.D., Langseth, M.G., and Von Herzen, R.P., 1987. Deep Sea Drilling Project geothermal measurements: a review. Rev. Geophys., 25:1563-1582.

(14) Becker, K., Langseth, M.G., and Von Herzen, R.P., 1983. Deep crustal geothermal measurements, Hole 504B, Deep Sea Drilling Project Legs 69 and 70. In Cann, J.R., Langseth, M.G., Honnorez, J., Von Herzen, R.P., White, S.M., et al, Init. Repts. DSDP, 69:Washington (U.S. Govt. Printing Office), 223-235.

(15) Becker, K., Langseth, M.G., Von Herzen, R.P., and Anderson, R.N., 1983. Deep crustal geothermal measurements, Hole 504B, Costa Rica Rift. J. Geophys. Res., 88:3447-3457.

(16) Becker, K., Langseth, M.G., Von Herzen, R.P., Anderson, R.N., and Hobart, M.A., 1985. Deep crustal geothermal measurements, Hole 504B, Deep Sea Drilling Project Legs 69, 70, 83, and 92. In Anderson, R.N., Honnorez, J., Becker, K., et al., Init. Repts. DSDP, 83:Washington (U.S. Govt. Printing Office), 405-418.

(17) Becker, K., Langseth, M.G., and Hyndman, R.D., 1984. Temperature measurements in Hole 395A, Leg 78B. In Hyndman, R.D., Salisbury, M.H., et al., Init. Repts. DSDP, 78B:Washington (U.S. Govt. Printing Office), 689-698.

\section{G. Permeability measurements and hydrofracture -- theory}

(18) Cooper, H.H., Bredehoeft, J.D., and Papadopulos, I.S., 1967. Response of a finite-diameter well to an instantaneous charge of water. Water Resour. Res., 3:263269.

(19) Papadopulos, S.S., Bredehoeft, J.D., and Cooper, H.H., 1973. On the analysis of “slug test" data. Water Resour. Res., 9:1087-1089. 
Technical Note No. 10

Page 88

(20) Bredehoeft, J.D., and Papadopulos, S.S., 1980. A method for determining the hydraulic properties of tight formations. Water Resour. Res., 16:233-238.

(21) Neuzil, C.E., 1982. On conducting the modified "slug" test in tight formations. Water Resour. Res., 18:439-441.

(22) Barker, J.A., and Black, J.H., 1982. Slug tests in fissured aquifers. Water Resour. Res., 19:1558-1564.

(23) Hayashi, K., Ito, T., and Abe, H., 1987. A new method for the determination of in situ hydraulic properties by pressure pulse tests and application to the Higashi Hachimantai geothermal field. J. Geophys. Res., 92:9168-9174.

(24) Hickman, S.H., and Zoback, M.D., 1983. The interpretation of hydraulic fracturing pressure-time data for in-situ stress determination. In U.S. National Committee for Rock Mechanics, Hydraulic Fracturing Stress Measurements: Proceedings of a Workshop December 2-5, 1981, National Academy Press, Washington, 44-54.

\section{H. Permeability measurements and hydrofracture -- DSDP examples}

(25) Anderson, R.N., and Zoback, M.D., 1982. Permeability, underpressures, and convection in the oceanic crust near the Costa Rica Rift, eastern equatorial Pacific. $J$. Geophys. Res., 87:2860-2868.

(26) Anderson, R.N., Zoback, M.D., Hickman, S.H., and Newmark, R.L., 1985. Permeability versus depth in the upper oceanic crust: in situ measurements in DSDP Hole 504B, eastern equatorial Pacific. J. Geophys. Res., 90:3659-3669.

(27) Hickman, S.H., Langseth, M.G., and Svitek, J.F., 1984. In situ permeability and pore-pressure measurements near the mid-Atlantic Ridge, Deep Sea Drilling Project Hole 395A. In Hyndman, R.D., Salisbury, M.H., et al, Init. Repts. DSDP, 
78B:Washington (U.S. Govt. Printing Office), 699-708.

\section{Large-scale resistivity experiment}

(28) Archie, G.E., 1942. The electrical resistivity log as an aid in determining some reservoir characteristics. Trans. AIME, 146:54-62.

(29) Von Herzen, R.P., Francis, T.J.G., and Becker, K., 1983. In situ large-scale electrical resistivity of ocean crust, Hole 504B. In Cann, J.R., Langseth, M.G., Honnorez, J., Von Herzen, R.P., White, S.M., et al, Init. Repts. DSDP, 69:Washington (U.S. Govt. Printing Office), 237-244.

(30) Becker, K., et al., 1982. In situ electrical resistivity and bulk porosity of the oceanic crust, Costa Rica Rift. Nature, 300:594-598.

(31) Becker, K., 1985. Large-scale electrical resistivity and bulk porosity of the oceanic crust, Deep Sea Drilling Project Hole 504B, Costa Rica Rift. In Anderson, R.N., Honnorez, J., Becker, K., et al., Init. Repts. DSDP, 83:Washington (U.S. Govt. Printing Office), 419-427. 
Technical Note No. 10

Page 90

\section{APPENDIX B. TABLE OF DOWNHOLE TOOL USAGE DURING ODP LEGS 101-146}

The following table lists tools run during the first 46 legs of the Ocean Drilling Program, through November 1992. The table is not detailed, but is instead intended to point the interested investigator toward appropriate volumes of ODP Initial Reports and Scientific Results. The table indicates only that a specific tool was run down the pipe at each specified site, not whether the deployment was successful, nor if data are available. Interested scientists should contact the Data Librarians at ODP/TAMU and LDEO, or individual tool developers, to determine if data exist for a particular run.

For third-party and specialty tools, the developer affiliation (for U.S. scientists) or country of origin (for non-U.S. scientists) is also listed. The following list of tool abbreviations is used for wireline-logging instruments in Table B-1.

\section{Schlumberger tools}

ACT Aluminum Clay

AMS Auxiliary Measurement (fluid temperature and resistivity)

BHC Borehole Compensated Sonic

CAL Mechanical Caliper

CNL Compensated Neutron (thermal only)

CNT Compensated Neutron (thermal and epithermal)

DIL Dual Induction

DLL Dual Laterolog

FMS Formation Microscanner

GPIT General Purpose Inclinometer

GR Total Gamma

GST Induced Spectral Gamma

HMT High-resolution Magnetometer/susceptibility

LDT Lithodensity 
LSS Long-spaced sonic

NGT Spectral Natural Gamma

SDT Digital Sonic

SFL Spherically Focused Resistivity

WST Well Seismic Tool (VSP)

\section{Non-Schlumberger specialty tools}

BHTV Borehole Televiewer

MCS Multichannel Sonic

PTF Pressure-Temperature-Flowmeter

VSP Vertical Seismic Profile

OSE Oblique Seismic Experiment

\section{ODP contacts}

For inquiries about wireline tools:

Manager of Technical Operations

Borehole Research Group

Lamont-Doherty Earth Observatory

Palisades, NY 10964 U.S.A.

Telephone: 914/365-8336 Fax: 914/365-3182

For inquiries about all other downhole tools:

Manager of Science Operations

Ocean Drilling Program

Texas A\&M University

1000 Discovery Drive

College Station, TX 77845-9547 U.S.A.

Telephone: 409/845-9297

Fax: 409/845-0876 


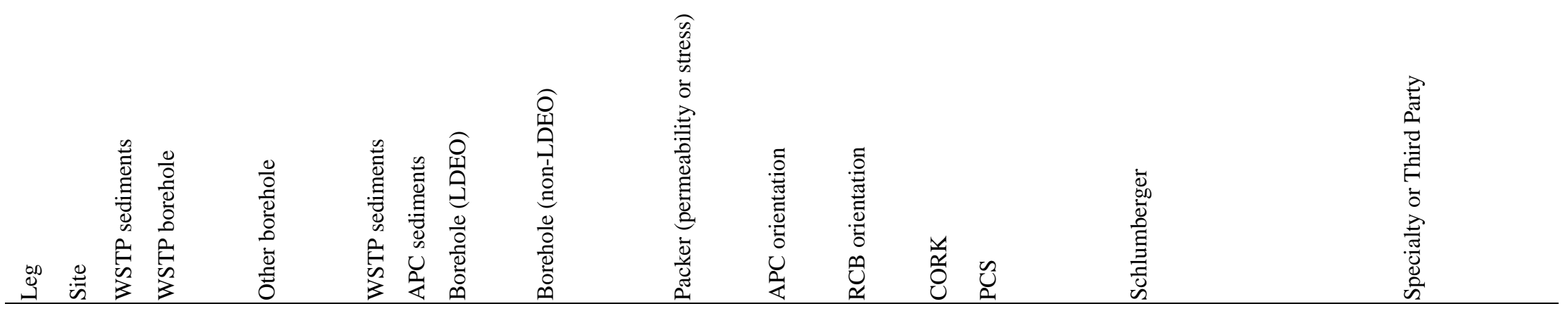

101626

627

634

102418

103637

638

639

641

$104 \quad 642$

643

644

$105 \quad 645$

646

647

$107 \quad 650$

651

652

107653

654

655

$108 \quad 659$

661

663

664

665
APC/WSTP TSP (Miami)

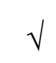

\section{$\checkmark$}

$\sqrt{ }$

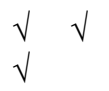

$\checkmark$
GR, CNT

GR, LDT, CNT

GR, CNL, GST

GR, LSS, DIL, SFL,

NGT, LDT, CNT, DLL (USGS); Magnetometer

(Germany);

Seismometer/OSE (WHOI);

GR, LSS, DIL, SFL,

CAL, NGT, LDT, CNT

GR, LSS, DIL, SFL,

CAL, NGT, LDT, CNT

GR, LSS, DIL, SFL,

CAL, NGT, LDT, CNT

NGT, LDT, CNT

GR, LSS, DIL, SFL,

CAL, NGT, LDT, CNT Seismometer/VSP (UTIG)

GR, LSS, DIL, SFL

GR, LSS, DIL, SFL, CAL

GR, LSS, DIL, SFL,

CAL, NGT, GST, CNT

GR, LSS, DIL, SFL, CAL

GR, LSS, DIL, SFL,

CAL, NGT, LDT, CNT

GR, LSS, DIL, SFL,

CAL, NGT, GST, CNT

GR, LSS, DIL, SFL, CAL

GR, LSS, DIL, SFL,

CAL, NGT, LDT, CNT

\section{MCS (LDEO)}

MCS (LDEO)

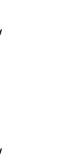

(n)


APC/WSTP, TSP (Miami) Germany

Repeat

$$
677
$$

111678

112679

$\begin{array}{ll}680 & \sqrt{ } \\ 681 & \sqrt{ } \\ 682 & \sqrt{ } \\ 683 & \sqrt{ } \\ 684 & \end{array}$

Formation

(Schlumberger)$$
\text { , Kuster }
$$

TRP (TAMU)

$\begin{array}{ll}\sqrt{ } & \sqrt{ } \\ \sqrt{ } & \sqrt{ } \\ \sqrt{ } & \sqrt{ } \\ \sqrt{ } & \sqrt{ }\end{array}$

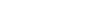

\section{France}

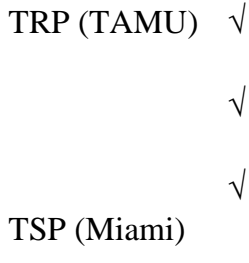

$\begin{array}{ll}\sqrt{ } & \sqrt{ } \\ \sqrt{ } \\ \sqrt{ }\end{array}$

$\begin{array}{ll}\sqrt{ } & \sqrt{ } \\ V & \\ & \sqrt{ } \\ \sqrt{ } & \sqrt{ } \\ & \sqrt{ } \\ & \sqrt{ }\end{array}$

$\begin{array}{ll}\sqrt{ } & \sqrt{ } \\ \sqrt{ } & \sqrt{ } \\ & \sqrt{ } \\ & \sqrt{ } \\ & \sqrt{ } \\ \sqrt{ } & \sqrt{ } \\ \sqrt{ } & \sqrt{ }\end{array}$

700

701

703

704

$115706 \sqrt{ }$

115707

708

$709 \sqrt{ }$

710

GR, LSS, DIL, SFL,

CAL, NGT, GST, ACT, Magnetometer (Germany); LDT, CNT, GPIT

Magnetic Susceptibility

(Germany); Large-scale resistivity (Miami)

GR, LSS, DIL, SFL, CAL

GR, LSS, DIL, SFL, CAL MCS (LDEO)

GR, LSS, DIL, SFL, CAL

NGT, GST, ACT, LDT, MCS (LDEO); Magentometer

CNT, DLL, WST

(Japan); BHTV (USGS)

GR, LSS, DIL, SFL,

CAL, NGT, GST, ACT,

LDT, CNT, AMS

GR, LSS, DIL, SFL

CAL, NGT, GST, ACT,

LDT, CNT, AMS

GR, LSS, DIL, SFL, CAL

GR, LSS, DIL, SFL, CAL

GR, BHC, DIL, SFL, CAL

NGT, GST, ACT

GR, BHC, DIL, SFL, CAL

NGT, LDT, CNT, GPIT,

GST, ACT

GR, BHC, DIL, SFL,

CAL, NGT, GST, ACT,

LDT, CNT, GPIT 
GR, BHC, DIL, SFL,

CAL, NGT, GST, ACT,

LDT, CNT, GPIT

GR, LSS, DIL, SFL,

CAL, NGT, GST, ACT, LDT

NGT, LSS, DIL, SFL,

CAL, GST, ACT, LDT, CNT

NGT, LSS, DIL, SFL

GR, BHC, DIL, SFL,

NGT, LDT, CNT, GPIT

GR, BHC, DIL, SFL,

NGT, LDT, CNT, GPIT,

GST, ACT

GR, BHC, DIL, SFL NGT, CNT, GST, GPIT GR, BHC, DIL, SFL

NGT, CNT, GST, GPIT GR, LSS, DIL, SFL,

CAL, NGT, LDT, CNT, GPIT, AMS, DLL, WST

BHTV (LDEO);

Magnetometer/Susceptibility (Washington); MCS (LDEO); Magnetometer (USGS);

Seismometer/VSP (WHOI)

GR, LSS, DIL, SFL,

CAL, NGT, LDT, CNT,

AMS

GR, LSS, DIL, SFL,

CAL, NGT, LDT, CNT

GR, LSS, DIL, SFL, CAL

GR, LSS, DIL, SFL,

CAL, NGT, LDT, CNT,

AMS

NGT, SDT, DIL, SFL, CAL, AMS

NGT, SDT, DIL, SFL, CAL, AMS

NGT, LSS, DIL, SFL,

CAL, LDT, CNT, ACT,

GST, GPIT 
GR, BHC, DIT, SFL, NGT, GST, ACT, CNT NGT, DIT, SDT, GPIT,

AMS, SFL

NGT, DIT, LSS, GPIT

CNT, SFL, CAL

NGT, SDT, DIT, SFL, GPIT, ACT, CNT, GST

NGT, SDT, DIT, SFL,

CAL, ACT, CNT, GST,

LDT

NGT, LSS, DIT, SFL,

CAL

NGT, CNT, LDT, ACT,

GST

NGT, LSS, DIT, SFL

BHTV (LDEO);

NGT, LSS, DIT, SFL,

Seismometer/VSP (WHOI)

MCD, CNT, LDT, ACT,

GST

NGT, LSS, DIT, SFL,

CAL, ACT, GST

NGT, LSS, DIT, SFL, CAL, ACT, GST, LDT, CNT, GPIT

NGT, LSS, DIT, SFL,

CAL

ACT, GST, LDT, CNT, BHTV (LDEO)

GPIT

NGT, DIT, SDT, SFL,

LDT

NGT, DIL, SDT, LDT,

SFL

GST, CNT, GPIT, ACT Magnetometer/Susceptibility (Washington)

NGT, SDT, DIT, SFL

NGT, ACT, GST

BHTV (LDEO)

NGT, LSS, DIT, SFL, FMS, GST, ACT, LDT, GPIT

NGT, LSS, DIT, SFL, FMS, GST, ACT, WST, GPIT 
NGT, LSS, DIT, SFL,

LDT, FMS, GPIT, ACT,

GST

795 V

128794

NGT, LSS, DIT, SFL, LDT

NGT, LSS, DIT, SFL, LDT, CNT, FMS, GPIT, ACT, GST

FMS, GPIT, NGT, DIT, $\quad$ BHTV (LDEO) SFL, LSS, CNT, ACT, GST

NGT, SDT, DIT, SFL

LSS, CNT, ACT, GST, NGT, SDT, DIT, SFL,

FMS, GPIT, LDT

LSS, CNT, ACT, GST,

NGT, SDT, DIT, SFL, FMS, GPIT, LDT

LSS, NGT, DIT, SFL, LDT, GST, ACT, FMS, GPIT

LSS, NGT, DIT, SFL, LDT, GST, ACT, FMS, GPIT

LSS, NGT, DIT, SFL,

LDT, GST, ACT, FMS, GPIT, WST

LSS, NGT, DIT, SFL, LDT, GST, ACT, FMS, GPIT, BHC

LSS, NGT, DIT, SFL, LDT, ACT, GST LSS, NGT, DIT, SFL, LDT, ACT, GST

LSS, NGT, DIT, SFL, LDT, ACT, GST, FMS, GPIT

$\checkmark$ SDT, NGT, CAL, DIT, SFL, LDT, CNT, ACT, ONDO (Japan); LAST I GST, WST

SDT, NGT, DIT, SFL, LDT, CAL

SDT, NGT, DIT, SFL, LDT, CAL, FMS, GPIT

SDT, NGT, DIT, SFL, LDT, CAL, FMS, GPIT SDT, NGT, DIT, SFL, LDT, CAL, ACT, GST

\section{(Canada)}

Seismometer/OSE (Japan); Deep resistivity (Japan)
BHTV (LDEO)

BHTV (LDEO)

SE (Japan) 


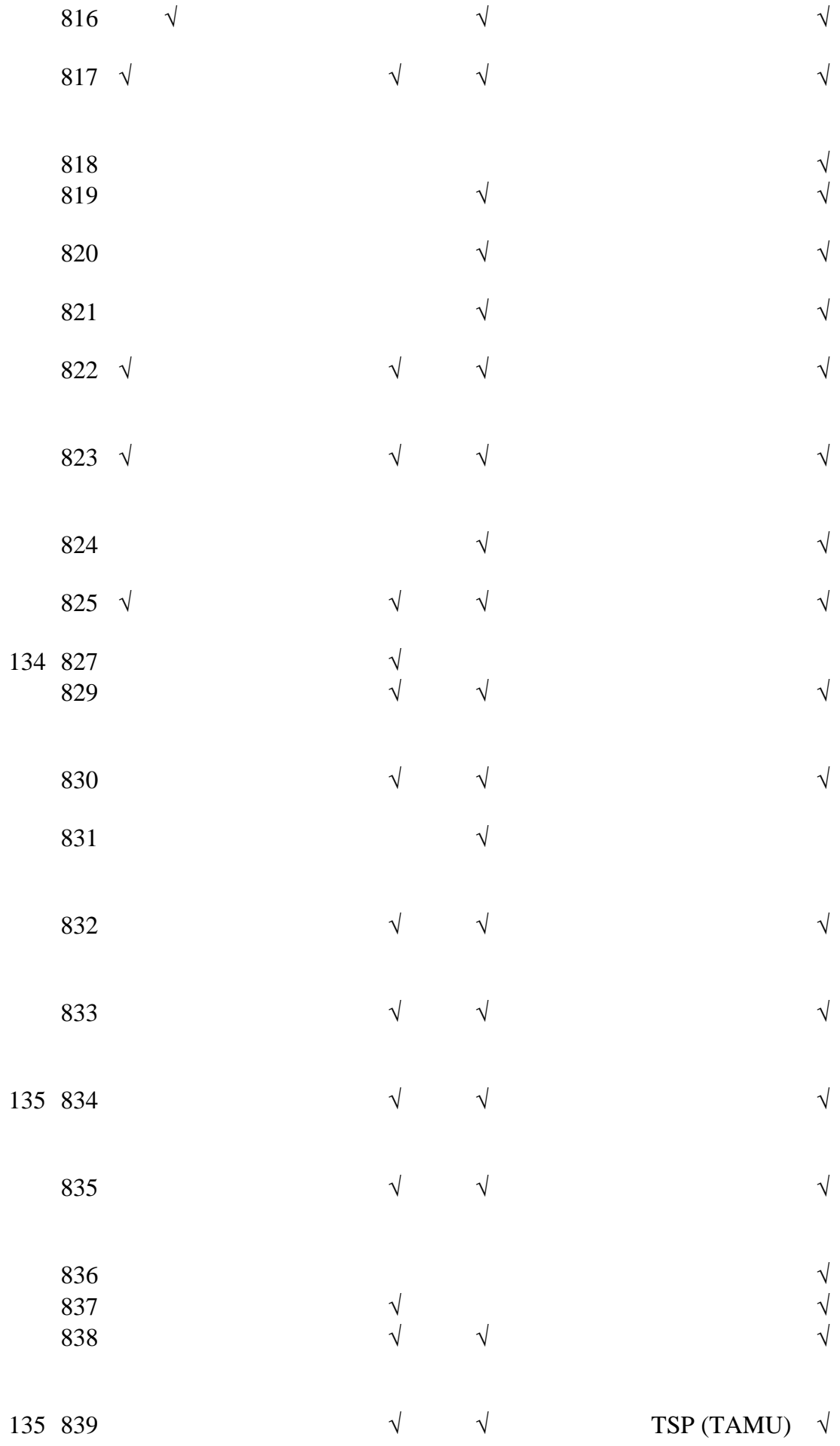

SDT, NGT, DIT, SFL, LDT, CAL, FMS, GPIT

SDT, NGT, DIT, SFL,

LDT, CAL, FMS, GPIT,

ACT, GST, WST, CNT

SDT, NGT, DIT, SFL,

LDT

SDT, NGT, DIT, SFL,

LDT, CAL, FMS, GPIT

SDT, NGT, DIT, SFL,

LDT, CAL, FMS, GPIT

SDT, NGT, DIT, SFL,

LDT, CAL, FMS, GPIT,

ACT,GST, CNT

SDT, NGT, DIT, SFL,

LDT, CAL, FMS, GPIT,

ACT, GST, CNT

SDT, NGT, DIT, SFL,

CAL

SDT, NGT, DIT, SFL,

CAL

LSS, NGT, DIT, SFL,

LDT, CAL, FMS, GPIT,

BHTV (LDEO)

ACT, GST, CNT

LSS, NGT, DIT, SFL,

LDT, CAL, ACT, GST

LSS, NGT, DIT, SFL,

BHTV(LDEO)

LDT, CAL, ACT, GST,

HMT

LSS, NGT, DIT, SFL,

LDT, CAL, FMS, GPIT,

HMT

LSS, NGT, DIT, SFL,

LDT, CAL, ACT, GST,

HMT

LSS, NGT, DIT, SFL, $\quad$ BHTV (LDEO)

LDT, FMS, GPIT, ACT,

GST

LSS, NGT, DIT, SFL,

LDT, FMS, GPIT, CNT,

CAL

LSS, NGT, DIT, SFL,

LDT, ACT, GST, CNT,

CAL, FMS, GPIT

LSS, NGT, DIT, SFL, $\quad$ BHTV (LDEO)

LDT, ACT, GST, CNT,

CAL, FMS, GPIT 
LDT, ACT, GST, CAL,

FMS, GPIT

LSS, NGT, DIT, SFL,

LDT, MCD, FMS, GPIT

LSS, NGT, DIT, SFL,

LDT, FMS, GPIT, ACT,

BHTV (LDEO)

GST

BHTV (LDEO); Flowmeter

(Miami)

SDT, NGT, DIT, SFL

LDT, FMS, GPIT, ACT,

GST

SDT, NGT, DIT, SFL,

LDT, FMS, GPIT, ACT,

GST

SDT, NGT, DIT, SFL,

LDT, FMS, GPIT, ACT,

GST

SDT, NGT, DIT, SFL

LDT, FMS, GPIT, ACT

GST

NGT, ACT, GST

SDT, NGT, DIT, SFL,

LDT, FMS, GPIT, ACT,

GST

SDT, NGT, DIT, SFL,

LDT, FMS, GPIT, ACT,

GST

SDT, NGT, DIT, SFL

LDT, FMS, GPIT, ACT,

GST

NGT, ACT, GST

NGT, DIT, SFL, GST, PTF (Japan)

LSS, GPIT, FMS

$\sqrt{ } \sqrt{ }$ LSS, NGT, DIT, SFL, $\quad$ PTF (Japan); Flowmeter LDT, FMS, GPIT, ACT, (Miami)

GST, CNT

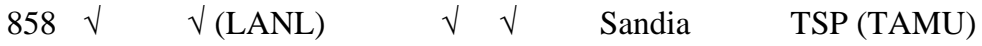

140504

France

LSS, NGT, DIT, SFL, PTF (Japan); Flowmeter LDT, FMS, GPIT (Miami)

FMS, GPIT, NGT, ACT, BHTV (LDEO); Flowmeter GST, DLL, LSS (Miami)

$\begin{array}{llllllll}141859 & \sqrt{ } & \sqrt{ } & \sqrt{ } & \sqrt{ } & \sqrt{ }\end{array}$

$860 \sqrt{ }$

$\sqrt{ }$ NGT, LSS, DIT, SFL,

LDT, ACT, GST, WST,

CAL

$\checkmark$ NGT, LSS, DIT, SFL,

CAL 
NGT, LSS, DIT, SFL,

LDT, ACT, GST, WST,

CAL, FMS, GPIT

NGT, CNT, LDT, SDT, Magnetometer (Japan) DIT, GST, ACT, FMS,

GPIT, SFL

NGT, CNT, LDT, SDT, DIT, GST, ACT, FMS, GPIT, SFL

NGT, CNT, LDT, LSS,

DIT, FMS, GPIT, SFL

NGT, CNT, LDT, SDT, Magnetometer (Japan) DIT, GST, ACT, FMS

GPIT, SFL

NGT, LDT, SDT, DIT,

GST, ACT, FMS, GPIT,

SFL

872

887

$146888 \sqrt{ }$

857

$891 \sqrt{ }$
TSP (TAMU)

NGT, LDT, SDT, DIT, GST, ACT, FMS, GPIT, SFL

NGT, LDT, SDT, DIT, GST, ACT, FMS, GPIT, SFL, NGT, LDT, SDT, DIT, FMS, GPIT, SFL

NGT, LDT, SDT, DIT, FMS, GPIT, SFL

NGT, LDT, SDT, DIT GST, ACT, FMS, GPIT, SFL, HMT

NGT, CNT, LDT, SDT, DIT, GST, ACT, FMS, GPIT, SFL, HMT

NGT, LDT, SDT, DIT, FMS, GPIT, SFL

$\sqrt{ }$ NGT, DIT, SFL, SDT, WST, LDT

TSP (TAMU) $\sqrt{ }$ $\sqrt{ }$

TSP (TAMU) $\checkmark$ NGT, DIT, SFL, SDT, WST, LDT, FMS, GPIT

LAST II (Canada); Geoprops (USA)

LAST II (Canada)

$\sqrt{ }$

$\checkmark$ NGT, DIT, SFL, SDT, Seismometer/VSP/OSE LDT, GST, ACT, FMS, (WHOI) GPIT

$\sqrt{ } \quad \sqrt{ }$ NGT, DIT, SFL, SDT, $\quad$ LAST I (Canada) LDT, CNT, FMS, GPIT, WST 